Aus der ehem. Arbeitsgruppe synaptische Plastizität (ehem. Leiter: Prof. Dr. rer. nat. S. Sigrist)

des European Neuroscience Institute, Göttingen

\title{
Elektrophysiologische Untersuchung der synaptischen Übertragung und Kurzzeitplastizität an der neuromuskulären Synapse von Drosophila melanogaster
}

\author{
INAUGURAL-DISSERTATION \\ zur Erlangung des Doktorgrades \\ der Medizinischen Fakultät der \\ Georg-August-Universität zu Göttingen
}

vorgelegt von

Andreas M.J. Frölich

aus

Düsseldorf

Göttingen, 2010 
Dekan: Prof. Dr. med. C. Frömmel

I. Berichterstatter: Prof. Dr. rer. nat. S. Sigrist

II. Berichterstatter: Prof. Dr. med. S. Hülsmann

Tag der mündlichen Prüfung: $\quad$ 02. 05. 2011 


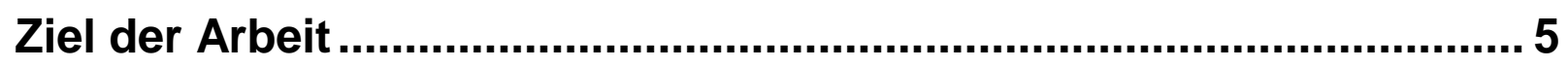

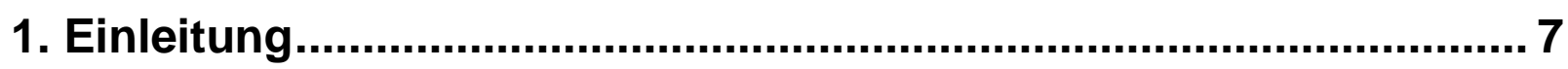

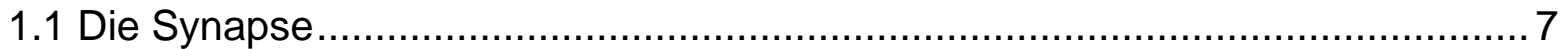

1.2 Die synaptische Plastizität................................................................. 12

1.2.1 Kurzzeitige Verstärkung synaptischer Signalübertragung ......................... 12

1.2.2 Kurzzeitige Abschwächung synaptischer Signalübertragung ..................... 15

1.3 Die Taufliege Drosophila melanogaster …………………………………..... 17

1.4 Die larvale neuromuskuläre Synapse von Drosophila melanogaster ................ 19

1.4.1 Aufbau der neuromuskulären Synapse ............................................... 19

1.4.2 Glutamatrezeptorkomplexe an der larvalen NMJ.....................................21

1.5 Dystroglycan und seine Rolle in der synaptischen Plastizität...........................23

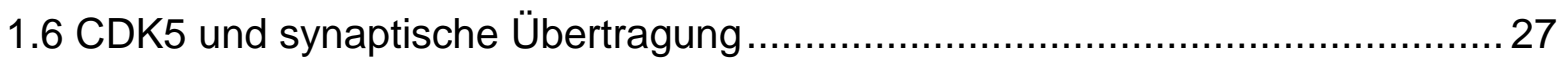

2. Methode

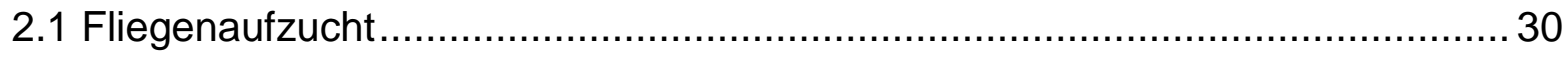

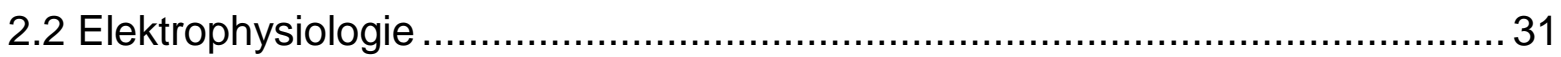

2.2.1 Grundlagen der Bioelektrizität an Zellmembranen ....................................31

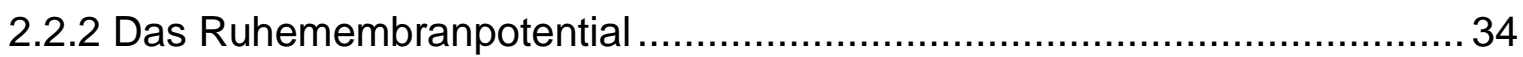

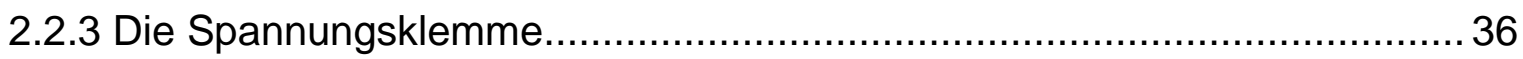

2.2.4 Die Zwei-Elektroden Spannungsklemme .................................................. 37

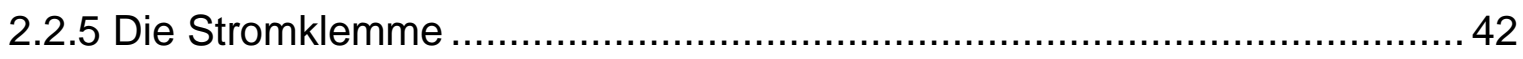

2.2.6 Experimentelles Vorgehen................................................................ 43

2.2.7 Verwendetes Material und Geräte ......................................................... 45

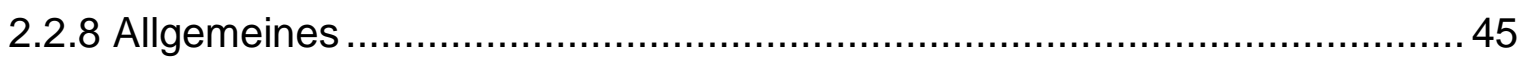

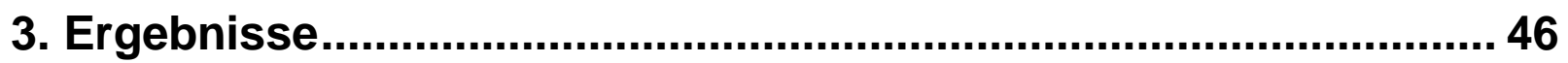

3.1 In-vivo-Untersuchung von Komponenten des Glutamatrezeptors ..................... 46

3.1.1 GFP-markiertes GluRIIB zeigt volle in-vivo-Funktionalität ......................... 46

3.1.2 Muskelspezifische Suppression von GluRIIE provoziert einen dramatischen

Abfall der postsynaptischen Sensitivität .........................................................50

3.1.3 Funktionelle Analyse der Funktion von GluRIIF für die synaptische

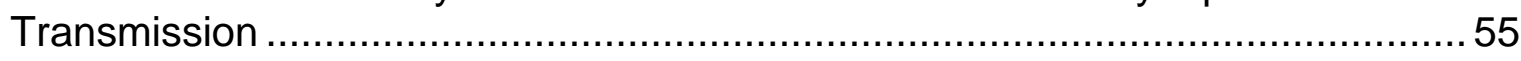

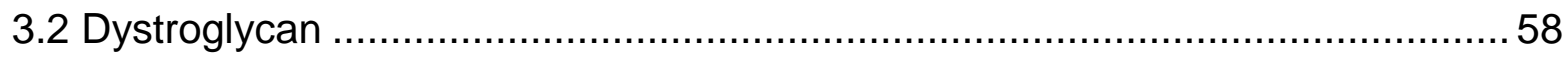

3.2.1 Suppression von Dystroglycan verändert die synaptische Übertragung..... 58

3.2.2 Dystroglycan beeinflusst die synaptische Kurzzeitplastizität ........................61

3.3 Funktionelle Analyse der Rolle von CDK5 für die synaptische Transmission ... 64

3.3.1 Suppression von CDK5 führt nicht zu einer Veränderung der synaptischen

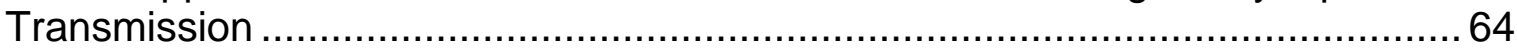

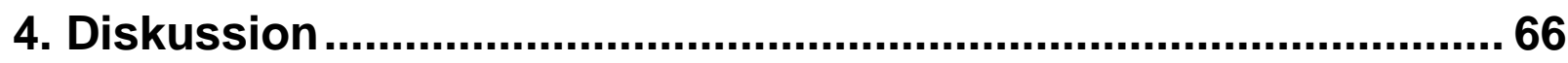


4.1 Funktion und Aufbau des ionotropen Glutamatrezeptorkomplexes bei Drosophila 66

4.1.1 IIA und IIB

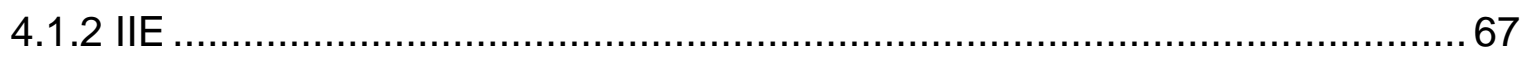

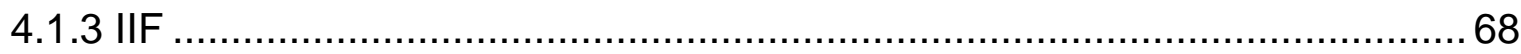

4.2 Die Bedeutung des Proteins Dystroglycan für die Synapse ............................ 71

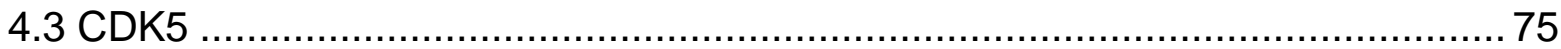

5. Publikationen zur Dissertation ...................................................... 78

6. Abkürzungsverzeichnis ............................................................... 79

7. Abbildungen und Tabellen ............................................................ 81

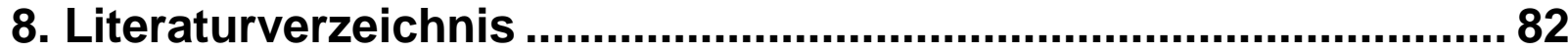

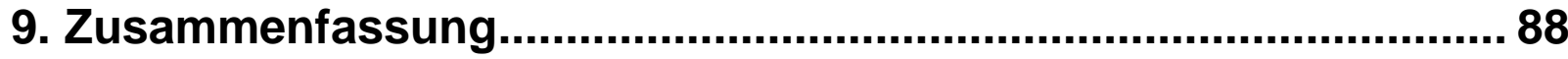




\section{Ziel der Arbeit}

Veränderungen in der synaptischen Übertragung (synaptische Plastizität) sind entscheidend wichtig für Physiologie und Pathophysiologie unseres Nervensystems. In dieser Arbeit wurden deshalb Mechanismen synaptischer Übertragung mit Hilfe des Modellorganismus Drosophila melanogaster untersucht. Dabei stand die physiologische Funktion der Synapse in vivo im Vordergrund, weswegen als methodischer Ansatz elektrophysiologische und genetische Analyse kombiniert wurden.

Ionotrope Glutamatrezeptoren (GluRs) dominieren die erregende Neurotransmission im ZNS des Menschen. Verwandte Rezeptoren sind aber auch an der neuromuskulären Synapse von Drosophila-Larven (NMJ) exprimiert. Die genaue Verteilung von GluR-Subtypen ist hierbei ein Schlüsselmechanismus für plastische Veränderungen. Deshalb wurde die Rolle der GluR-Untereinheiten GluRIIB, IIE und IIF an der NMJ studiert. Dies geschah mit der Fragestellung, welche Rolle die einzelnen Untereinheiten für die Kinetik und Funktion der fertigen Rezeptorkomplexe spielen. Ein fluoreszenzmarkiertes (GFP) GluRIIB-Konstrukt sollte außerdem mit der Frage untersucht werden, ob seine Funktion durch die Markierung verändert wurde und ob es für weitergehende Experimente (In vivo Visualisierung) einsetzbar ist.

Das Protein CDK5 wurde bereits mehrfach mit der synaptischen Übertragung in Verbindung gebracht, ohne dass seine Funktion bisher abschließend erklärt werden konnte. Daher erschien es sinnvoll, in einem elektrophysiologischen in vivo Experiment die Funktion von CDK5 näher zu untersuchen. Dies ist insbesondere vor dem Hintergrund einer möglichen Rolle von CDK5 in der Pathogenese der Alzheimerschen Erkrankung von Interesse.

Das Glykoprotein Dystroglycan wird allgemein mit den Muskeldystrophien, erblichen Erkrankungen der Skelettmuskulatur, in Verbindung gebracht. Doch auch die synaptische Übertragung und Plastizität hängen wahrscheinlich von diesem Molekül ab. Vielfältige Funktionen sind beschrieben worden, etwa die Beeinflussung des 
Wachstums postsynaptischer Strukturen, veränderte Langzeitplastizität und sogar verstärkte Aggressivität von Tumorzellen. Die Frage nach dem genauen Einfluss von Dystroglycan auf die synaptische Funktion blieb bislang jedoch unzureichend beantwortet und wurde in dieser Arbeit untersucht. Ausgehend von den Erkenntnissen der vorangehenden Experimente wurde dann ein Stimulationsprotokoll entwickelt, mit dem der Frage nach einem Einfluss von Dystroglycan auf die synaptische Plastizität nachgegangen wurde. Für das Verständnis der Pathophysiologie der Muskeldystrophien, aber auch der Abläufe an den Synapsen Gesunder könnte dies neue Impulse geben. 


\section{Einleitung}

\subsection{Die Synapse}

Die Kommunikation zwischen einzelnen Zellen und Zellverbänden ist eine zentrale Herausforderung für jedes mehrzellige Lebewesen. Nur durch Kommunikation kann die Funktion der Bestandteile des Organismus aufeinander abgestimmt werden und einem für das Überleben des gesamten Lebewesens sinnvollen Zweck dienen. Im Laufe der Evolution haben sich verschiedene Systeme der Zellkommunikation entwickelt, von denen das komplexeste wohl das Zentrale Nervensystem des Menschen darstellt.

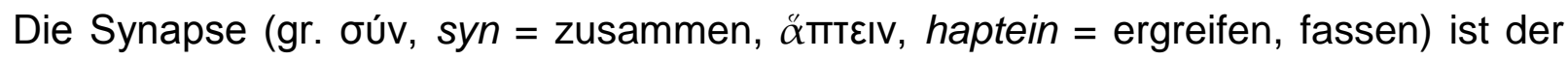
Ort der Informationsübertragung zwischen zwei Zellen im Nervensystem. Es gibt elektrische und chemische Synapsen. Die elektrische Synapse (gap junction) schafft eine direkte Verbindung zweier Zellinnenräume, die die Übermittlung sowohl elektrischer Signale (z.B. die Erregungsausbreitung in Herzmuskelzellen) als auch die Ausbreitung chemischer Botenstoffe von Zelle zu Zelle ermöglicht. Das monomere, transmembranöse Protein Connexin lagert sich zu einem Komplex in der Membran, Connexon genannt, zusammen. Jeweils zwei solcher Komplexe verbinden zwei benachbarte Zellen und bilden so eine elektrische Synapse (Abb. 1-1). Bei der chemischen Synapse sind beide Zellen durch den synaptischen Spalt von einander getrennt (Abb. 1-2). Über das Axon der Senderzelle erreicht ein elektrisches Signal, das Aktionspotential (AP), die Nervenendigung (Bouton). Das AP ist eine sich entlang der Nervenfaser ausbreitende Veränderung des Membranpotentials der Axonmembran. Fortgeleitet wird das AP durch Öffnung spannungsabhängiger lonenkanäle in der Zellmembran. Deren Öffnung führt zu einem lonenstrom, der die Membranerregung unterhält und fortleitet. Das AP wird an der präsynaptischen Membran in ein chemisches Signal umgewandelt. Dies geschieht durch das Öffnen spannungsabhängiger Calciumkanäle. Die darauf folgende Erhöhung der intrazellulären $\mathrm{Ca}^{2+}$-Konzentration verursacht die Fusion synaptischer Vesikel mit der Membran. Die Vesikel sind mit einem chemischen Botenstoff, dem Neurotransmitter gefüllt, der durch die Fusion in den synaptischen Spalt gelangt. An der 
Empfängerzelle, also postsynaptisch, wird der Transmitter von spezifischen Rezeptormolekülen gebunden. Dies können ionotrope Rezeptoren sein, bei denen es sich um ionenselektive Kanäle handelt, die durch Binden des Neurotransmitters geöffnet werden.

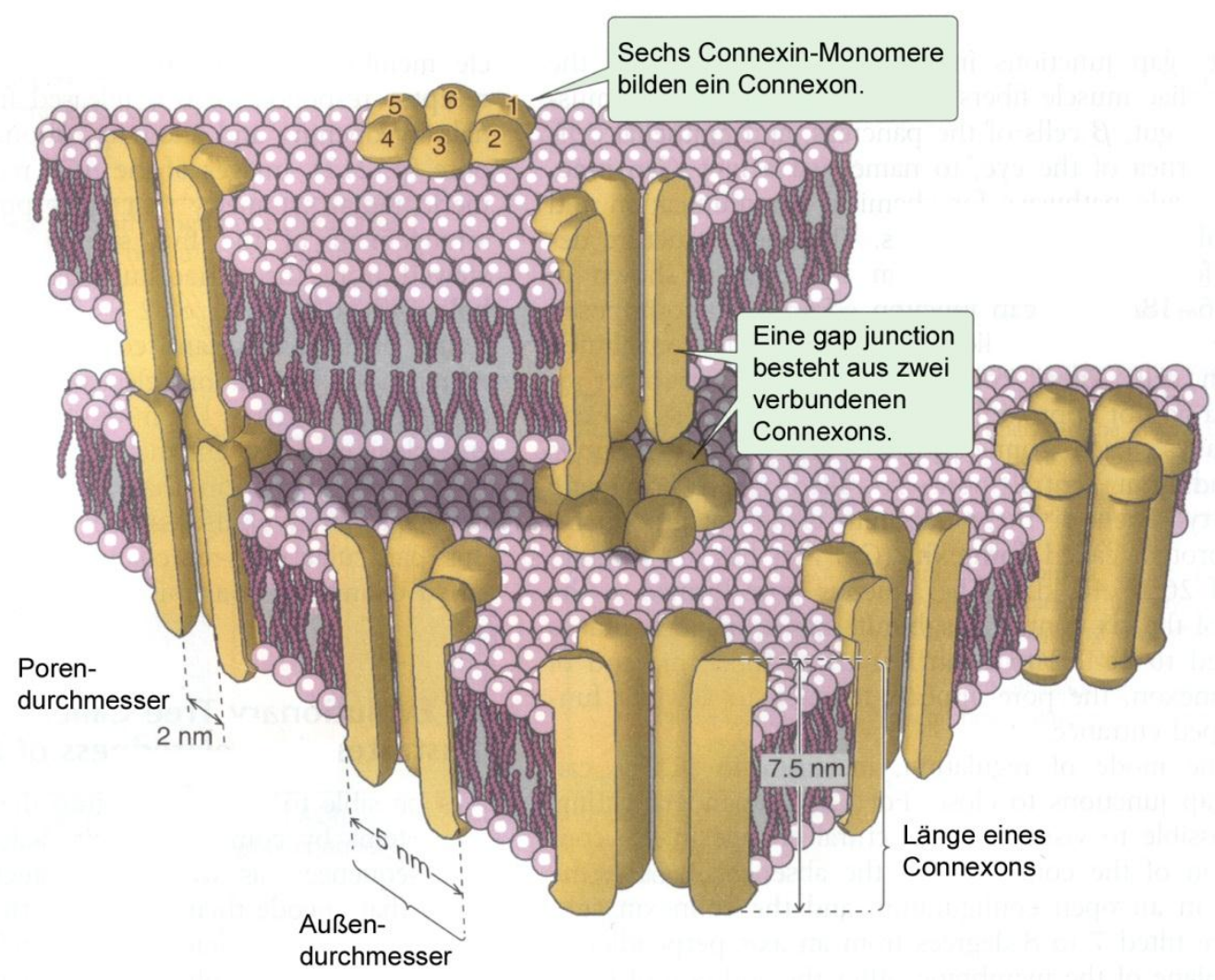

\section{Abb. 1-1 Die elektrische Synapse.}

Dargestellt sind die Zellmembranen zweier benachbarter Zellen, in denen sich Connexin-Monomere zu Connexons zusammengelagert haben. Die Verbindung zweier Connexons stellt einen elektrischen und chemischen Kontakt zwischen den Nachbarzellen her (modifiziert nach Boron and Boulpaep 2003, S. 166).

Die metabotropen Rezeptoren hingegen führen, beispielsweise durch Aktivierung eines G-Proteins, zur Veränderung der Konzentration so genannter "second messenger", also chemischer Substanzen, die das Signal innerhalb der Zelle weiterleiten. Ist eine Zelle mit ionotropen Rezeptoren ausgestattet, so entstehen, abhängig von Transmitter und Rezeptor, verschiedene lonenströme über der 
Membran. Diese können die Membran entweder erregen oder einer Erregung entgegen wirken. Diese lonenströme verursachen dabei Potentialschwankungen, die als inhibitorische und exzitatorische postsynaptische Potentiale (IPSP und EPSP) bezeichnet werden. Die räumliche und zeitliche Aufsummierung derartiger Potentiale kann an der Empfängerzelle zur Auslösung eines neuen Aktionspotentials führen, das die Erregung weiterleitet. Zu den genauen Mechanismen der Bioelektrizität und Zellerregung siehe Kapitel 2.2.1(S. 31).

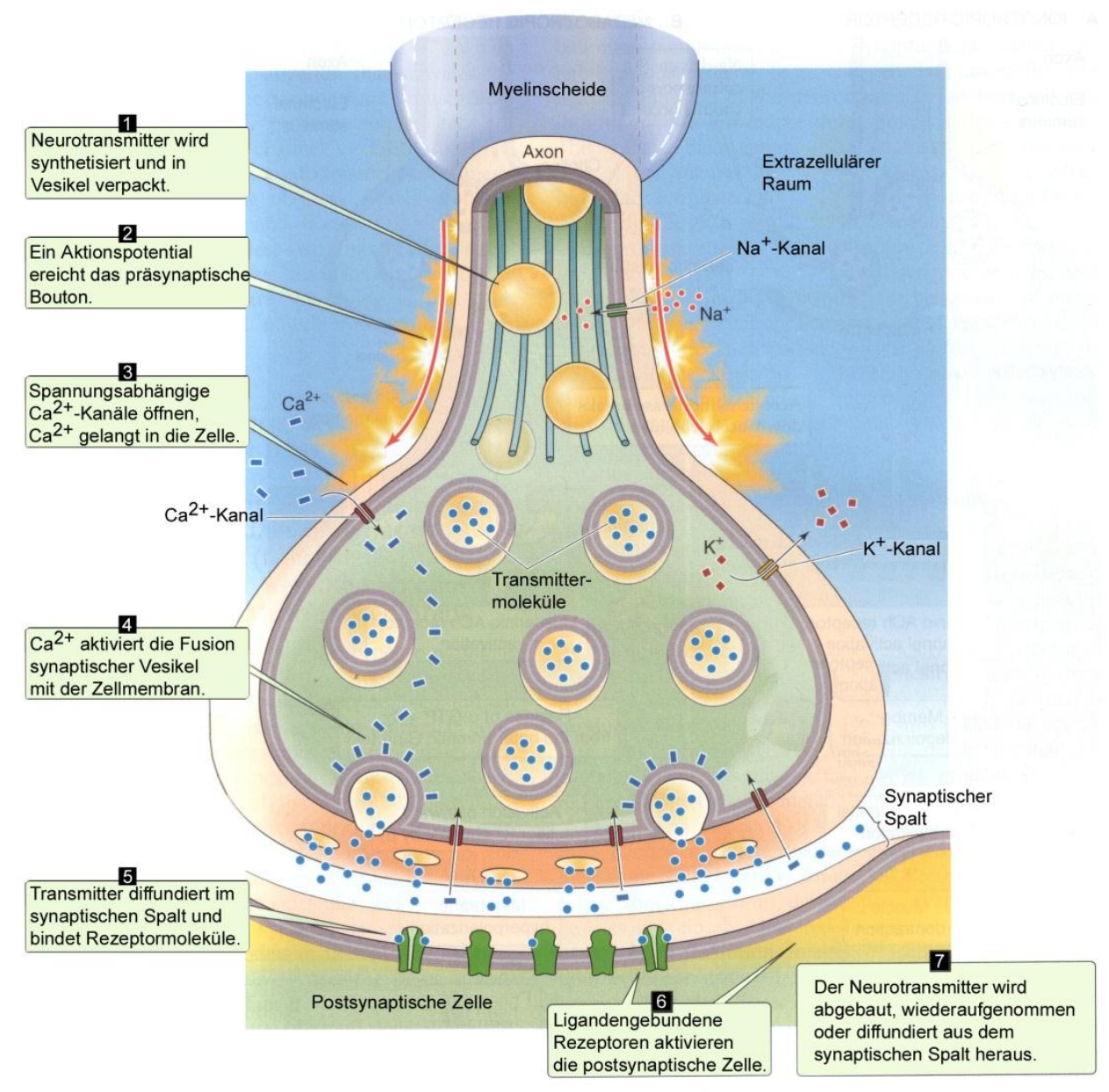

\section{Abb. 1-2 Die chemische Synapse.}

Der Prozess der synaptischen Signalübertragung an der chemischen Synapse ist hier vereinfacht in sieben Schritten dargestellt (modifiziert nach Boron and Boulpaep 2003, S. 207).

Zur Beschreibung der quantitativen Aspekte synaptischer Übertragung gibt es ein anschauliches Modell, die Quantenhypothese (Schneggenburger et al. 2002). Sie 
beschreibt die Abhängigkeit der postsynaptischen Antwort auf ein AP. Sie zeigt den Zusammenhang zwischen dem über die postsynaptische Membran messbaren Stromfluss (postsynaptic current, PSC), der Amplitude des einzelnen Quantums (Quantengröße, q, postsynaptische Antwort auf die Freisetzung eines einzigen Vesikels), der Anzahl der vorhandenen Freisetzungsorte $\mathrm{N}$ und der Freisetzungswahrscheinlichkeit für ein Quantum (release probability, p).

$$
P S C=\mathrm{Npq}
$$

Nach diesem Modell ergibt sich eine Änderung der PSC also aus einer Änderung von $\mathrm{N}, \mathrm{p}$, q oder einer Kombination. Dieses Modell wird für unsere Betrachtung sowohl der synaptischen Übertragung als auch der synaptischen Plastizität von Bedeutung sein. Im Zusammenhang mit der Quantenhypothese ist anzumerken, dass eine ganze Reihe verschiedener Modifikationen erstellt worden sind, um zu beschreiben, dass nicht für jedes Vesikel dieselbe Freisetzungswahrscheinlichkeit und -kinetik gilt. Eine gängige Einteilung der Vesikel beschreibt drei so genannte pools, also Gruppen von Vesikeln mit ähnlichen Eigenschaften (Rizzoli und Betz 2005). Der readily releasable pool (RRP) beinhaltet Vesikel, die bei jeglicher Stimulation unmittelbar freigesetzt werden. Der recycling pool (RP) stellt die Vesikel dar, die bei moderater Stimulation freigesetzt werden, und unter physiologischen Bedingungen stetig ersetzt werden. Vesikel des reserve pool (RSP) schließlich gelangen nur bei massiver Stimulation zur Fusion. Obwohl diese drei pools an unterschiedlichen synaptischen Systemen beobachtet worden sind, so ist ihre Einteilung dennoch nicht endgültig, da beispielsweise auch innerhalb des RRP unterschiedliche Freisetzungskinetiken gefunden worden sind (Sakaba und Neher 2001). Das Konzept der Vesikel-Pools ist jedoch noch nicht vollständig etabliert und so werden RP und RSP von einigen Autoren zum recycling pool zusammengefasst (Kidokoro et al. 2004).

Für die Funktion der Synapse ist entscheidend, dass das Signal auch wieder beendet werden kann. Hierfür stehen unterschiedliche Mechanismen zur Verfügung, die abhängig vom untersuchten synaptischen System - den Neurotransmitter entweder 
mit Hilfe spezieller Transportproteine wieder in die präsynaptische Zelle aufnehmen oder zu einem spezifischen Abbau der Transmittermoleküle führen. Darüber hinaus wird die Dauer und Stärke des Signals auch durch die Diffusion aus dem synaptischen Spalt heraus in den übrigen Extrazellulärraum begrenzt. Auch verfügt der Rezeptor selbst über eine Art „Abschaltautomatik“: Der Begriff Desensitisierung beschreibt den Übergang des Rezeptormoleküls in einen inaktiven Zustand selbst in Anwesenheit von Neurotransmitter, so dass das übertragene Signal trotz gebundenem Transmitter abklingt.

Die Synapse kennt aber keinesfalls nur die Zustandsformen „an“ und „aus“. Die synaptische Übertragung ist vielmehr ein komplexer Prozess, der zahlreiche verstärkende und abschwächende Mechanismen beinhaltet, die man unter dem Begriff der synaptischen Plastizität zusammenfasst. Die oben umrissene synaptische Signalübertragung findet sich sowohl zwischen Nervenzellen als auch zwischen Nerven- und Muskel-, Drüsen- oder hormonproduzierenden Zellen und darüber hinaus nicht nur beim Menschen, sondern in den unterschiedlichsten Organismen. 


\subsection{Die synaptische Plastizität}

Um eine optimale Anpassung an sich ändernde Umweltbedingungen sicherzustellen, müssen neuronale Systeme in der Lage sein, ihre Funktionsweise aktivitätsabhängig zu ändern. Bislang ist noch weitgehend unverstanden, wie komplexe Anpassungsreaktionen, etwa das Erlernen einer motorischen Fähigkeit oder das Wiedererkennen eines Bildes, zustande kommen. Auf der Ebene der Synapse aber kennt man mehrere Phänomene, bei denen die Stärke der synaptischen Übertragung durch die Aktivität des Neurons verändert werden kann. Hierbei ist es wichtig, zwischen zwei prinzipiellen Formen der synaptischen Plastizität zu unterscheiden. Die Effekte können einerseits für kurze Zeit, d.h. im Rahmen von Sekunden bis Minuten, wirksam sein oder aber die Funktion der Synapse für Stunden, Tage oder sogar noch länger verändern. Um diesem Unterschied Rechnung zu tragen, spricht man von Kurzzeitplastizität und Langzeitplastizität. Gedächtnisleistungen lassen sich in ähnlicher Weise unterscheiden, beispielsweise das unmittelbare Nachsingen einer Melodie als Kurzzeitleistung oder das Erkennen eines alten Freundes auf einem Foto als Langzeitleistung. Aus diesem Grund geht man davon aus, dass Kurzzeit- und Langzeitplastizität für das Einspeichern und Abrufen von Informationen in unserem Gehirn eine wichtige Rolle spielen. In dieser Arbeit wurden Aspekte der Kurzzeitplastizität untersucht. Mittlerweile ist eine Vielzahl unterschiedlicher Mechanismen bekannt (Abb. 1-3), die die synaptische Übertragung entweder verstärken oder abschwächen, deren Wirkung aber im Bereich von Sekunden bis Minuten wieder zu Ende ist (Zucker und Regehr 2002).

\subsubsection{Kurzzeitige Verstärkung synaptischer Signalübertragung}

Die verstärkenden Effekte (short-term synaptic enhancement, STE) unterscheiden sich untereinander vor allem durch den Zeitbereich, in dem sie aktiv sind. Der wahrscheinlich am kürzesten wirksame Mechanismus ist die Bahnung. Sie ist zu beobachten, wenn zwei Stimuli sehr kurz (10-1000 ms, je nach untersuchtem synaptischem System) nacheinander appliziert werden. Die Antwort auf den zweiten Stimulus kann dann um ein vielfaches höher sein als die auf den ersten. Etwas länger 
wirksam sind die Augmentation, die im Bereich von Sekunden anhält und die posttetanische Potenzierung (PTP), die die synaptische Übertragung für einige Minuten verstärken kann.

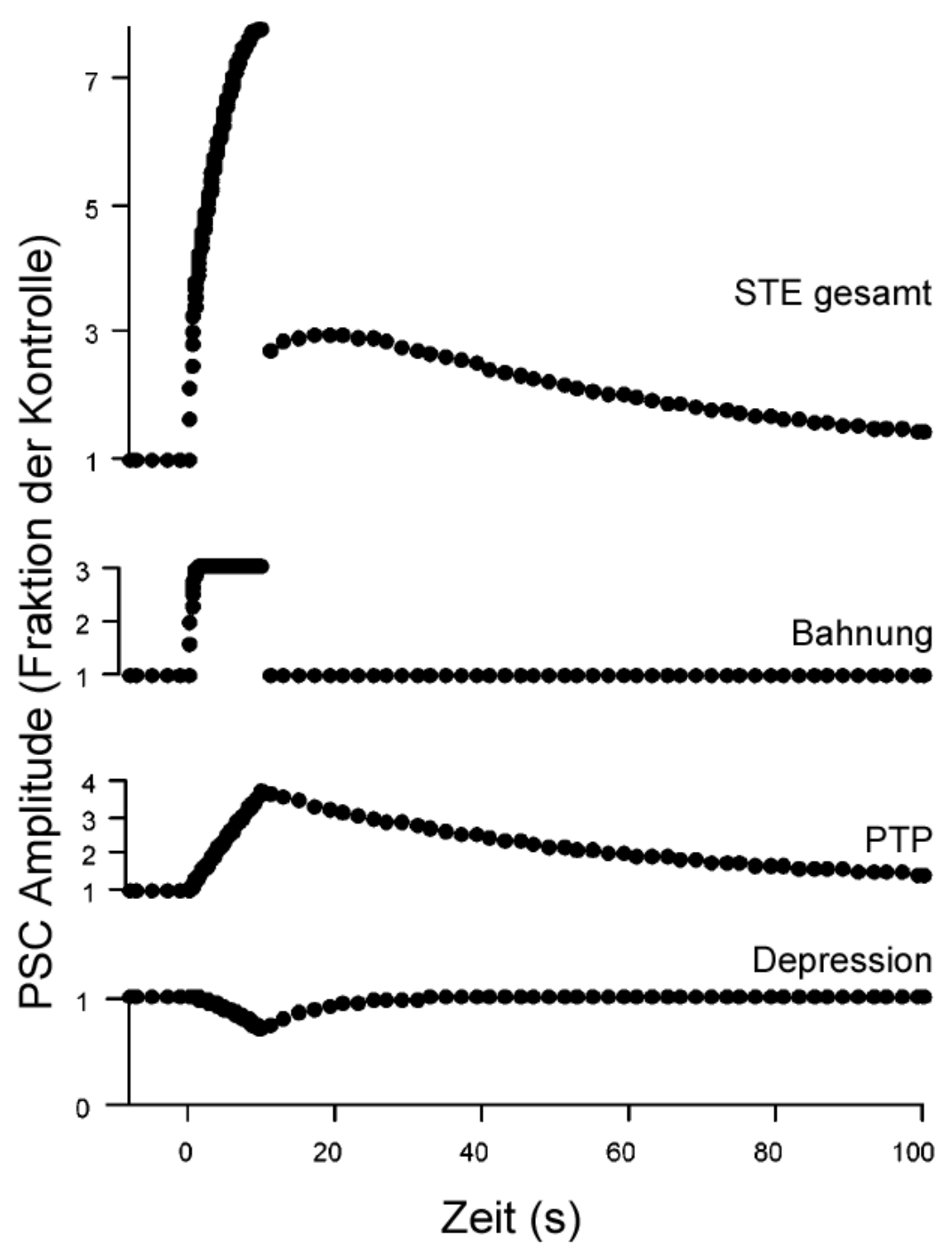

\section{Abb. 1-3 Formen der Kurzzeitplastizität.}

Simuliertes Experiment, bei dem ein synaptischer Eingang mit $0,5 \mathrm{~Hz}$ stimuliert wurde, wobei die Amplitude der PSC konstant blieb. Darauf folgte eine Stimulation mit $10 \mathrm{~Hz}$ für $10 \mathrm{~s}$ und die Amplitude stieg auf ca. das 8-fache des Ausgangswertes (oben). Die gesamte Erhöhung der Amplitude setzt sich aus unterschiedlichen Formen der Kurzzeitplastizität zusammen: Bahnung, PTP und Depression. Während die Bahnung bereits im Bereich von Millisekunden wieder beendet ist, erkennt man das langsamere Zurückgehen von PTP und Depression (modifiziert nach Zucker und Regehr, 2002, S. 358) 
Allen Formen des STE ist gemein, dass sie höchstwahrscheinlich ausschließlich präsynaptischen Ursprungs sind. Dies lässt sich daraus ableiten, dass alle bisherigen Untersuchungen gezeigt haben, dass es zwar zu einer Erhöhung der Quantengröße (quantal content, QC, Anzahl der pro Stimulus freigesetzten Vesikel), nicht jedoch zu einer Erhöhung der Antwort auf das einzelne Vesikel (quantal size, q) kommt (Fisher et al. 1997). Da die Vesikel präsynaptisch freigesetzt werden, die Antwort aber postsynaptisch entsteht, lassen mehr freigesetzte Vesikel ohne eine Veränderung der Antwort auf das einzelne Vesikel darauf schließen, dass das STE ein präsynaptisches Phänomen ist.

Die Frage, wie diese vermehrte Vesikelfreisetzung zustande kommt, ist aber weniger leicht zu beantworten. Die so genannte "Calcium-Hypothese“ (Katz und Miledi 1968) ist ein Modell, das zur Erklärung sämtlicher Formen des STE herangezogen wurde. Die Hypothese besagt, dass $\mathrm{Ca}^{2+}$-lonen, die während des ersten Stimulus in das Axon gelangt sind, die Vesikelfreisetzung bei den folgenden Stimuli verstärken. Weitere Untersuchungen haben bestätigt, dass eine experimentelle Erhöhung der präsynaptischen intrazellulären $\mathrm{Ca}^{2+}-$ Konzentration $\left(\left[\mathrm{Ca}^{2+}\right]_{\mathrm{i}}\right)$, etwa durch Photolyse $\mathrm{Ca}^{2+}$-bindender Chelatoren (Kamiya und Zucker 1994) oder durch ionophoretische Injektion von $\mathrm{Ca}^{2+}$-Ionen (Charlton et al. 1982) die Freisetzung der Vesikel erleichtert. Dies ist nicht auf die Antwort auf einen künstlichen Stimulus beschränkt, auch die Frequenz spontaner exzitatorischer postsynaptischer Potentiale (miniature excitatory postsynaptic potentials, mPSP) kann erhöht sein. Diese Beobachtungen ließen die Frage aufkommen, ob es sich bei Bahnung, Augmentation und PTP um jeweils verschiedene und vor allem vom Prozess der Vesikelfreisetzung zu unterscheidende Mechanismen handelt, da die Vesikelfreisetzung ja auch wesentlich von $\left[\mathrm{Ca}^{2+}\right]_{\mathrm{i}}$ abhängt. Obwohl die Frage nach den genauen Entstehungsorten des STE noch nicht abschließend geklärt ist, scheint doch klar zu sein, dass die einzelnen Formen des STE voneinander zu trennende Prozesse darstellen, die entweder an verschiedenen Stellen der Präsynapse stattfinden, oder deren Kinetik durch unterschiedliche Diffusion, Bindung, Ein- und Ausstrom von $\mathrm{Ca}^{2+}$-Ionen bestimmt wird (Zucker und Regehr 2002). 


\subsubsection{Kurzzeitige Abschwächung synaptischer Signalübertragung}

Eine ganz andere Form der Kurzzeitplastizität ist die Kurzzeitdepression (short-term synaptic depression, STD). Hierbei erfolgt eine Abschwächung der synaptischen Übertragung bei wiederholter Stimulation. Typisch auch für die in dieser Arbeit untersuchte Synapse ist z.B. ein Zusammenhang zwischen Stimulationsfrequenz und postsynaptischer Antwort: Je höher die Stimulationsfrequenz, desto niedriger fällt die postsynaptische Antwort aus. Da während der Übergänge von niederfrequenter in hochfrequente Stimulation Übergänge existieren, spricht man in diesem Zusammenhang auch vom Ruhewert (steady state) einer Stimulation. Der steady state stellt das sich nach einiger Zeit einstellende, stabile Antwortniveau einer Synapse bei gleich bleibender Stimulation dar. Wie erwähnt, ist der steady state als Zeichen der STD abhängig von der Stimulationsfrequenz, also bei hochfrequenter Stimulation der Synapse meist niedriger als bei niedrigen Stimulationsfrequenzen.

Im Gegensatz zum STE, das wahrscheinlich ausschließlich präsynaptisch entsteht, sind bei der STD prä- und postsynaptische Komponenten gefunden worden. Präsynaptisch kann die Freisetzung von Neurotransmitter durch die Erschöpfung eines Vorrats freisetzungsbereiter Vesikel (also des RRP, (Schneggenburger et al. 2002)) vermindert sein. Bei jedem AP wird eine Fraktion des ursprünglichen Vorrats an Vesikeln ausgeschüttet, während ein Wiederauffüllen der Vorräte durch Endozytose und Bereitstellung neuer Vesikel nur mit einer bestimmten Geschwindigkeit möglich ist. Dadurch kommt es bei stärkerer Beanspruchung der Synapse zu einer verminderten Transmitterfreisetzung. Dieses Erschöpfungsmodell ist der wohl am weitesten verbreitete Erklärungsansatz zur STD.

Neben dem Erschöpfungsmodell können aber auch von prä- und postsynaptisch in den synaptischen Spalt gelangte modulatorische Botenstoffe die synaptische Übertragung verändern, beispielsweise durch Wirkung auf metobotrope Rezeptoren der Präsynapse (Bogdanik et al. 2004). Schließlich kann auch die Desensitisierung der Rezeptormoleküle an der Postsynapse für die STD mit verantwortlich sein. Im Falle eines ionotropen Rezeptors beschreibt die Desensitisierung den Umstand, dass der Rezeptor auch mit gebundenem Agonisten in einem geschlossenen Zustand vorliegen kann. Ein gängiges Modell beschreibt Rezeptormoleküle in vier Zuständen: Ungebunden, mit gebundenem Agonisten, offen mit gebundenem Agonisten und 
desensitisiert (geschlossen mit immer noch gebundenem Agonisten) (Jones und Westbrook 1996). Da die Rezeptoren unter physiologischen Bedingungen dem Transmitter in unterschiedlichen Zeit- und Konzentrationsverläufen ausgesetzt sind und die Dissoziationskonstanten für die Übergänge zwischen den einzelnen Zustandsformen sich von Rezeptor zu Rezeptor unterscheiden, ist der Einfluss der Desensitisierung auf die STD nur schwierig einzuschätzen. 


\subsection{Die Taufliege Drosophila melanogaster}

Drosophila melanogaster ist einer der am weitesten verbreiteten Modellorganismen und insbesondere in der Genetik schon seit langer Zeit hilfreich. Daher stehen heute eine Reihe potenter genetischer Werkzeuge zur Verfügung, die es ermöglichen, viele unterschiedliche Fragestellungen mit Drosophila zu bearbeiten.

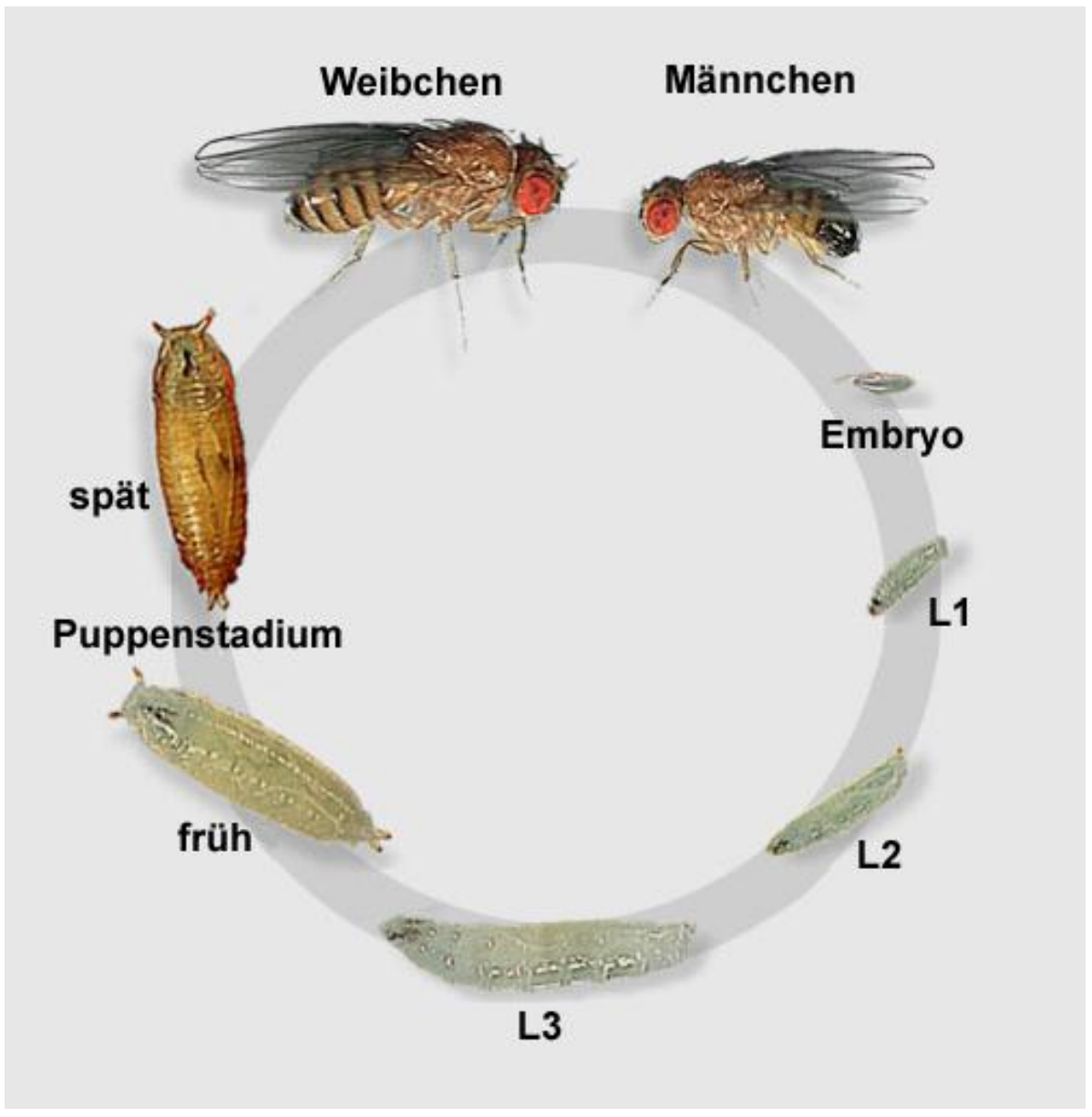

\section{Abb. 1-4 Der Lebenszyklus von Drosophila melanogaster.}

Darstellung der verschiedenen Entwicklungsstadien von Drosophila. Die Larven schlüpfen nach ca. 22 Stunden, nach je einem (L1) und weiteren zwei (L2) Tagen häutet sich die Larve und verpuppt sich nach drei Tagen im Stadium L3. Nach ca. 5 Tagen im Puppenstadium schlüpft die adulte Fliege (modifiziert von Weigmann et al. 2003)

Die Weibchen legen bis zu 400 Eier, aus denen bei $25^{\circ} \mathrm{C}$ nach ca. 22 Stunden die Larven des ersten Entwicklungsstadiums (L1) schlüpfen. Die Larven wachsen rasch, 
nach zwei Häutungen (Stadien L2, L3) verlassen sie den Futterbrei und beginnen sich zu verpuppen. Nach insgesamt ca. 10 Tagen schlüpft die Imago (Weigmann et al. 2003). Diese kurze Generationszeit ist einer der Vorteile der Arbeit mit Drosophila, daneben ist die Handhabung der Tiere einfach und ihre Haltung kostengünstig. Neben vielfältigen Möglichkeiten zum Erzeugen von Mutanten ist außerdem das UAS/Gal4System von Bedeutung. Dieses genetische Instrument erlaubt die kontrollierte Expression eines bestimmten Gens zu einem definierten Zeitpunkt und sogar in spezifischem Gewebe (Brand und Perrimon 1993). Dadurch können sehr genaue funktionelle Fragestellungen bearbeitet werden.

Prinzipiell kann Drosophila in allen Lebensabschnitten von Embryo über Larve bis hin zur adulten Fliege untersucht werden. Aufgrund der guten Zugänglichkeit insbesondere für die verwendeten elektrophysiologischen Techniken wurde das larvale Entwicklungsstadium L3 für diese Arbeit gewählt. Die Larven sind in diesem Stadium relativ groß und dadurch leichter zu präparieren. Die Größe der Muskelzellen bietet darüber hinaus den Vorteil höherer Stabilität bei den invasiven elektrophysiologischen Verfahren. 


\subsection{Die larvale neuromuskuläre Synapse von Drosophila melanogaster}

Für diese Arbeit wurde die neuromuskuläre Synapse (neuromuscular junction, NMJ) von Larven der Taufliege Drosophila melanogaster untersucht. Dieses synaptische Modellsystem ist elektrophysiologisch sehr gut zugänglich, da in den Larven die Muskelzellen durch Präparation leicht freigelegt werden können, ohne dass sie verletzt werden. Außerdem stehen bei Drosophila, wie oben erwähnt, eine Vielzahl genetischer Methoden zur Verfügung, die es erlauben, gezielt einzelne Bestandteile der Synapse zu verändern und die funktionellen Konsequenzen zu untersuchen. Darüber hinaus sind viele der Gene, die für die Proteine der NMJ kodieren, in der Evolution hoch konserviert, so dass sich an diesem Modell entdeckte Funktionsprinzipien mit hoher Wahrscheinlichkeit auf die Säugetiere und somit auch auf den Menschen übertragen lassen. Darüber hinaus besteht eine Reihe von strukturellen und funktionellen Gemeinsamkeiten mit exzitatorischen Synapsen im menschlichen Gehirn, die die NMJ von Drosophila als Modellsynapse überaus interessant machen. Diese Gemeinsamkeiten erstrecken sich auf den Neurotransmitter und die postsynaptischen Rezeptormoleküle, sie werden unter 1.4.2 näher besprochen.

\subsubsection{Aufbau der neuromuskulären Synapse}

Die 30 abdominellen Muskelfasern der Larve sind in sich segmental wiederholenden Einheiten angeordnet, die jeweils von Nerven des entsprechenden Segments versorgt werden (Bate et al. 1999). Die einzelnen Muskeln sind individuell identifizierbar und werden nach Lage und Größe eingeteilt und benannt (Abb. 1-5). Die Nerven erreichen den zu innervierenden Muskel bereits während der Embryonalentwicklung, das Wachstum der präsynaptischen Strukturen und des Muskels setzt sich aber bis in das Larvenstadium L3 fort. Der dabei erreichte Größenzuwachs ist enorm, die Muskeln erreichen mehr als das 100-fache ihrer ursprünglichen Größe.

Die NMJ besteht aus den terminalen Aufzweigungen der Nervenfasern, die an den Kontaktpunkten mit der Muskelzelle zwei unterschiedliche Typen von Boutons bilden 
(Johansen et al. 1989; Atwood et al. 1993). Typ-I-Boutons sind größer im

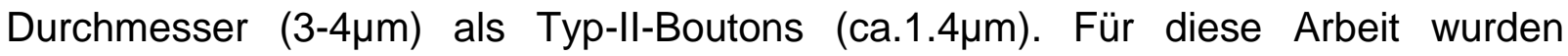
elektrophysiologische Ableitungen vom ventralen longitudinalen Muskel 6 verwendet. An diesem Muskel finden sich ausschließlich Endigungen vom Typ I (Johansen et al. 1989). Der den Muskel versorgende Nerv enthält typischerweise jeweils zwei verschiedene Axone. Das eine Axon bildet Boutons vom Typ lb (b für „big“), das andere solche vom Typ Is (s für „small"). Typ lb-Boutons sind in Größe, Mitochondrienreichtum und Ausdehnung des subsynaptischen Retikulums den Typ IsBoutons überlegen (Atwood et al. 1993).
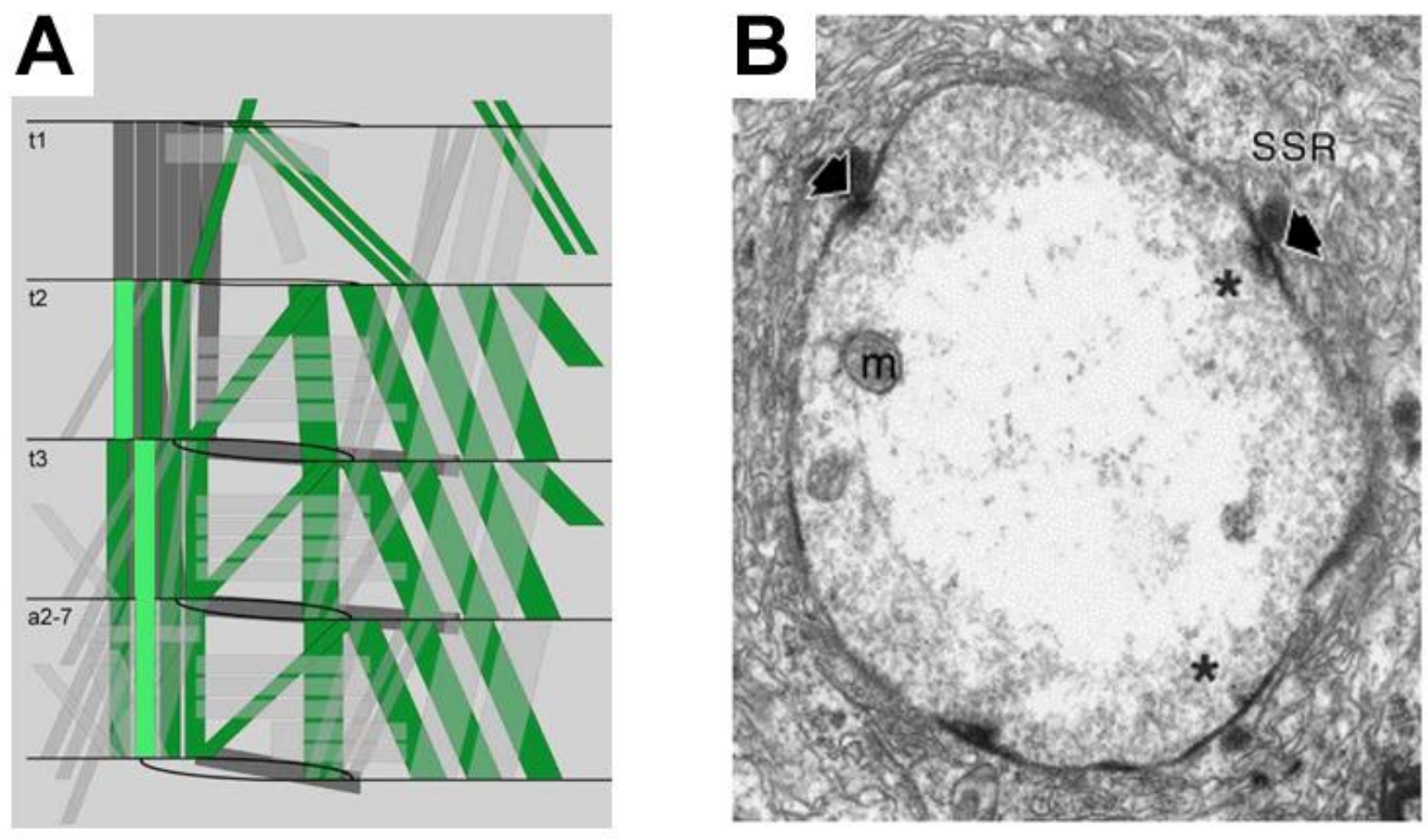

\section{Abb. 1-5 Struktur der neuromuskulären Synapse von Drosophila.}

A, Schematische Darstellung der inneren Muskelschichten einer Larve. Hellgrün hervorgehoben ist der in dieser Arbeit untersuchte ventrale longitudinale Muskel Nr. 6. Die grauen Muskelgruppen liegen weiter extern (modifiziert von Weigmann et al. 2003). B, Elektronenmikroskopische Aufnahme eines Typ-I Boutons von Muskelfaser 6. Markiert sind ein Mitochondrium (m), präsynaptische aktive Zonen ${ }^{*}$ ), das subsynaptische Retikulum (SSR) sowie T-Bars (dicke Pfeile) (modifiziert nach Aberle et al. 2002, S. 554). 
Ultrastrukturell (Abb. 1-5) stellt sich an der NMJ von Drosophila eine enge Verbindung von prä- und postsynaptischer Membran dar. Auf beiden Seiten des synaptischen Spalts findet sich elektronendichtes Material, präsynaptisch als aktive Zone (AZ) bezeichnet, postsynaptisch als postsynaptische Verdichtung (postsynaptic density, PSD). In der AZ finden sich besondere Strukturen, die aufgrund ihrer Form als T-Bars („T-Balken“) bezeichnet werden (Zhai und Bellen 2004). Diese Strukturen stehen in engem Zusammenhang mit der Freisetzung synaptischer Vesikel und der synaptischen Signalübertragung und spielen auch eine wichtige Rolle für die synaptische Kurzzeitplastizität (Kittel et al. 2006). An der Postsynapse findet sich darüber hinaus eine Spezialisierung der Membran, das so genannte subsynaptische Retikulum (SSR), dass u.a. für Calcium-Speicherung und Freisetzung verantwortlich ist.

\subsubsection{Glutamatrezeptorkomplexe an der larvalen NMJ}

Der Transmitter an der larvalen NMJ ist Glutamat (Jan und Jan 1976), genau wie bei vielen exzitatorischen Synapsen im menschlichen Gehirn. Ionotrope Glutamatrezeptoren (iGluRs) werden klassischerweise nach experimentell ermittelten Agonisten benannt und in N-Methyl D-Aspartat (NMDA)- und nicht-NMDA-Rezeptoren unterteilt (Dingledine et al. 1999). Zu den nicht-NMDA-Rezeptoren gehören die AMPA-Rezeptoren (Agonist: $\alpha$-Amino-3-Hydroxy-5-Methyl-4-Isoxazolpropionsäure, AMPA) und die Kainat-Rezeptoren. iGluRs sind homo- oder heterooligomere Proteinkomplexe, deren einzelne Bestandteile, die Glutamatrezeptor-Untereinheiten, integrale Membranproteine sind.

Das Drosophila-Genom kodiert für ca. 30 verschiedene GlutamatrezeptorUntereinheiten (Sprengel et al. 2001). Die iGluRs von Drosophila sind den nichtNMDA-Rezeptoren der Säugetiere in Struktur und Funktion verwandt. Die genaue Zusammensetzung der funktionalen ionotropen Glutamatrezeptoren an der NMJ ist noch Gegenstand der Forschung. Fünf Bausteine wurden bereits identifiziert (Schuster et al. 1991; Petersen et al. 1997; Qin et al. 2005), nämlich die Untereinheiten GluRIIA, GluRIIB sowie GluRIII/IIC, GluRIID und GluRIIE. Für die Expression und Funktion von Glutamatrezeptoren essentiell sind die Untereinheiten 
III, IID und IIE. Mutationen von jeder dieser Untereinheiten führen zu embryonaler Letalität (Qin et al. 2005). Die Untereinheiten IIA und IIB sind differenziert zu betrachten. Werden die Gene für beide Rezeptoren unterdrückt, so überleben die Tiere nicht das Embryonalstadium. Wird dagegen eine der Untereinheiten reexprimiert, so entwickeln sich die Larven und es kommt zu spezifischen funktionalen Veränderungen bezüglich der Kanalkinetik und der synaptischen Plastizität (DiAntonio et al. 1999). Im Rahmen dieser Arbeit wurden die funktionellen Eigenschaften der Untereinheiten IIB und IIE näher untersucht sowie die kürzlich entdeckte Untereinheit IIF erstmals elektrophysiologisch charakterisiert.

Man nimmt an, dass funktionale Glutamatrezeptorkomplexe Tetramere der einzelnen Untereinheiten darstellen (Rosenmund et al., 1998). Abbildung 1-6 zeigt ein Modell der Tetramerbildung bei Säugetier-Glutamatrezeptoren.

Monomers

$\mathrm{N}$

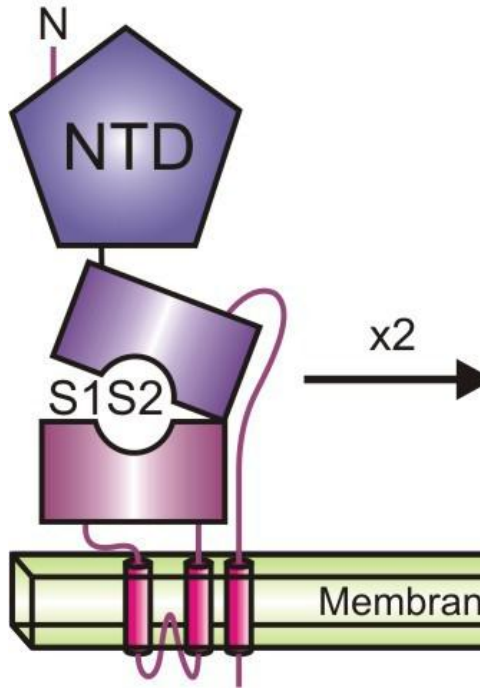

Dimer of monomers

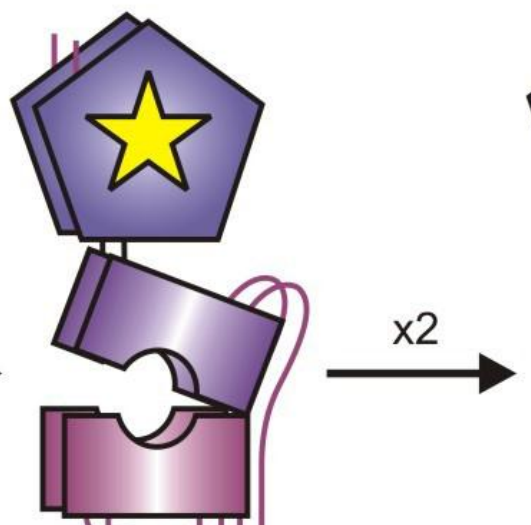

Dimer of dimers

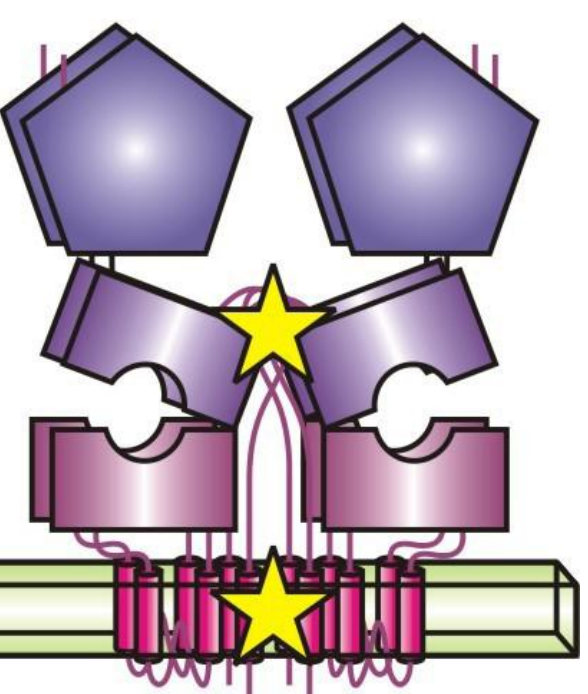

\section{Abb. 1-6 Modell des nicht-NMDA-Glutamatrezeptors.}

Schematische Darstellung der tetrameren Struktur von nicht-NMDA-Rezeptorkomplexen beim Säugetier (Madden, 2002, S. 96). Aufgrund der homologen Struktur der Drosophila-iGluRs nimmt man ein ähnliches Modell für Drosophila an (Rosenmund et al. 1998). 


\subsection{Dystroglycan und seine Rolle in der synaptischen Plastizität}

Der Dystrophin-Glykoprotein-Komplex (DGK, Abb. 1-7) ist eine Gruppe von Proteinen, die vor allem durch ihre Rolle in den Muskelerkrankungen vom Typ Duchenne und Becker bekannt geworden sind. Das Krankheitsbild ist gekennzeichnet durch den fortschreitenden Funktionsverlust und Abbau der Skelett- und Herzmuskulatur. Die schneller verlaufende und leider auch häufigere Form ist die Muskeldystrophie vom Typ Duchenne, bei der die Erkrankten bereits als junge Erwachsene sterben. Die Erkrankung beginnt oft im Bereich der Becken- und Oberschenkelmuskulatur, die progredient schwächer wird. Die Patienten müssen dann meist einen Rollstuhl benutzen. Zum Tode führt letztlich die Schwäche der Atemmuskulatur und des Herzens, die im späteren Verlauf der Krankheit zunehmend abgebaut werden. Das Protein Dystrophin, das bei diesen Krankheiten verändert oder gar nicht exprimiert wird und ihnen auch den Namen „Dystrophinopathien" gegeben hat, ist für die Stabilität von Muskelfasern enorm wichtig. Doch nicht nur die Funktion der Muskeln ist beeinträchtigt, in einigen Formen der Muskeldystrophien kommen darüber hinaus auch Beeinträchtigungen der Gehirnfunktion vor. In deren Pathogenese könnte das Molekül Dystroglycan aufgrund seiner zentralen Expression eine wichtige Rolle spielen (Montanaro und Carbonetto 2003).

In seiner Gesamtheit dient der DGK der Verankerung und Stabilisierung der Skelettund Herzmuskelzelle (Ahn und Kunkel 1993). Dabei darf aber nicht übersehen werden, dass das Dystrophin und eine Reihe verwandter Proteine auch in zahlreichen anderen Geweben, unter anderem in Nervengewebe, gefunden wurden. Die Rolle der Proteine des DGK ist daher keinesfalls auf die mechanische Stabilisierung der Muskelzelle beschränkt (Ahn und Kunkel 1993). Dystrophin stellt eine Verbindung zwischen dem kontraktilen Apparat im Inneren der Muskelzelle und der Zellmembran dar (Abb. 1-7). Es interagiert mit dem Cytoskelettprotein Aktin über seinen N-Terminus und unter anderem mit dem transmembranären Protein Dystroglycan (DG) über seinen C-Terminus (Greener und Roberts 2000). 


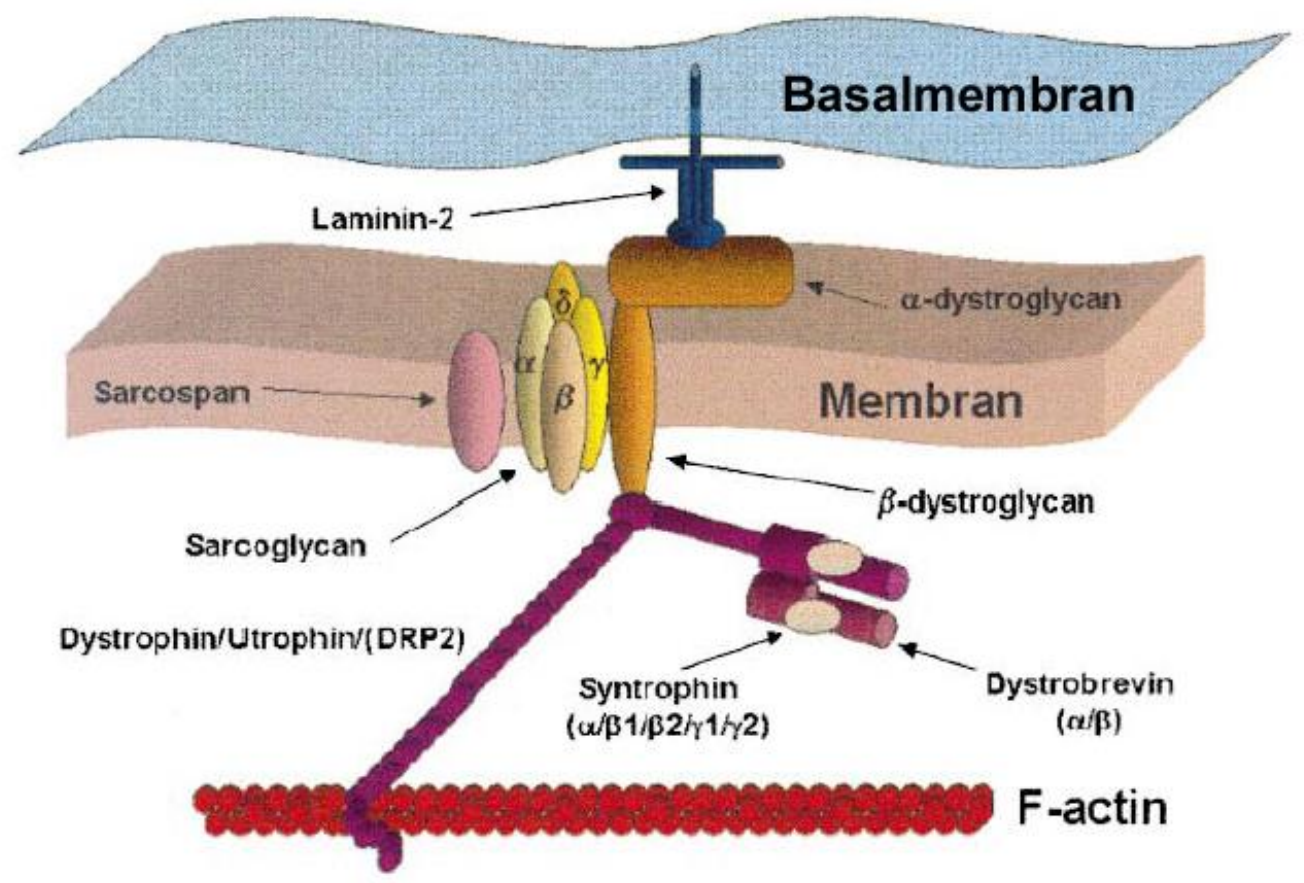

\section{Abb. 1-7 Der Dystrophinkomplex.}

Schematischer Überblick über die Proteine des Dystrophinkomplexes. Zu erkennen ist die molekulare Verankerung des Zytoskeletts im Extrazellulärraum. Die Proteine Dystrophin und Dystroglycan bilden eine zusammenhängende Struktur, die Aktin und Laminin miteinander verbinden (modifiziert nach Greener und Roberts, 2000, S. 14).

DG (Abb. 1-8) wurde 1992 erstmals charakterisiert (Ibraghimov-Beskrovnaya et al. 1992) und schon zu diesem Zeitpunkt mit der Pathogenese der Dystrophinopathien in Verbindung gebracht. Das Gen (DAG1) für Dystroglycan liegt auf dem menschlichen Chromosom 3 und enthält zwei Exons und ein Intron. Aus dem primären Transkript entstehen durch proteolytische Spaltung zwei Untereinheiten, das a-Dystroglycan und das $\beta$-Dystroglycan (Sgambato und Brancaccio 2005), die gemeinsam einen funktionalen dimeren Proteinkomplex bilden. Die $\beta$-Untereinheit durchzieht die Muskelzellmembran und stellt die Verbindung mit Dystrophin (in Muskelzellen) bzw. Utrophin (in Epithelien) her, während die $\alpha$-Untereinheit das Bindeglied für extrazelluläre Strukturproteine wie etwa dem Laminin (Ibraghimov-Beskrovnaya et al. 1992) darstellt. Die beiden Untereinheiten sind durch nicht-kovalente Bindungen aneinander geheftet (Sciandra et al. 2001). 


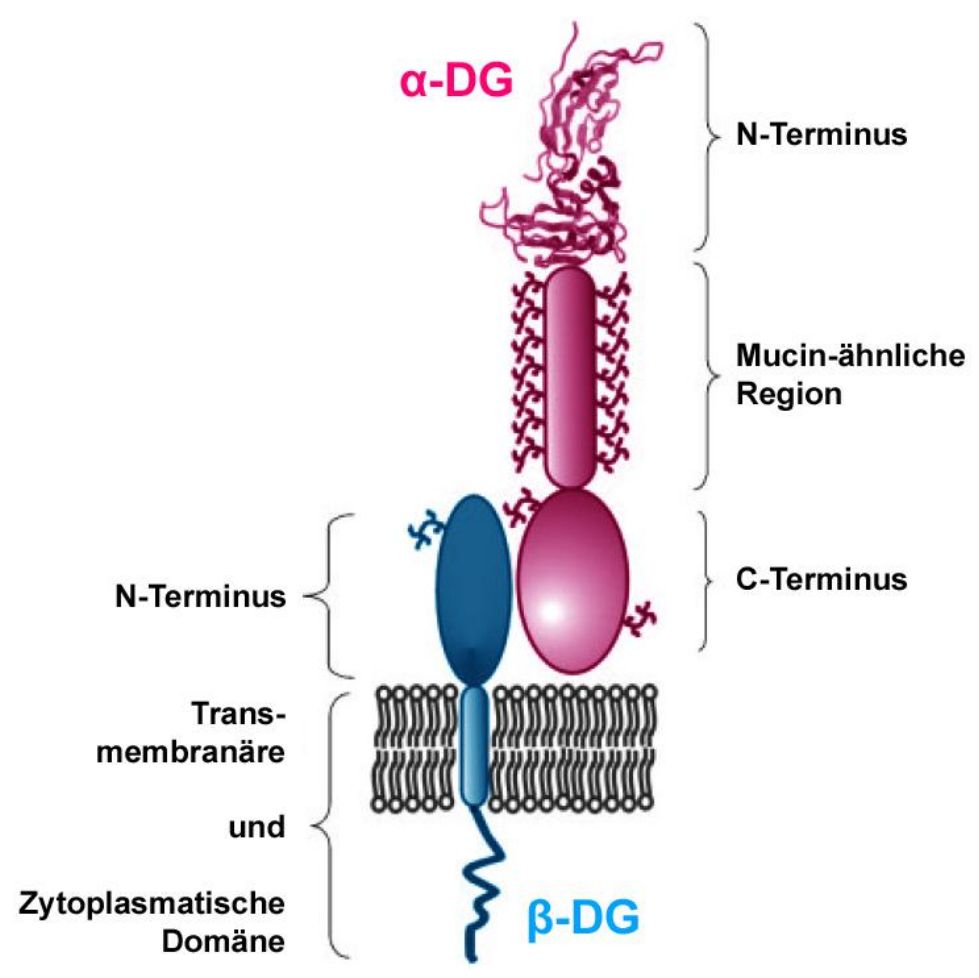

\section{Abb. 1-8 Dystroglycan.}

Darstellung der Struktur des DG-Dimers. Neben den prinzipiellen Domänen ( $\alpha-D G, \beta-D G)$ des Komplexes ist die auffällige Glykosylierung insbesondere im Bereich der Mucin-ähnlichen Region erkennbar (modifiziert nach Sgambato und Brancaccio, 2005, S. 164).

Das $\alpha$-DG ist insbesondere in einer so genannten Mucin-ähnlichen Region vielfach glykosyliert. Diese Kohlenhydrathülle dient dem Protein zum einen als Schutz vor extrazellulären Proteasen (Sgambato und Brancaccio 2005), zum anderen beeinflusst sie aber auch die Funktion und insbesondere das Bindungsvermögen des DG (Winder 2001).

Obwohl es sich bei DG der Struktur und Bindungspartner nach um ein Adhäsionsprotein handelt, so scheint seine Funktion doch weitaus vielfältiger zu sein. In Epithelien steht seine Expression offenbar mit der Entstehung und Malignität von Krebszellen in Zusammenhang. Eine verminderte Expression von DG führt in bestimmten Tumorzellinien beispielsweise zu einem Verlust der Polarisierungsfähigkeit der Zellen und wurde mit einer gesteigerten Invasivität von 
Tumorzellen assoziiert (Muschler et al. 2002). DG spielt darüber hinaus eine wichtige Rolle bei der Entwicklung postsynaptischer Strukturen im zentralen und peripheren Nervensystem (Grady et al. 2000; Sgambato und Brancaccio 2005). So ist seine Expression im oberen Halsganglion von Mäusen nach der Durchtrennung des Axons vermehrt (Zaccaria et al. 2001), was eine Funktion bei posttraumatischen synaptischen Umbauvorgängen nahe legt. Diese Umbauvorgänge aber bedienen sich vermutlich ähnlicher Mechanismen wie die synaptische Plastizität, was die Untersuchung von DG im Rahmen der synaptischen Übertragung interessant macht. Für die synaptische Langzeitplastizität konnte sogar schon gezeigt werden, dass ein Fehlen von Dystroglycan in Form einer Nullmutante die Langzeitplastizität nahezu vollständig beseitigt (Moore et al. 2002). Ob DG auch eine Rolle bei der Kurzzeitplastizität spielt, ist bisher nur unzureichend geklärt und soll in dieser Arbeit anhand von Drosophila-Mutanten näher untersucht werden. Vor kurzem konnte gezeigt werden, dass sich DG-Mutanten von Drosophila als Modellorganismen zur Erforschung der Muskeldystrophie eignen (Shcherbata et al. 2007), da sie viele Phänotypen der Erkrankung rekapitulieren. 


\subsection{CDK5 und synaptische Übertragung}

CDK5 ist eine Serin/Threonin-Kinase aus der Familie der Cyclin-abhängigen Kinasen (CDK). Bei den CDKs handelt es sich allgemein um Proteine, die durch Phosphorylierung verschiedener Bindungspartner insbesondere Funktionen bei der Regulation des Zellzyklus und Stoffwechsels, aber auch verschiedenste andere Aufgaben übernehmen (Morgan 1995). Generell zeichnen sich die CDKs dadurch aus, dass für ihre Aktivierung die Bindung eines weiteren Proteins aus der Gruppe der so genannten Cycline nötig ist.

CDK5 weicht in dieser Hinsicht von den anderen CDKs ab, da es nicht durch Cycline, sondern durch die Proteine p35 und p39, sowie deren Spaltprodukte p25 und p29 aktiviert wird (Cheung et al. 2006). Es konnte gezeigt werden, dass die Funktion und Substratspezifität von CDK5 durch die verschiedenen Aktivatoren unterschiedlich beeinflusst wird (Angelo et al. 2006). Abhängig vom Expressionsmuster der Aktivatoren in verschiedenen Geweben ergibt sich so eine Vielzahl möglicher Aufgaben von CDK5. Es überrascht daher nicht, dass allein für den Bereich Synapse bereits eine große Anzahl von Untersuchungen existiert, die einen Einfluss von CDK5 auf prä-, post- und extrasynaptische Funktionsabläufe nahe legen, die die synaptische Funktion direkt beeinflussen. Es konnte eine Reihe von Interaktionspartnern von CDK5 identifiziert werden, die an der synaptischen Übertragung beteiligt sind. Dazu gehören beispielsweise präsynaptische Proteine wie das an der Bildung des Fusionskomplexes beteiligte Munc-18, Spannungsabhängige Calcium-Kanäle oder die für die Transmittersynthese zuständige Tyrosinhydroxylase, aber auch postsynaptische Proteine wie das PSD-95, welches an der korrekten Anordnung der Bestandteile der PSD inklusive der Rezeptoren beteiligt ist (Angelo et al. 2006). Obwohl ein recht breites Spektrum an Untersuchungen auf einen Einfluss von CDK5 auf die synaptische Übertragung hinweist, so ist doch die Art dieses Einflusses weitaus weniger gut verstanden. So konnten Hinweise auf eine transmissionsverstärkende Wirkung von CDK5 gefunden werden, die durch Beeinflussung der Interaktion von Munc-18 und Syntaxin-1, einem ebenfalls am Fusionskomplex beteiligten Membranprotein, zustande kommt (Fletcher et al. 1999). Andererseits konnte aber auch ein negativer Einfluss von CDK5 auf die synaptische 
Übertragung gefunden werden: CDK5 ist in der Lage, spannungsabhängige Calciumkanäle zu phosphorylieren und die Kanalfunktion dadurch zu beeinträchtigen, was die Transmitterfreisetzung behindert (Tomizawa et al. 2002). Darüber hinaus deuten weitere Untersuchungen auf einen negativen Einfluss von CDK5 über verschiedene Mechanismen (Angelo et al. 2006).

Doch die Funktion von CDK5 ist sicher nicht auf eine direkte Beeinflussung der synaptischen Übertragung beschränkt. Wie schon die vielfältigen Interaktionsmöglichkeiten des Proteins nahe legen, scheint es in viele zelluläre Prozesse als Regulator eingebunden zu sein. Dies schließt auch eine Bedeutung bei pathologischen Vorgängen mit ein. So wird derzeit beispielsweise eine Beteiligung von CDK5 an der Pathophysiologie der Alzheimer'schen Erkrankung diskutiert. Die auch als Morbus Alzheimer bekannte Krankheit gehört zu den neurodegenerativen Krankheiten, bei denen ein Verlust von Nervenzellen zur zunehmenden Funktionseinschränkung des zentralen Nervensystems führt. Betroffene Personen leiden unter einer progredienten Beeinträchtigung von Intelligenz, Gedächtnis und Persönlichkeit bei erhaltenem Bewusstsein. Bei der Alzheimer'schen Erkrankung finden sich verschiedene pathologische Veränderungen im Gehirn, sowohl auf makroskopischer wie auch mikroskopischer Ebene. Ein typisches histologisches Kennzeichen sind die so genannten Neurofibrillenbündel in den Perikarya von Nervenzellen im Gehirn. Es handelt sich dabei um Proteinstrukturen, die sich zu einem großen Teil aus dem Tau-Protein zusammensetzen, einem normalen Zellstrukturprotein, das jedoch bei der Alzheimerschen Erkrankung in übermäßig stark phosphorylierter Form vorliegt (Mi und Johnson 2006; Wang et al. 2007). In gesunden Zellen fungiert das Tau-Protein als Stabilisator der Mikrotubuli und fördert deren Polymerisation (Weingarten et al. 1975). Dieser Prozess ist bei Morbus Alzheimer offenbar gestört. Die Neurofibrillenbündel, die wie erwähnt zum Großteil aus Tau bestehen, akkumulieren in der Zelle und führen letztlich zum Untergang des Neurons. Dieser Prozess ist nicht auf die Alzheimersche Erkrankung beschränkt. Die Entdeckung dieses Krankheitsmechanismus hat zum Begriff der "Tauopathien“ geführt. Darunter werden neurodegenerative Krankheiten zusammengefasst, bei denen abnorme Tau-Komplexe gefunden wurden (Lee et al. 2001). Neben Morbus 
Alzheimer sind dies seltenere Erkrankungen wie die progressive supranukleäre Blickparese und Morbus Pick.

Nachdem das Tau-Protein entdeckt und seine Beteiligung an den Neurofibrillenbündeln offensichtlich wurde, fand man heraus, dass Tau bei Morbus Alzheimer in vermehrt phosphorylierter Form vorliegt (Mi und Johnson 2006). Der Grund dafür ist noch unklar, jedoch werden große Anstrengungen unternommen, die Bindungspartner von Tau und ihre Rolle in der Entstehung abnormer Tau-Strukturen $\mathrm{zu}$ identifizieren. Zu den vielen in diesem Zusammenhang untersuchten Proteinen gehört auch die CDK5. In verschiedenen Neuronen konnte immunhistochemisch eine Akkumulierung von CDK5 bei Morbus Alzheimer gezeigt werden (Pei et al. 1998). Darüber hinaus gelang der Nachweis, dass verschiedene Kombinationen von Proteinkinasen nötig sind, um Tau von seinem normalen Zustand in den vermehrt phosphorylierten „Alzheimer-Zustand“ zu bringen (Wang et al. 2007). Gemeinsam mit anderen Kinasen scheint CDK5 also an der Entstehung der Neurofibrillenbündel und damit der Alzheimerschen Erkrankung beteiligt zu sein.

In vielen Untersuchungen standen also vor Allem Fragen nach Substraten und Bindungspartnern von CDK5 im Vordergrund. Die Kenntnis solcher Interaktionspartner ist wichtig, dennoch darf nicht übersehen werden, dass das die Funktion des Proteins sich nicht allein aus seinem Bindungsverhalten ableiten lässt. Die Bedeutung für die synaptische Übertragung aber ist bislang unzureichend untersucht. Um der Frage weiter nachzugehen, in welcher Weise CDK5 auf die synaptische Transmission wirkt, erschien es sinnvoll, anhand eines verhältnismäßig übersichtlichen und gut zugänglichen Modellsystems wie Drosophila die Bedeutung von CDK5 für die Synapse in vivo zu untersuchen. 


\section{Methode}

\subsection{Fliegenaufzucht}

Die Aufzucht der Fliegen geschah bei $25^{\circ} \mathrm{C}$ in Standard-Kulturgefäßen mit Apfelagar und Trockenhefe. Einige Stämme wurden bei $29^{\circ} \mathrm{C}$ aufgezogen, dies ist im Ergebnisteil jeweils vermerkt. Für Kreuzungen mussten unbefruchtete weibliche Tiere selektiert werden. Hierfür wurden alle Fliegen aus einer mit Puppen besetzten Flasche entfernt und anschließend bei $25^{\circ} \mathrm{C}$ Aufzuchttemperatur alle 8 Stunden die frisch geschlüpften Weibchen entnommen. Die verwendeten Fliegenstämme sind in Tabelle 2-1 aufgeführt.

\begin{tabular}{|c|c|c|}
\hline Name & Genetik & Quelle \\
\hline W1 & $\frac{\mathrm{w}-}{\mathrm{w}-} ; \frac{+}{+} ; \frac{ \pm}{+}$ & (Castiglioni 1951) \\
\hline$d g 1554$ & piggybac insertion $d g_{e 01554}$ & $\begin{array}{l}\text { (Laurent Bogdanik, Institut de } \\
\text { Génomique Functionnelle, } \\
\text { Département de Neurobiologie, } 141 \\
\text { Rue de la Cardonille, Montpellier, } \\
\text { Cedex 5, F-34094, France) }\end{array}$ \\
\hline IIB-Genomisch & $\frac{\mathrm{w}-}{\mathrm{w}-} ; \frac{\mathrm{dfcl}^{\mathrm{h} 4}}{\mathrm{~A} 22} ; \frac{\text { UAS-gluRIIB }}{+}$ & (Schmid, 2006) \\
\hline IIB-GFP & $\frac{\mathrm{w}-}{\mathrm{w}-} ; \frac{\mathrm{dfcl}^{\mathrm{h} 4}}{\mathrm{~A} 22} ; \frac{\mathrm{UAS}^{-g l u R I I B}{ }^{\mathrm{GFP897}}}{+}$ & (Schmid, 2006) \\
\hline$I I E-R N A i^{*}$ & $\frac{\mathrm{w}-}{\mathrm{w}-} ; \frac{\text { UASgluRIIERNAi }}{+} ; \frac{24 \mathrm{~B}-\mathrm{Gal} 4}{+}$ & (Schwarz, 2007) \\
\hline$I I F-R N A i^{*}$ & $\frac{\mathrm{w}-}{\mathrm{w}-} ; \frac{\text { UASgluRIIFRNAi }}{+} ; \frac{24 \mathrm{~B}-\mathrm{Gal} 4}{+}$ & (Schwarz, 2007) \\
\hline$W 1-24 B^{*}$ & $\frac{\mathrm{w}-}{\mathrm{w}-} ; \frac{+}{+} ; \frac{24 \mathrm{~B}-\mathrm{Gal} 4}{+}$ & (Schwarz, 2007) \\
\hline
\end{tabular}

\section{Tabelle 2-1 Genetik verwendeter Tiere.}

Dargestellt sind die Genotypen aller verwendeten Larven. Das 4. Chromosom ist nicht angegeben. ${ }^{*}$ Die Aufzucht der RNAi-Linien und von W1-24B geschah bei $29^{\circ} \mathrm{C}$. 


\subsection{Elektrophysiologie}

Grundsätzlich gibt es mehrere elektrophysiologische Methoden, mit denen man die Signalübertragung an Synapsen quantifizieren kann. Zunächst ist die Frage nach dem zu messenden Signal zu stellen. Dies kann einerseits das über einer Membran herrschende Spannungspotential sein, andererseits kann auch der über die Membran fließende Strom von Interesse sein. Für beide Arten von Messung gibt es jeweils eine prinzipielle elektrophysiologische Schaltung: Die Spannungsklemme zur Messung des elektrischen Stroms und die Stromklemme zur Messung der Spannung. Grundsätzlich lassen sich beide Messverfahren mit dem gleichen experimentellen Aufbau durchführen. Bei vielen Experimenten ist es sogar nötig, beide Verfahren direkt nacheinander am selben Untersuchungsobjekt anzuwenden. Bevor jedoch die beiden Verfahren und ihre Anwendungsvarianten genauer besprochen werden, sollen einige Grundlagen elektrischer Phänomene an der Zellmembran erläutert werden.

\subsubsection{Grundlagen der Bioelektrizität an Zellmembranen}

Elektrischer Strom ( $($ ) ist definiert als Quotient aus der durch einen Leiter bewegten Ladung $(Q)$ pro Zeit (t). Die Maßeinheit des elektrischen Stroms ist das Ampere (A). In einem elektrophysiologischen Experiment fließt Strom grundsätzlich auf zwei Arten. Zum einen durch die metallischen Leiter und Elektroden des Messapparates, zum anderen durch das Zytoplasma, über die Membran, im Bad und innerhalb der Messpipetten in salzhaltigen Lösungen. Während in metallischen Leitern die frei beweglichen Elektronen die Ladungsträger darstellen, so sind es in den Lösungen die verschiedenen Kationen und Anionen. Der Leiter, durch den der elektrische Strom fließt, ist durch seinen elektrischen Widerstand $(R)$ gekennzeichnet, die Maßeinheit ist das Ohm $(\Omega)$. Die Zellmembran hat einen hohen elektrischen Widerstand, da sie aufgrund ihrer physikalischen Eigenschaften von den gelösten lonen kaum zu überwinden ist. Dies liegt vor allem an der chemischen Zusammensetzung der Membran aus Phospholipiden, die über lange hydrophobe Kohlenstoffketten verfügen. Ein geladenes Teilchen benötigt eine außerordentlich hohe Energie, um sich in dieser Umgebung zu lösen, der Eintritt eines lons in die Membran ist daher unter normalen 
Bedingungen extrem unwahrscheinlich. Ein lonenfluss über die Membran ist nahezu ausschließlich über spezielle transmembranäre Proteine möglich. Diese Proteine können passiv leitende Kanäle in der Membran darstellen, in deren Inneren die Löslichkeit bestimmter lonen stark erhöht ist, man spricht dann von mehr oder weniger ionenselektiven Kanälen. Neben der bloßen Erleichterung der Diffusion können bestimmte Proteine aber auch unter Energieaufwand Teilchen über die Membran transportieren, man spricht dann von primär aktivem Transport, falls Adenosintriphosphat (ATP) die Energie bereitstellt, oder von sekundär aktivem Transport, falls der Transporter den Konzentrationsgradienten eines anderen Teilchens als Energiequelle ausnutzt. Für die Betrachtung der Bioelektrizität sind diese Proteine insofern wichtig, als dass sie die Grundlage für die Entstehung der Konzentrationsgradienten an der Membran darstellen. Unter 2.2.2 wird die Bedeutung der Konzentrationsgradienten näher besprochen.

Elektrischer Strom fließt zwischen Orten mit einer Spannungsdifferenz. Dies bedeutet, dass ein Ladungsträger Energie verliert oder aufnimmt, wenn er sich zwischen Punkten mit unterschiedlichen elektrischen Potentialen bewegt. Die Spannung (U), gemessen in Volt (V), gibt die Energie an, die ein solcher Ladungsträger dabei aufnimmt oder verliert. Spannung, Strom und Widerstand stehen im elektrischen Stromkreis nach dem Ohm'schen Gesetz miteinander in Verbindung:

$$
U=I R
$$

Für elektrophysiologische Messungen ist dieses Gesetz eine wichtige Grundlage. Der elektrische Widerstand ist der Kehrwert der elektrischen Leitfähigkeit $(G)$, gemessen in Siemens (S). Die Leitfähigkeit von Zellmembranen ist ein sehr interessanter Parameter, da sie direkt mit dem Öffnungszustand der lonenkanäle zusammenhängt. Geöffnete lonenkanäle stellen in der Membran Orte dar, an denen der sonst hohe Membranwiderstand $\left(R_{\mathrm{m}}\right)$ stark erniedrigt wird. In einem vereinfachten Modell kann man sich die geöffneten Kanäle daher als parallel geschaltete (da in der Membran nebeneinander liegende) Leiter vorstellen. Die Gesamtleitfähigkeit errechnet sich dann als Summe der einzelnen Leitfähigkeiten der geöffneten Kanäle. Über die Änderung von $G$ kann man daher das Öffnen und Schließen der Kanäle beurteilen. Andere Parameter, die $G$ beeinflussen, können weitgehend außer Betracht gelassen 
werden, da sie während eines Experimentes Konstanten darstellen. Es sind dies vor allem die Dicke, Zusammensetzung und Ausdehnung der Membran sowie die Temperatur. Zur Beurteilung der Leitfähigkeit wird das Ohm'sche Gesetz herangezogen. Einer der Parameter $U$ oder I wird experimentell konstant gehalten, der andere über den Messapparat verfolgt - im Ergebnis lässt sich die Leitfähigkeit bestimmen. Dabei muss immer bedacht werden, dass $G$ mit dem Öffnungszustand aller lonenkanäle zusammenhängt. Eine Erhöhung von $G$ bedeutet nicht zwangsläufig, dass Transmittermoleküle ihre Rezeptoren aktiviert haben. So können z.B. auch spannungsgesteuerte lonenkanäle abhängig vom Membranpotential öffnen und zu einer Veränderung der Leitfähigkeit führen. Dieses Problem lässt sich mit der Spannungsklemme umgehen und wird unter 2.2.4 näher besprochen.
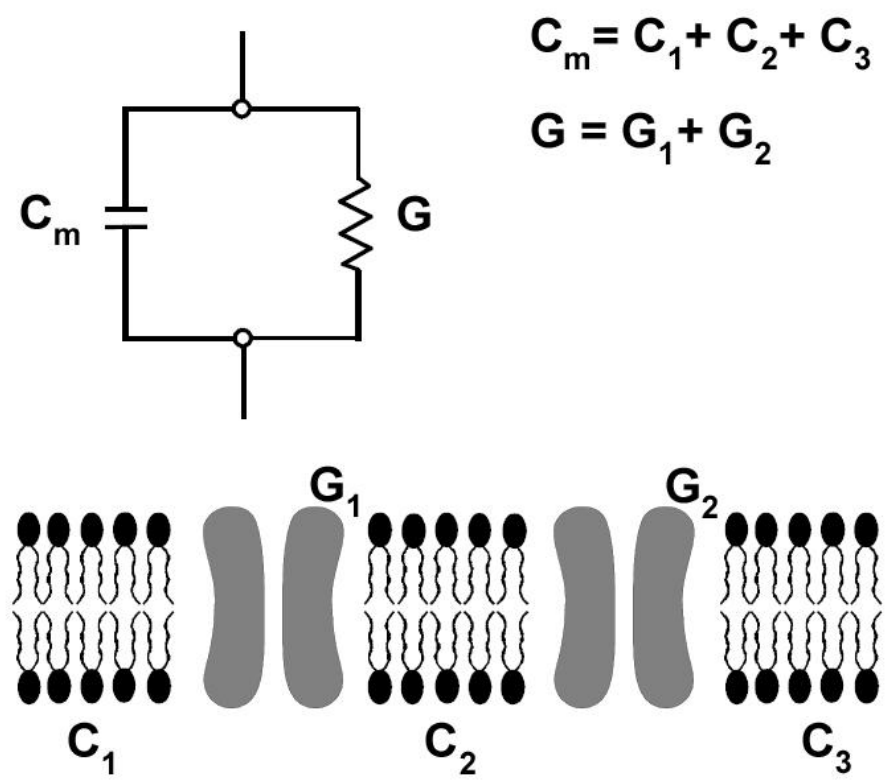

\section{Abb. 2-1 Vereinfachtes elektrisches Modell der Zellmembran}

Dargestellt sind ein elektrischer Schaltplan des Modells sowie ein Schema der Zellmembran. Die Leitfähigkeiten zweier lonenkanäle $\left(G_{1}, G_{2}\right)$ addieren sich zur Gesamtleitfähigkeit $G$. Gleiches gilt für die Kapazität der Membranabschnitte $\left(C_{1}, C_{2}, C_{3}\right)$, die sich zur Membrankapazität addieren. $C_{\mathrm{m}}$ und $G$ sind parallel geschaltet (modifiziert nach Sherman-Gold, 2006, S. 22).

Neben $R_{\mathrm{m}}$ bzw. $G$ verfügt die Membran über eine weitere wichtige Eigenschaft, nämlich die Membrankapazität $\left(C_{\mathrm{m}}\right)$. Sie wird unter 2.2.5 in ihrer Bedeutung näher besprochen, soll aber hier schon erwähnt werden, damit wir ein an dieser Stelle ein 
grundlegendes Modell der Zellmembran einführen können, in dem die wesentlichen elektrischen Eigenschaften zusammengefasst sind (Abb. 2-1). Abhängig von Dicke, Fläche und Zusammensetzung verfügt die Membran über eine Kapazität ( $C$, Einheit ist das Farad, F). Jeder Abschnitt der Zellmembran lässt sich vereinfacht als ein Plattenkondensator vorstellen, die gesamte Membran als eine Parallelschaltung dieser Kondensatoren, oder einfach als ein großer Kondensator. Bei Parallelschaltung errechnet sich die Gesamtkapazität, also $C_{\mathrm{m}}$, demnach als Summe der Kapazitäten der einzelnen Membranabschnitte.

\subsubsection{Das Ruhemembranpotential}

Bisher haben wir betrachtet, welchen Gesetzmäßigkeiten der Stromfluss über der Membran unterliegt. Im Folgenden soll erläutert werden, welche treibenden Kräfte überhaupt zu einem Stromfluss führen.

Zwischen der Innen- und Außenseite der Zellmembran herrscht für die meisten Ionen ein Konzentrationsgefälle. Das bedeutet, dass die Konzentration der Teilchen auf der einen Seite größer ist als auf der anderen. Dieser Unterschied kommt durch die verschiedensten Transportproteine zustande und ist stark vom untersuchten biologischen System abhängig, auf die Entstehung des Konzentrationsgradienten soll hier nicht näher eingegangen werden. Nach dem Fick'schen Diffusionsgesetz führt das Konzentrationsgefälle zu einem Nettostrom von lonen in Richtung des Ortes mit der niedrigeren Konzentration (Despopoulos und Silbernagel 2003, S. 20). Da es sich bei den lonen aber um Ladungsträger handelt, bedeutet jede Bewegung eine Verschiebung von Ladung, so dass ein dem Konzentrationsgefälle entgegen gesetztes Potential entsteht. Dieses Potential nennt sich Diffusionspotential $(E)$. Je mehr lonen entlang des Konzentrationsgefälles diffundieren, desto größer wird $E$, bis sich ein Gleichgewicht einstellt. Die Lage des Gleichgewichts für ein lon X beschreibt die allgemeine Nernst-Gleichung (Despopoulos und Silbernagel 2003, S. 32).

$$
\mathrm{E}_{\mathrm{x}}=\left(\frac{\mathrm{RT}}{\mathrm{z}_{\mathrm{x}} \mathrm{F}}\right) * \ln \left(\frac{[\mathrm{X}]_{\mathrm{a}}}{[\mathrm{X}]_{\mathrm{i}}}\right)
$$

$\mathrm{R}$ ist die allgemeine Gaskonstante, $T$ die Temperatur (in Kelvin, $\mathrm{K}$ ), $\mathrm{z}_{\mathrm{x}}$ ist die 
Wertigkeit des lons $\mathrm{X}$ und $\mathrm{F}$ die Faraday-Konstante (Ladung pro mol). [X]a gibt die extrazelluläre, [X]i die intrazelluläre Aktivität von X an. Unter Aktivität versteht man die wirksame Konzentration, sie hängt von der molaren Konzentration aller gelösten Ionensorten ab und ist als Ausdruck der gegenseitigen Interaktion der lonen geringer als die molare Konzentration. Das Diffusionspotential im Gleichgewicht wird auch Gleichgewichtspotential (für Ion $\mathrm{X}$ : $E_{\mathrm{x}}$ ) genannt. Im Gleichgewicht ist der Nettoionenstrom für das betreffende lon gleich null. In einer lebenden Zelle ist aber nicht nur eine Art von Ion, sondern viele verschiedene zu finden. Das tatsächliche Ruhemembranpotential $\left(V_{\mathrm{m}}\right)$ ist eine Kombination der Gleichgewichtspotentiale der vorhandenen Ionen. Es wird auch als Umkehrpotential (reversal potential, $V_{\text {rev }}$ ) bezeichnet, da sich der Nettoionenstrom bei Erreichen von $V_{\mathrm{m}}$ umkehrt. Für $V_{\mathrm{m}}$ selbst gilt, dass der Nettoionenstrom aller lonen gleich null ist. $V_{m}$ ist, wie aus der NernstGleichung ersichtlich, abhängig von den Konzentrationsdifferenzen der beteiligten Ionen, darüber hinaus spielt aber auch der Permeabilitätskoeffizient $P$ für jedes Ion eine Rolle. Er ist ein konzentrationsunabhängiges Maß für die Durchlässigkeit der Membran für ein bestimmtes Ion. Anschaulich bedeutet dies folgendes: Je größer $P$ für ein lon $\mathrm{X}$ im Verhältnis zu $P$ der anderen beteiligten Ionenarten, desto größer ist der Einfluss des Gleichgewichtspotentials von $\mathrm{X}$ auf $V_{\mathrm{m}}$. Die Goldman-Gleichung (Boron und Boulpaep 2003, S. 153) beschreibt diesen Zusammenhang und ermöglicht die Berechnung von $V_{\mathrm{m}}$ an Membranen, die für verschiedene lonensorten permeabel sind. Sie geht von der Annahme aus, dass der totale Ionenstrom der Summe der lonenströme der einzelnen Ionenarten entspricht. Die Goldman-Gleichung berücksichtigt in der hier präsentierten einfachen Form nur die für $V_{m}$ wichtigsten lonen $\mathrm{K}^{+}, \mathrm{Na}^{+}$und $\mathrm{Cl}^{-}$.

$$
\mathrm{V}_{\mathrm{m}}=-\frac{\mathrm{RT}}{\mathrm{F}} *\left(\frac{\mathrm{P}_{\mathrm{K}}\left[\mathrm{K}^{+}\right]_{\mathrm{i}}+\mathrm{P}_{\mathrm{Na}}\left[\mathrm{Na}^{+}\right]_{\mathrm{i}}+\mathrm{P}_{\mathrm{Cl}}\left[\mathrm{Cl}^{-}\right]_{\mathrm{a}}}{\mathrm{P}_{\mathrm{K}}\left[\mathrm{K}^{+}\right]_{\mathrm{a}}+\mathrm{P}_{\mathrm{Na}}\left[\mathrm{Na}^{+}\right]_{\mathrm{a}}+\mathrm{P}_{\mathrm{Cl}}\left[\mathrm{Cl}^{-}\right]_{\mathrm{i}}}\right)
$$

Wir sind nun in der Lage, ausgehend von den Konzentrationsgradienten der beteiligten lonen eine Voraussage über $V_{\mathrm{m}}$ zu treffen. Dieser Zusammenhang stellt die Grundlage zur Analyse und Interpretation der elektrophysiologischen Messdaten dar. Im Folgenden sollen nun die verwendeten Methoden und die mit innen untersuchten Parameter beschrieben werden. 


\subsubsection{Die Spannungsklemme}

Das Grundlegende Prinzip der Spannungsklemme wurde bereits in den 1950er Jahren von Hodgkin und Huxley (Hodgkin et al. 1952) zur Charakterisierung des Aktionspotentials eingesetzt. Der Aufbau besteht aus zwei intrazellulären Elektroden, einem Feedback-Mechanismus und einer extrazellulären Referenzelektrode. Die eine intrazelluläre Elektrode, auch "Spannungselektrode“ genannt, dient dazu, das Membranpotential in Bezug zur Referenzelektrode, die sich in der Badlösung befindet, zu messen. Ein externer Signalgeber, der vom Experimentator gesteuert wird, liefert ein so genanntes Haltepotential (command voltage, $V_{c m d}$ ), also einen Sollwert für das Membranpotential. Ein Verstärkerbaustein vergleicht dann das Haltepotential mit dem aktuell gemessenen Membranpotential. Besteht eine Differenz zwischen den beiden Potentialen, so sendet der Verstärkerbaustein einen zur Differenz proportionalen Strom durch die zweite intrazelluläre Elektrode, die daher auch "Stromelektrode“ genannt wird. Dieser Strom, auch „Haltestrom“ $\left(I_{h}\right)$ genannt, ist in Richtung und Stärke von der gemessenen Spannungsdifferenz $(\varepsilon)$ abhängig und sorgt dafür, dass die Spannungsdifferenz im Idealfall neutralisiert wird. Das Membranpotential der Zelle entspricht dann dem Haltepotential. Der eigentliche Messwert ist hierbei der über die Stromelektrode applizierte Strom. Sofern mögliche Störfaktoren (allen voran die Kondensatoreigenschaften der Membran), die im Folgenden besprochen werden, neutralisiert werden können, ist der gemessene Strom direkt proportional zur Leitfähigkeit der Membran. Es gilt dabei das umgeformte Ohm'sche Gesetz:

$$
I=U G
$$

Wie oben erwähnt, ist die Änderung der Leitfähigkeit ein direktes Abbild des Öffnungszustandes der lonenkanäle und eignet sich somit hervorragend zur Quantifizierung der synaptischen Übertragung. Die Spannungsklemme löst nun auch das Problem der spannungsabhängigen lonenkanäle. Da das Membranpotential während des gesamten Experiments konstant auf Höhe des Haltepotentials steht, ist keine Veränderung am Öffnungszustand der spannungsabhängigen Kanäle zu erwarten. Die ermittelte Leitfähigkeit ist bei der Spannungsklemme also ein recht genaues Abbild des Öffnungszustandes der transmittergesteuerten lonenkanäle. 


\subsubsection{Die Zwei-Elektroden Spannungsklemme}

Die Zwei-Elektroden Spannungsklemme (two-electrode voltage clamp, TEVC) ist eine Anwendungsvariante der Spannungsklemme. Spannungselektrode (microelectrode, ME1) und Stromelektrode (ME2) sind hierbei zwei extrem feine Glaspipetten. Hodgkin und Huxley, die mit dem Riesenaxon des Tintenfisches gearbeitet haben (Hodgkin et al. 1952), setzten bei ihren Experimenten als Elektroden feine Drähte ein, die direkt in die Zelle eingebracht bzw. auf die Membran aufgelegt wurden. Dieses Verfahren ist bei kleineren, empfindlicheren Zellen nicht möglich, ohne die Zelle massiv zu beschädigen. Die TEVC erlaubt durch die Verwendung von Glaspipetten, die Verbindung ins Zellinnere auf schonendere Weise herzustellen, so dass auch etwas kleinere Zellen, wie beispielsweise die abdominellen Muskelzellen von Drosophila, untersucht werden können. Dennoch ist die TEVC in ihrer Einsetzbarkeit beschränkt. Pipettenform und Spitzendurchmesser sollten so gewählt werden, dass die penetrierte Zelle möglichst wenig verletzt wird. Auf der anderen Seite muss die gewählte Pipette bestimmte elektrische Eigenschaften besitzen, damit die Spannungsklemme in der Lage ist, auch zeitlich eng aneinander liegende Ereignisse aufzulösen. Im Folgenden soll zunächst der Aufbau, die Einstellungsmöglichkeiten und Probleme der TEVC erläutert werden. Im Anschluss daran wird unter 2.2.6 das experimentelle Vorgehen beschrieben.

Der prinzipielle Aufbau der TEVC ist in der Abbildung 2-2 zu erkennen. Die präparierte Larve befindet sich in einer Messkammer und wird mit einem Mikroskop betrachtet. Die Glaspipetten werden mit Hilfe von Mikromanipulatoren über der Präparation bewegt, die Kontrolle des Verstärkers und die Aufnahme des Messsignals erfolgen am Computer. Die Stimulation der Synapsen geschieht über den zugehörigen Segmentnerven, der in eine Ansaugelektrode hineingesogen wird. Mit einem externen Stimulator werden über kurze Strompulse Aktionspotentiale ausgelöst. Dieser Stimulator ist an den Verstärker angeschlossen, so dass sich die Stimulation über standardisierte Protokolle am Computer erreichen lässt. Zwei wesentliche Phänomene sind mit der TEVC messbar. Durch die Stimulation und darauf folgende Transmitterausschüttung entstehen postsynaptische Kanalöffnungen, die normalerweise zu EPSPs führen würden (vgl. Kap. 1.1, S. 7). Die TEVC hält nun das Potential konstant, der Ausgleichstrom ist als evozierter exzitatorischer 


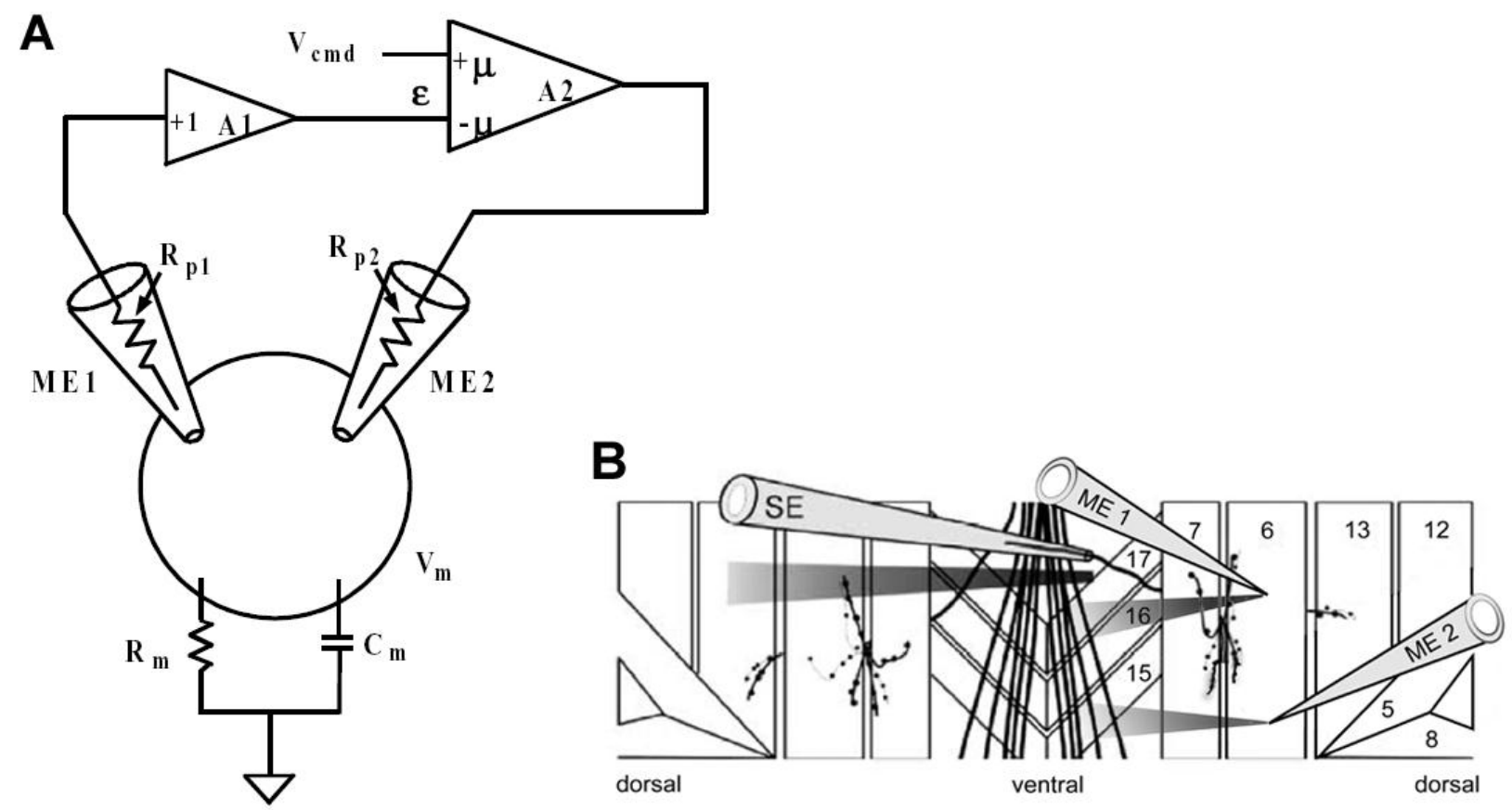

\section{Abb. 2-2 Aufbau der TEVC.}

A, schematischer Schaltplan der TEVC mit Spannungselektrode (ME1), Stromelektrode (ME2) und zwei Verstärkerbausteinen A1 und A2. Die gemessene Spannungsdifferenz $\varepsilon$ bewirkt einen Stromfluss über ME2, der $V_{m}$ in Richtung $V_{\text {cmd }}$ verändert. Die Zellmembran entspricht dem in Abb. 2-1 dargestellten Modell (modifiziert nach Sherman-Gold, 2006, S.64). B, mikroskopisches Schema der TEVC an der neuromuskulären Synapse einer Drosophila-Larve. Zu erkennen sind ME1, ME2, die Ansaugelektrode (SE) sowie die nummerierten Muskelfasern und der eingesaugte Segmentnerv (modifiziert nach Pawlu et al. 2004, S. 608).

postsynaptischer Strom (evoked excitatory junctional current, eEJC) messbar. Der andere messbare Vorgang ist die spontane Fusion einzelner Vesikel mit der präsynaptischen Membran, die nach demselben Mechanismus als so genannter „Miniatur"-exzitatorischer postsynaptischer Strom (miniature excitatory junctional current, mEJC) messbar ist. Diese mEJCs sind von besonderer Bedeutung, da sie als Antwort der postsynaptischen Membran auf die präsynaptische Fusion eines einzigen Vesikels zu betrachten sind. Im Vergleich mit den eEJCs können so differenzierte Aussagen darüber getroffen werden, ob eine Veränderung von Quanteninhalt oder Quantengröße vorliegt. 


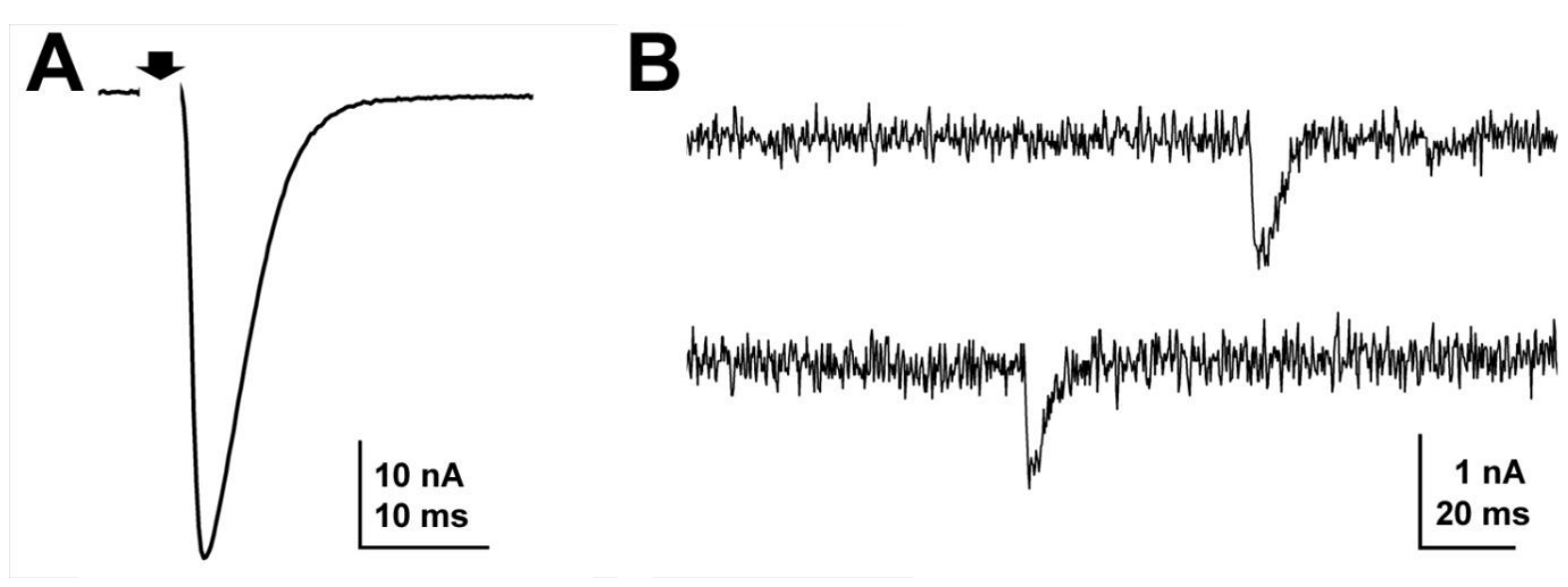

\section{Abb. 2-3 Beispielaufnahmen der TEVC.}
A, Beispielsignal eines eEJC. Der Pfeil markiert die Position des entfernten Stimulationsartefaktes
B, Beispielausschnitt aus einer Messung von mEJCs, es sind zwei Ereignisse erkennbar.

eEJCs bewegen sich im Bereich von -20 bis $-100 \mathrm{nA}$, mEJCs dagegen weisen eine Amplitude von meist nur ca. -1 nA auf. Aus diesem Grund müssen die Einstellungen der TEVC zur Messung von eEJCs und mEJCs jeweils verändert werden, da bei den mEJCs das Hintergrundrauschen noch aggressiver vermieden werden muss. Die genauen Einstellungen finden sich unter 2.6. Beispiele für die Messsignale von mEJCs und eEJCs sind in Abbildung 2-3 dargestellt.

Für das zeitliche Auflösungsvermögen der TEVC ist eine Eigenart der Zellmembran bedeutsam, die bisher noch nicht ausführlich besprochen wurde. Wie bereits oben erwähnt, weist die Membran Kondensatoreigenschaften auf. $C$ gibt die Menge an Ladung ( $Q$, Einheit ist das Coulomb, $C$ ) an, die ein Kondensator bei einer bestimmten Spannung aufnehmen kann. Es gilt:

$$
C=Q / U
$$

Daraus folgt, dass sich bei jeder Änderung von $U$ (bzw. von $V_{\text {cmd }}$ ) auch eine Änderung von $Q$ ergibt, die Membran also ge- bzw. entladen wird. Das Laden der Membran aber benötigt Zeit, deswegen ist dieser Zusammenhang für die Funktion der TEVC von entscheidender Bedeutung. Ausgehend von einer ungeladenen Membran ändert sich die Spannung gemäß einer Exponentialfunktion:

$$
U_{(\mathrm{t})}=U_{\max }{ }^{*}\left(1-e^{-\mathrm{t} / \mathrm{T}}\right)
$$

$U_{\max }$ ist die angelegte Spannung $\left(V_{c m d}\right)$, e die Eulersche Zahl und t die so genannte Zeitkonstante (Einheit Sekunde, s). Nach r Sekunden ist $U$ beim Ladevorgang des 
Kondensators auf

$$
\left(1-e^{-1}\right) * U_{\max }
$$

angestiegen, dies sind ungefähr $63,2 \%$ von $U_{\max }$. Je größer $\mathrm{T}$, desto länger dauern Lade- und Entladevorgang. Nach 5т Sekunden ist die Membran zu über 99\% geladen. Der dabei fließende Strom wird auch als kapazitativer Stromfluss bezeichnet. Er verhält sich nach dem Ohm'schen Gesetz genau invers zur Spannung. Zu Beginn des Ladevorgangs fließt der maximale Strom, er nimmt exponentiell ab und strebt dem neuen Gleichgewichtswert $\left(I_{h}\right)$ entgegen. Den Verlauf von $U$ und $I$ bei der Umladung der Membran illustriert Abbildung 2-4.
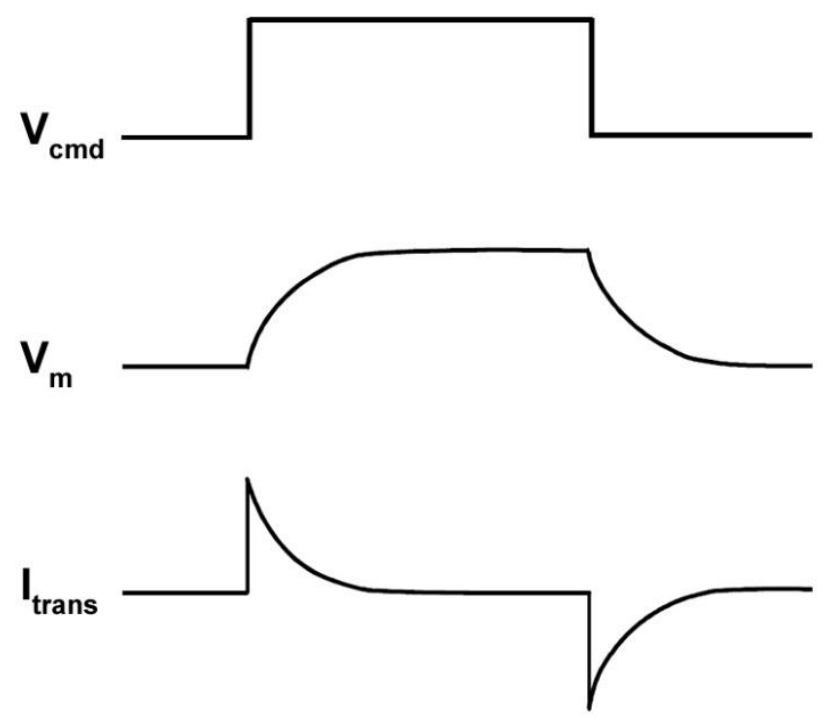

\section{Abb. 2-4 Lade- und Entladevorgang der Zellmembran bei der TEVC}

Dargestellt ist der Verlauf von $V_{m}$ und des transient über die Membran fließenden kapazitativen Stroms $\left(l_{\text {trans }}\right)$ als Antwort auf eine Änderung des Haltepotentials $\left(V_{c m d}\right)$. Zu beachten ist, dass aus Gründen der Übersichtlichkeit der Haltestrom $\left(I_{h}\right)$ nicht dargestellt ist. Der Verlauf des gesamten über die Membran fließenden Stroms ergibt sich als Summe aus $I_{\mathrm{h}}$ und $l_{\text {trans }}$ (modifiziert nach Sherman-Gold, 2006, S.12).

Die Antwort von $V_{\mathrm{m}}$ auf eine Änderung von $V_{\text {cmd }}$ ist identisch mit der Reaktion von $I_{\mathrm{m}}$ auf eine Änderung von $G$ (Sherman-Gold, 2006, S. 45). Daraus folgt für unsere Betrachtung, dass $\mathrm{T}$ nicht nur bei einer experimentellen Veränderung von $V_{\mathrm{cm}}$ das Messsignal beeinflusst, sondern auch bei einer Leitfähigkeitsänderung der Membran, also dem zu beobachtenden Parameter unseres Experiments. Die Minimierung von T stellt deswegen ein zentrales Anliegen des Experimentators dar, wenn er die zeitliche Auflösung der TEVC optimieren möchte. Dauert der Ladevorgang länger, so stellt das 
Messsignal der TEVC die Änderung der Membranleitfähigkeit nicht mehr akkurat dar, denn der kapazitative Stromfluss überlagert den eigentlich interessanten Parameter $/ \mathrm{h}$ dann für längere Zeit jedes Mal, wenn eine Änderung von $G$ erfolgt.

Wie in unserem Modell in Abbildung 2-1 erkennbar, stellt sich die Membran als eine Parallelschaltung eines Widerstandes und eines Kondensators dar. In einer solchen Schaltung gilt für die Zeitkonstante (Sherman-Gold, 2006, S. 13):

$$
\mathrm{T}=R C
$$

In der TEVC-Schaltung berücksichtigen wir nun zusätzlich den Pipettenwiderstand und den Verstärker. Für die TEVC bedeutet dies, dass t umso größer wird (und damit das Laden umso länger dauert), je größer $R_{\mathrm{p} 2}$ (der Pipettenwiderstand der Stromelektrode) ist. Für ein kleines $T$ und eine Verbesserung des zeitlichen Auflösungsvermögens sollte daher $R_{\mathrm{p} 2}$ möglichst niedrig gewählt werden. Dies bedingt aber eine eher breite Pipettenspitze mit einem größeren Innendurchmesser. Dadurch wird die Zelle stärker verletzt und es kann leichter zu Leckströmen durch einen weniger dichten Abschluss zwischen Pipettenaußenseite und Zellmembran kommen. Der beste Kompromiss ergab sich für Pipetten mit einem Widerstand von 10-20 M , die für alle Experimente verwendet wurden. Zur Bestimmung des Pipettenwiderstandes siehe 2.2.5

Zur weiteren Kompensation des Problems verfügt der Verstärker über eine so genannte „gain-Steuerung“. Mit dieser lässt sich der aus der gemessenen Spannungsdifferenz $\varepsilon$ resultierende Stromfluss beeinflussen, sodass die TEVC die Ladezeit der Membrankapazität verkürzen kann. Es gilt die Gleichung (Sherman-Gold, 2006, S. 45):

$$
\mathrm{T}=R_{\mathrm{P} 2} C_{\mathrm{m}} / \mu
$$

Hierbei ist $\mu$ der Wert der gain-Kontrolle. Je höher $\mu$, desto kleiner wird T. Das Problem bei einer Erhöhung von $\mu$ liegt in der Induzierung von Koppelung, bei der $l_{\mathrm{h}}$ zu einer überschießenden Korrektur von $V_{\mathrm{m}}$ führt, die von der TEVC selbst wieder gemessen wird und einen entgegen gesetzten $I_{\mathrm{h}}$ zur Folge hat. Die Schaltung weist dadurch zunächst ein höheres Rauschen auf und beginnt schließlich zu oszillieren.

Die Optimierung von t wurde mit einer $10 \mathrm{~ms}$ dauernden Erhöhung von $V_{\text {cmd }}$ um $10 \mathrm{mV}$ ermöglicht. Aus dem resultierenden Verlauf von $V_{\mathrm{m}}$ wurde $\mathrm{T}$ abgelesen und durch Veränderung von $\mu$ auf den gewünschten Wert justiert. 


\subsubsection{Die Stromklemme}

Das Prinzip der Stromklemme (current clamp) dient der Messung von $V_{\mathrm{m}}$. Der experimentelle Aufbau ist ähnlich wie bei der TEVC. Im Gegensatz zur TEVC wird bei der Stromklemme jedoch nur eine intrazelluläre Elektrode (ME1) benötigt. Der Verstärker misst die Potentialdifferenz $\left(V_{\mathrm{p}}\right)$ zwischen ME1 und der Badelektrode. Idealerweise verfügt der Verstärker über einen hohen Widerstand, so dass nur ein sehr geringer Strom über die Elektrode fließt und $V_{\mathrm{m}}$ möglichst wenig beeinflusst wird (Sherman-Gold, 2006, S. 27).

Die Stromklemme wurde im Rahmen dieser Arbeit für die Bestimmung des Membranpotentials, des Pipettenwiderstandes und des so genannten Eingangswiderstandes (input resistance, $\mathrm{IR}$ ) eingesetzt. $V_{\mathrm{m}}$ lässt sich aus der Grundschaltung direkt ablesen. Zur Bestimmung der Pipettenwiderstände wird die so genannte „Bridge-Balance“-Technik eingesetzt (Sherman-Gold, 2006, S. 29). Es wird Ein kurzer Strompuls über ME1 gegeben und der resultierende Spannungsabfall verfolgt. Über den Verstärker wird dann ein zu diesem Spannungsabfall proportionales Spannungssignal generiert und von $V_{p}$ abgezogen. Das Signal wird manuell so eingestellt, dass während des Strompulses gar kein Spannungsabfall mehr stattfindet. Der Pipettenwiderstand ergibt sich dann als Quotient aus Spannungssignal und Strompulsamplitude. Zur Bestimmung des Eingangswiderstandes wird derselbe Vorgang wiederholt, sobald sich beide Pipetten intrazellulär befinden. Aus dem nun neu messbaren Spannungsabfall lässt sich IR berechnen. 


\subsubsection{Experimentelles Vorgehen}

Für elektrophysiologische Messungen wurden Larven im Stadium L3 verwendet. Die Tiere wurden in eisgekühlter, $\mathrm{Ca}^{2+}$-freier HL-3-Lösung (Stewart et al. 1994) präpariert. Die Larven wurden in die Messkammer gelegt, die bei allen Experimenten eine HL-3Lösung mit $1 \mathrm{mM}\left[\mathrm{Ca}^{2+}\right]$ bei einer Temperatur von $20-22{ }^{\circ} \mathrm{C}$ enthielt. Die Glaspipetten für ME1 und ME2 wurden mit $15 \mu \mathrm{l} 3 \mathrm{M} \mathrm{KCl-Lösung} \mathrm{gefüllt} \mathrm{und} \mathrm{mittels} \mathrm{der}$ Pipettenhalterung über der Präparation in Position gebracht. Mit Hilfe der OffsetKontrolle des Verstärkers wurden die so genannten „Junktionspotentiale“ (junction potentials) ausgeglichen. Dabei handelt es sich um Potentiale, die durch elektrostatische Aufladung der Grenzschichten zwischen Elektrodenspitze und Flüssigkeit sowie zwischen Pipetten- und Badlösung entstehen (Sherman- Gold, 2006, S. 30)). Die Pipettenwiderstände wurden bestimmt, wie unter 2.2.5. erläutert. Verwendete Pipetten hatten einen Widerstand von 10-20 M $\Omega$. Der den zu untersuchenden Muskel versorgende Nerv wurde mit dem Mikroskop bei 400 -facher Vergrößerung aufgesucht und in die Ansaugelektrode manuell mittels Unterdruck hineingezogen. Mit dem Mikromanipulator wurden ME1 und ME2 über der zu untersuchenden Zelle in Position gebracht. Für diese Arbeit wurde der ventrale longitudinale Muskel 6 in den abdominellen Segmenten A2 bis A4 verwendet.

Der Verstärker wurde in den Spannungsklemm-Modus gebracht und die Zellmembran mit ME1 penetriert. Das gemessene initiale Membranpotential lag bei allen für die Analyse herangezogenen Zellen bei -55 bis $-85 \mathrm{mV}$, der nach Einbringen von ME2 ermittelte Eingangswiderstand war $\geq 4 \mathrm{M} \Omega$. Der Verstärker wurde in den TEVC-Modus geschaltet. Zur Messung der mEJCs wurde $V_{\text {cmd }}$ auf $-80 \mathrm{mV}$ eingestellt, für die eEJCs wurde bei allen Protokollen ein Haltepotential von -60 mV gewählt. Anschließend wurde die gain-Kontrolle adjustiert. Für die Messung von mEJCs wurde $\mu$ so gewählt, dass T Werte von $0.7-1.1 \mathrm{~ms}$ annahm, dieser Wert ist als empirischer Kompromiss von Signal-zu-Rausch-Verhältnis und zeitlichem Auflösungsvermögen zu werten. Für die Messung evozierter Ströme konnte $\mu$ aufgrund der wesentlich höheren Amplitude der eEJCs auf den größtmöglichen Wert eingestellt werden, bei dem noch keine Oszillation auftrat $(\mathrm{T}=400-700 \mu \mathrm{s})$. Bei allen analysierten Messungen war der Haltestrom stets geringer als $-10 \mathrm{nA}$. 
Die Stimulation geschah über einen 0,3 ms dauernden Strompuls. Um sicherzustellen, dass beide Axone des angesaugten Nerven stimuliert werden, wurde die Stimulationsamplitude auf den 1,5-fachen Wert erhöht, der zur Rekrutierung beider Axone nötig war. Die mEJCs wurden vor der Stimulation für 90 s aufgezeichnet. Die Messung der eEJCs erfolgte durch Stimulation bei einer Frequenz von 0,2 Hz, die 15 ersten Antworten wurden analysiert. Nach einer Pause von 30 Sekunden wurde die Zelle für 10 Sekunden mit $10 \mathrm{~Hz}$ stimuliert. Hierbei wurden die letzten 50 Signale ausgewertet. Für bestimmte Versuche wurde ein Doppelpulsprotokoll angewandt, bei dem die Zellen 15-mal mit zwei Pulsen im Abstand von 20 ms erregt wurden, die Daten wurden anschließend gemittelt.

Die Analyse der Messungen geschah am Computer. Die Amplitude der eEJCs wurde aus den gemittelten Messwerten abgelesen, die mEJCs wurden mittels einer Suchautomatik gesammelt, überlappende Ereignisse oder fragliche Artefakte wurden entfernt und anschließend die durchschnittliche Amplitude sowie Frequenz bestimmt. Der Quanteninhalt wurde als Quotient aus eEJC-Amplitude und mEJC-Amplitude errechnet. Die graphische Darstellung der Ergebnisse geschah ebenfalls am Computer. Verwendete Programme siehe Tab. 2-2. 


\subsubsection{Verwendetes Material und Geräte}

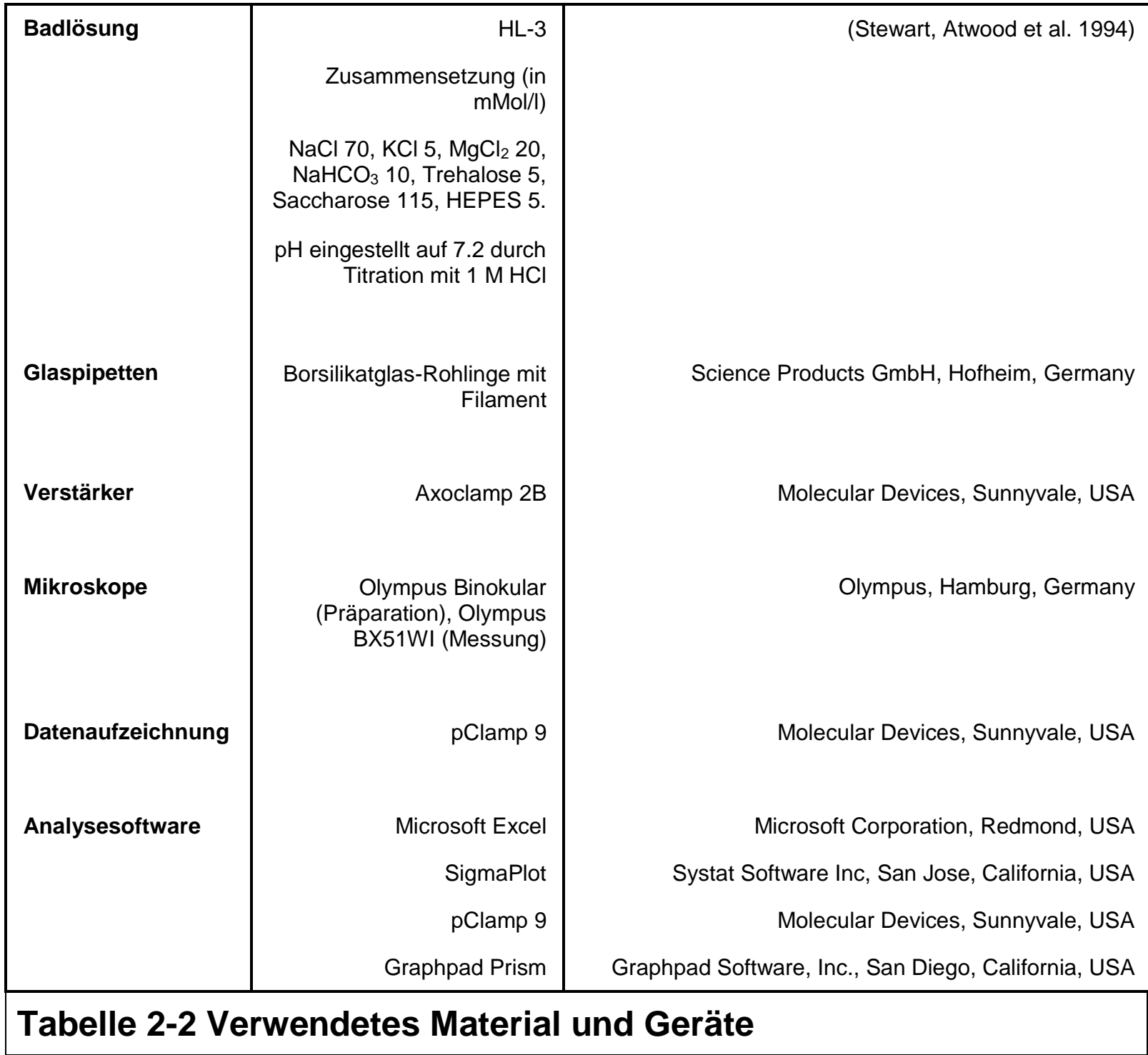

\subsubsection{Allgemeines}

Sofern nicht anders angegeben, wurde zur statistischen Analyse der Daten der ungepaarte t-test verwendet. $\mathrm{n}$ gibt die Anzahl untersuchter Zellen an, $\mathrm{p}$ das Ergebnis des t-tests. In den Abbildungen gezeigte Balken stellen den Mittelwert \pm den Standardfehler des Mittelwertes dar. Falls angegeben, so stehen Sternchen (*) für das Signifikanzniveau $\left({ }^{*}=p<0,05 ;{ }^{* *}=p<0,01 ;{ }^{* * *}=p<0,001\right)$. 


\section{Ergebnisse}

\subsection{In-vivo-Untersuchung von Komponenten des Glutamatrezeptors}

\subsubsection{GFP-markiertes GluRIIB zeigt volle in-vivo-Funktionalität}

Die Glutamatrezeptoruntereinheit IIB nimmt zusammen mit IIA eine Sonderstellung unter den fünf bisher identifizierten Einheiten IIA, IIB, III, IID und IIE ein. Während III, IID und IIE für das Überleben der Embryonen unverzichtbar sind, so reicht entweder IIA oder IIB aus, um eine Entwicklung über das Embryonalstadium hinaus zur Larve zu ermöglichen (Qin et al. 2005). Konsequenterweise führt auch die Unterdrückung von entweder IIA oder IIB nicht zur embryonalen Letalität, wenn auch zu nachhaltigen Defekten der Neurotransmission (Petersen et al. 1997; DiAntonio et al. 1999; Kittel et al. 2006). Um die Bedeutung der Untereinheit IIB in vivo besser untersuchen zu können, wurde eine genetische Fusion mit dem Grün Fluoreszierenden Protein (GFP) erstellt, damit die fluoreszenzmikroskopische Beobachtung der Dynamik des Proteins in lebenden Larven der Fruchtfliege Drosophila möglich wurde (Rasse et al. 2005). Vorbedingung hierbei war, dass die GFP-Markierung von IIB ohne Auswirkung auf die Funktion des Rezeptorkomplexes bliebe. Um dies zu prüfen, wurden GluRIIA; GluRIIB Doppel-Nullmutanten erzeugt (GluRIIA ${ }^{\text {null. }}$; GluRIIBnull). In diesem Hintergrund wurde ein genomisches GluRIIB-Konstrukt exprimiert (Nsil/Ncol-Konstrukt der GluRIIBkodierenden Region mit ca. 700 Basenpaaren upstream und ca. 500 Basenpaaren downstream, im Folgenden bezeichnet als IIB-Genomisch). Es wurde ein fluoreszenzmarkiertes Konstrukt IIB-GFP durch Insertion einer GFP-Fluorophore erstellt (Schmid et al., 2008, Rasse et al., 2005).

Die Ergebnisse der elektrophysiologischen Untersuchung sind in Abbildung 3-1 dargestellt. Die Reexpression je eines der beiden GluRIIB-Konstrukte ließ die sonst letale Doppelmutante überleben. Die Amplitude und der zeitliche Verlauf der eEJCs waren weder bei niederfrequenter Stimulation mit $0,2 \mathrm{~Hz}$ (IIB-Genomisch: $46.94 \pm$ $4.82 \mathrm{nA}, \mathrm{n}=10$; IIB-GFP: $45.47 \pm 3.92 \mathrm{nA}, \mathrm{n}=10, \mathrm{p}=0,8157$ ) noch bei Stimulation mit $10 \mathrm{~Hz}$ (IIB-Genomisch: $23.08 \pm 2.12 \mathrm{nA}, \mathrm{n}=10$; IIB-GFP: $21.15 \pm 1.91 \mathrm{nA}, \mathrm{n}=10, \mathrm{p}=$

$0,5078)$ signifikant unterschiedlich. Die Larven beider Konstrukte zeigten bei hochfrequenter Stimulation also eine deutliche Kurzzeitdepression mit einer 
Verringerung der Amplitude auf ca. $50 \%$ des bei $0,2 \mathrm{~Hz}$ gemessenen Wertes. Dies spricht ebenfalls für eine normale synaptische Funktion und unveränderte Plastizität (Zum Vergleich W1: $10 \mathrm{~Hz} /$ 0,2 Hz-Quotient: 44,05 nA / 79,95 nA, dies entspricht einer Abnahme der eEJC-Amplitude auf ca. $60 \%$ bei hochfrequenter Stimulation).

A

IIB-GFP

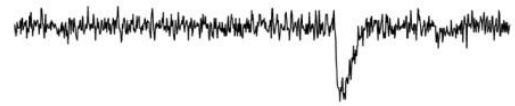

IIB genomisch

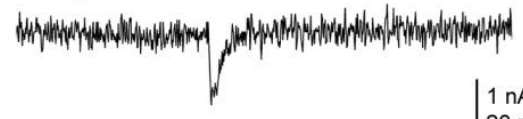

C

$0,2 \mathrm{~Hz}$ Stimulation IIB-GFP IIB genomisch

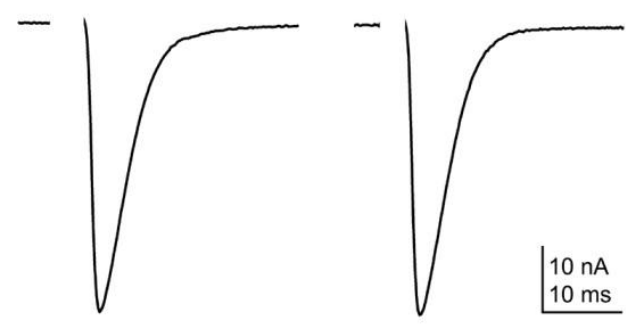

B
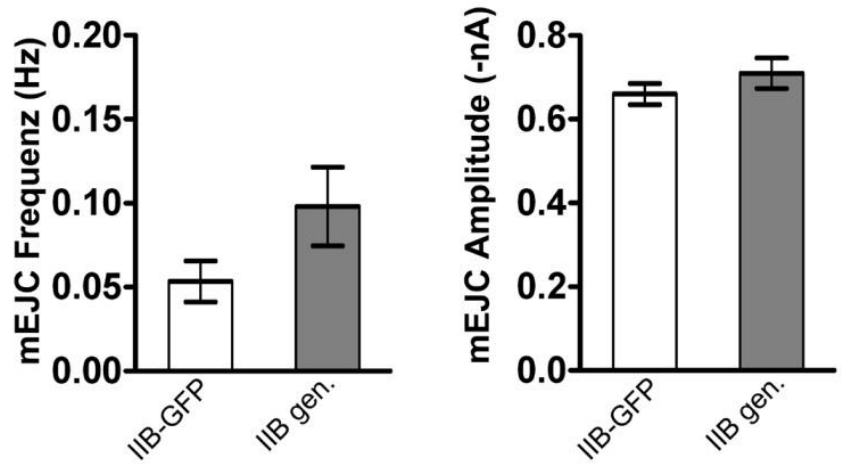

D $0,2 \mathrm{~Hz}$ Stimulation $10 \mathrm{~Hz}$ Stimulation

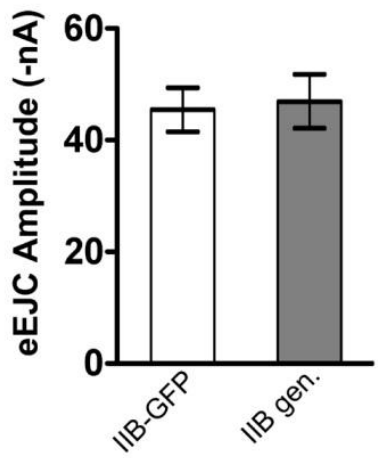

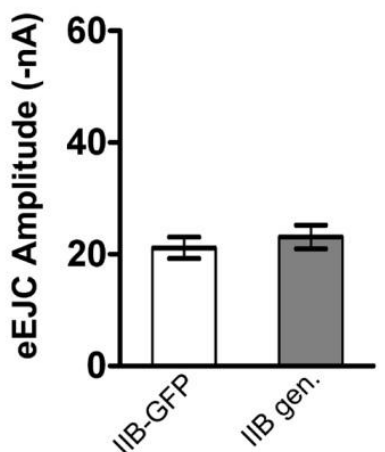

\section{Abb. 3-1. IIB-GFP zeigt keinen Hinweis auf eine Veränderung der synaptischen Funktion dieser Untereinheit.}

A, Messung der mEJCs. Exemplarisch sind hier zwei mEJC-Ereignisse dargestellt. B, Amplitude und Frequenz der mEJCs sind zwischen IIB-Genomisch und IIB-GFP nicht signifikant unterschiedlich. C, Beispielspuren der eEJCs. D, Die eEJCs zeigen sowohl bei Stimulation mit $0,2 \mathrm{~Hz}$ als auch mit $10 \mathrm{~Hz}$ keinen signifikanten Unterschied zwischen den beiden Konstrukten. Die Kurzzeitdepression ist in beiden Fällen erhalten.

Die Messung der mEJC-Amplitude (IIB-Genomisch: $0.710 \pm 0.036 \mathrm{nA}, \mathrm{n}=10$; IIB-GFP: $0.660 \pm 0.0253 \mathrm{nA}, \mathrm{n}=9, \mathrm{p}=0$,2842) und Frequenz (IIB-Genomisch: $0.098 \pm 0.023 \mathrm{~Hz}$, 
$\mathrm{n}=10 ;$ IIB-GFP: $0.053 \pm 0.012 \mathrm{~Hz}, \mathrm{n}=9, \mathrm{p}=0,1200$ ) ergab keinen signifikanten Unterschied zwischen IIB-Genomisch und IIB-GFP. Die relativ niedrige gemessene Frequenz der mEJCs steht in Einklang mit der verwendeten Messtechnik, da die gemessene Amplitude nahe am Hintergrundrauschen der TEVC liegt.

Insgesamt erlauben die Daten den Schluss, dass GFP-markiertes GluRIIB volle in vivo Funktionalität behält. Dadurch eignet sich dieses Konstrukt hervorragend zur weiteren Charakterisierung der Struktur und Funktionsabläufe an der neuromuskulären Synapse (Schmid et al 2008). Abgesehen davon lassen sich weitere Informationen aus diesem Experiment ziehen. Vergleicht man die Daten von IIBGenomisch und IIB-GFP mit Daten von Wildtyp-Larven, so fallen zwei wesentlich Unterschiede auf. Zum einen ist die Amplitude der eEJCs und mEJCs in WildtypLarven deutlich höher (nicht dargestellt), zum anderen ist die Zeitkonstante des Rückgangs der eEJCs т (decay $\mathrm{T}$ ) in den IIB-Konstrukten deutlich geringer (Abbildung 3-2, $p<0,05$ für WT und IIB, decay-T-Daten von WT und IIA mit freundlicher Genehmigung von Dr. Robert Kittel, Institut für klinische Neurobiologie, Würzburg).

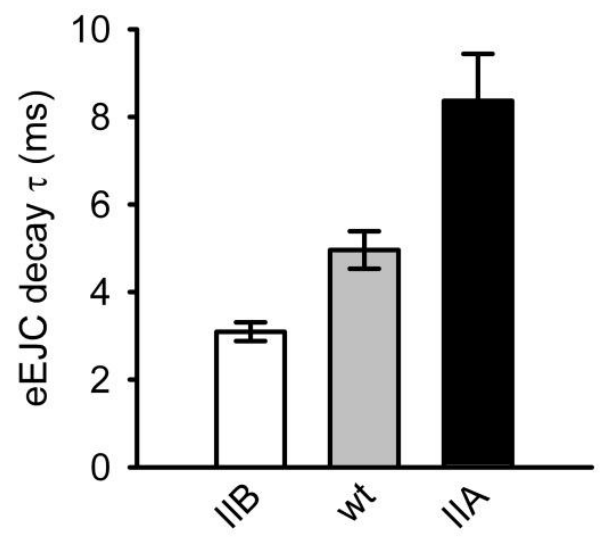

\section{Abb. 3-2. Unterschiede der eEJC decay $T$ in Wildtyp, IIA- und IIB- Konstrukten.}

Dargestellt sind die decay-T-Werte von Larven, die nur IIB- (kein IIA) bzW. nur IIA- (kein IIB) Rezeptorkomplexe exprimieren. Die übrigen Rezeptoruntereinheiten sind unverändert. Im Vergleich zum Wildtyp (WT) bieten die IIA-Konstrukte einen langsam abfallenden Strom, die IIB-Konstrukte hingegen einen schnell abfallenden Strom. $p<0,05$ für WT und IIA; $p<0,05$ für WT und IIB (Abbildung mit freundlicher Genehmigung von Dr. Robert Kittel, Institut für klinische Neurobiologie, Würzburg). 
Der postsynaptische Strom fließt also deutlich kürzer, der Rezeptorkomplex mit IIB hat gegenüber den Wildtyp-Rezeptorkomplexen eine veränderte Schließungskinetik. Konstruiert man Larven, die nur GluRIIA und kein GluRIIB exprimieren, so ergibt sich ein anderes Bild: Diese Tiere weisen eine im Vergleich zum Wildtyp (WT) erhöhte Amplitude der eEJCs und mEJCs (nicht dargestellt) und ein ebenfalls erhöhtes decay $\tau$ auf (Abbildung 3-2, p<0,05 für WT und IIA, mit freundlicher Genehmigung von Dr. Robert Kittel, Institut für klinische Neurobiologie, Würzburg).

Ausgehend von der Beobachtung, dass in Wildtyp-Larven sowohl GluRIIA- als auch GluRIIB- Rezeptorkomplexe vorkommen (Sigrist et al. 2002), ergab sich die Hypothese, dass Amplitude und Kinetik des Wildtyp-eEJC ein Mischbild aus dem großamplitudigen, langsam abfallenden Strom in IIA-Rezeptorkomplexen und dem niedrigamplitudigen, schnell abfallenden Strom in IIB-Rezeptorkomplexen darstellen (DiAntonio et al. 1999). Wahrscheinlich handelt es sich hierbei um distinkte Komplexe, die entweder GluRIIA oder GluRIIB enthalten. Aufgabe zukünftiger Untersuchungen wird es sein, die unterschiedliche Funktion der beiden Untereinheiten für synaptische Entwicklung und Funktion näher zu untersuchen. 


\subsubsection{Muskelspezifische Suppression von GluRIIE provoziert einen dramatischen Abfall der postsynaptischen Sensitivität}

Die Rezeptoruntereinheiten GluRIIE und GluRIIF gehören zu den lebensnotwendigen nicht-NMDA-Untereinheiten an der Drosophila-NMJ. Im Gegensatz zu GluRIIA, GluRIIB und GluRIIC zeigt ihre Aminosäuresequenz jedoch eine engere Verwandtschaft mit den Kainat-Rezeptoren der Säugetiere, ähnlich wie der hier nicht untersuchte GluRIID (Qin et al. 2005; Schwarz 2007).

Zur Untersuchung der Funktion dieser Untereinheiten wurden RNAi-Konstrukte eingesetzt. Bei dieser Technik wird durch Überexpression eines bestimmten RNAAbschnittes die Zerstörung komplementärer mRNA durch zelleigene Enzyme induziert (Zamore et al. 2000). Dadurch kann die Expression eines bestimmten Proteins, in diesem Falle der Glutamatrezeptoruntereinheiten, gezielt unterdrückt werden. Die RNAi-Sequenz wurde mithilfe des Treibers 24B-Gal4 in den Muskelzellen exprimiert, die veränderten Tiere waren Kreuzungen von 24B-Gal4 mit IIE- bzW. IIF-RNAi. Als Kontrolltiere dienten Kreuzungen von 24B-Gal4 und W1 (W1 24B). Zur Genetik der verwendeten Tiere siehe auch 2.1.

Die Glutamatrezeptorkomponente IIE gehört zu essentiellen Untereinheiten (Qin et al. 2005). Eine genetische Mutante zeigt embryonale Letalität, NMJs formen sich zwar, allerdings lokalisieren die Untereinheiten GluRIIA, GluRIII/IIC und GluRIID nicht an diese NMJs (Qin et al. 2005). Dies suggeriert, dass es sich bei GluRIIE um eine für sämtliche Glutamatrezeptorkomplexe essentielle Untereinheit handelt. Allerdings bleibt offen, inwiefern GluRIIE für die weitere larvale Entwicklung und synaptische Funktion von Bedeutung ist. Daher wurde mit Hilfe einer RNAi-Suppression untersucht, welche Veränderungen sich bei unterdrücktem GluRIIE für die larvale synaptische Transmission in vivo ergeben. Die Ergebnisse fasst Abbildung 3-3 zusammen.

Im Vergleich zu W1-24B fiel bei IIE-RNAi die stark verminderte Amplitude der eEJCs auf, die auf ca. 20-25\% der Amplitude der Wildtyp-eEJCs abgesunken war. Dies war sowohl bei Stimulation mit 0,2 Hz (W1-24B: $72.80 \pm 4.455 \mathrm{nA}, \mathrm{n}=10$; IIE-RNAi: $19.52 \pm$ $1.527 \mathrm{nA}, \mathrm{n}=6, \mathrm{p}<0.0001$ ) als auch mit $10 \mathrm{~Hz}$ zu beobachten (W1-24B: $49.16 \pm 3.503$ $\mathrm{nA}, \mathrm{n}=10 ;$ IIE-RNAi: $9.118 \pm 0.5243 \mathrm{nA}, \mathrm{n}=6, \mathrm{p}<0.0001)$. Diese deutliche 
Beeinträchtigung der synaptischen Übertragung lässt sich zwanglos mit einer Verminderung der Menge von postsynaptisch exprimierten Rezeptoren vereinbaren.

A $0,2 \mathrm{~Hz}$ Stimulation

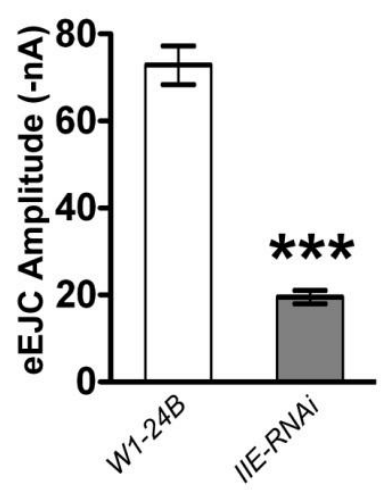

C
$10 \mathrm{~Hz}$ Stimulation

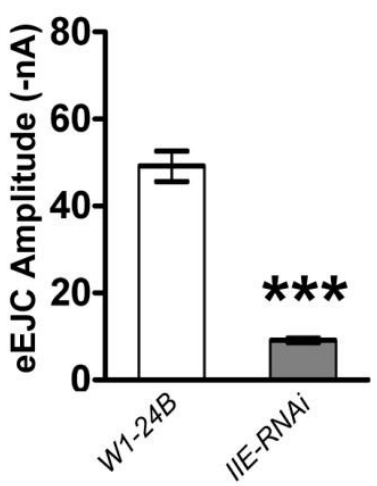

\section{B $0,2 \mathrm{~Hz}$ Stimulation}

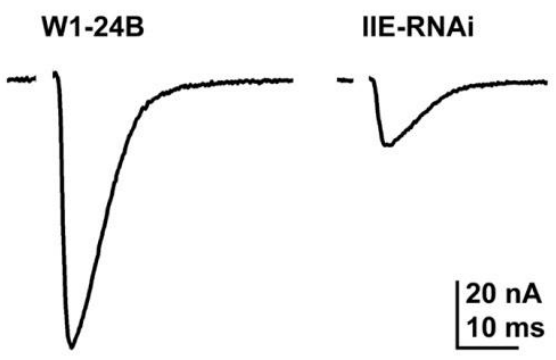

W1-24B

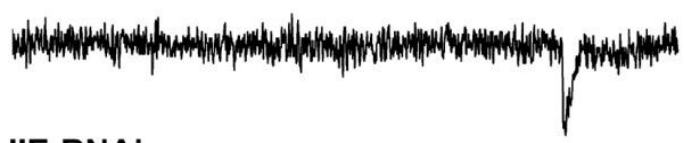

IIE-RNAi

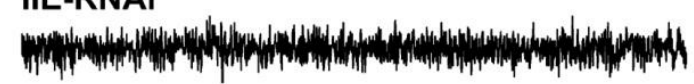

$1 \mathrm{nA}$

$50 \mathrm{~ms}$

\section{Abb. 3-3. Stark verminderte synaptische Übertragung bei IIE-RNAi.}

A, Im Vergleich zu den Kontrolltieren ist bei IIE-RNAi die Amplitude der eEJCs sowohl bei niederfrequenter als auch bei hochfrequenter Stimulation stark vermindert. B, Beispiele für aufgenommene eEJCs. C, Beispielspuren der Messung der mEJCs.

Zur weiteren Klärung wurden daher die mEJCs analysiert. Diese waren nur bei einem von sechs untersuchten IIE-RNAi-Tieren überhaupt nachweisbar, mit im Vergleich zu W1-24B (W1-24B: $0.4689 \pm 0.1003 \mathrm{~Hz}, \mathrm{n}=9)$ extrem geringer Frequenz $(0,07 \mathrm{~Hz})$ und niedriger Amplitude (-0,50 nA). Dies lässt sich auf die Aufnahmetechnik zurückführen: Geht man davon aus, dass die mEJCs in ihrer Amplitude ähnlich vermindert sind wie die eEJCs (also auf etwa 25\%), so würde man für sie Werte im Bereich von -0.2 nA erwarten (etwa 25\% der Amplitude von Wildtyp-mEJCs). Ereignisse dieser Größenordnung aber liegen sehr nah an der Grenze des Hintergrundrauschens der 
TEVC, so dass keine sichere Aussage über die tatsächliche Frequenz der mEJCs gemacht werden kann, da eine große Anzahl von mEJCs unterhalb der Nachweisegrenze liegen dürften. Mit hoher Wahrscheinlichkeit ist also die Amplitude der mEJCs stark vermindert. Es wäre auch denkbar, dass das apparente Fehlen von mEJCs auf tatsächlich fehlende mEJCs hinweist, beispielsweise durch fehlende synaptische Glutamatrezeptoren. Da die eEJCs jedoch deutlich vermindert sind, erscheint die Erklärung plausibler, dass die mEJCs in ähnlicher Weise erniedrigt und daher nicht nachweisbar sind. Der darüber hinaus ebenfalls bestimmte decay- $T$ war nicht signifikant unterschiedlich (W1-24B: $5.065 \pm$ 0.4123, $\mathrm{n}=10$; IIF-RNAi: $5.770 \pm$ 0.6303, $n=6, p=0,3441)$.

Bei der hochfrequenten Stimulation der Zellen fiel auf, dass die eEJCs bei IIE-RNAi etwas stärker abfielen als bei W1-24B. Auch erschien bei den Messungen die Kurzzeitdepression bei IIE-RNAi schneller einzusetzen. Um dies zu quantifizieren, wurde ein Doppelpuls-Messprotokoll verwendet, bei dem im kurzen Abstand von 20 ms zweimal direkt nacheinander stimuliert wurde (Abb. 3-4). Dies wurde 15-mal mit Pausen von je $4 \mathrm{~s}$ wiederholt, der Median der ersten (eEJC1) und weiten Stimulation (eEJC2) wurde ermittelt. Das Verhältnis eEJC2/eEJC1 gibt an, ob es zu einer Bahnung oder Abschwächung der synaptischen Übertragung kommt. Während W124B-Tiere die zweite Stimulation mit einer im Vergleich zur ersten dezent erhöhten Amplitude beantworten, so ist der zweite Ausschlag bei IIE-RNAi niedriger als der erste $(W 1-24 B$ : eEJC2/eEJC1 $=1.038 \pm 0.03068, \mathrm{n}=9$; IIE-RNAi: eEJC2/eEJC1 = $0.7000 \pm 0.02302, n=5, p<0.0001)$. 
A Doppelpuls-Verhältnis

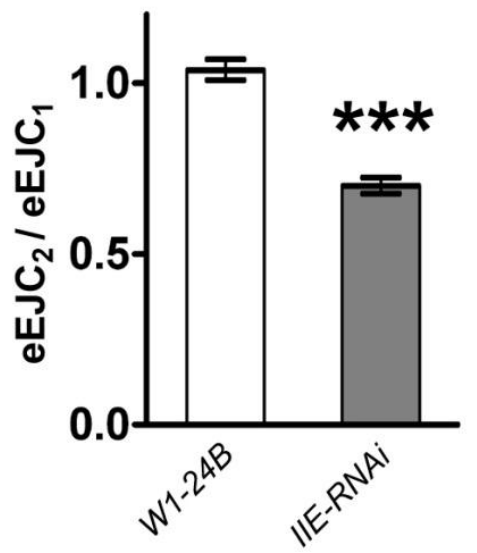

B Doppelpuls-Stimulation

W1-24B

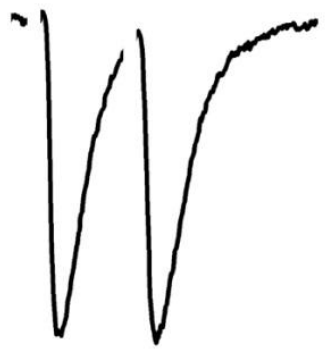

IIE-RNAi

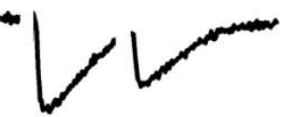

$20 \mathrm{nA}$

$25 \mathrm{~ms}$

\title{
Abb. 3-4. Doppelpuls-Stimulation bei IIE-RNAi offenbart STD.
}

\begin{abstract}
A, Das Verhältnis eEJC2/eEJC1 ist bei IIE-RNAi deutlich niedriger als bei den Kontrollen. Die Synapse zeigt eine synaptische Kurzzeitdepression (STD), die im Bereich von Millisekunden wirksam ist.

B, Exemplarische Aufzeichnungen des Doppelpuls-Protokolls bei W1-24B und IIE-RNAi.
\end{abstract}

Die Erklärung des Wildtyp-Verhaltens liegt darin, dass durch die schnelle Abfolge der Stimulation die präsynaptische $\mathrm{Ca}^{2+}-$ Konzentration rasch ansteigt, so dass beim zweiten Puls eine effektivere Rekrutierung der Vesikel des RRP stattfindet. Dieses Phänomen wurde detailliert an der Bruchpilot-Mutanten untersucht (Kittel et al., 2006). Bei dieser Mutante kommt es u.a. zu einer Misslokalisation von $\mathrm{Ca}^{2+}-K a n a ̈ l e n$, wodurch es zu einer chronisch erniedrigten Freisetzungswahrscheinlichkeit der Vesikel kommt. Die Mutante profitiert dann besonders von der intrazellulären Erhöhung der $\mathrm{Ca}^{2+}-$ Konzentration. Bruchpilot-Mutanten zeigen bei der DoppelpulsStimulierung eine starke Erhöhung von eEJC2 im Verhältnis zu eEJC1, also genau anders herum als bei IIE-RNAi.

Die Beobachtung an IIE-RNAi Larven lässt sich dann am ehesten als Ausdruck eines Kompensationsmechanismus interpretieren: Durch die verminderte Amplitude der eEJCs ist es wahrscheinlich, dass das präsynaptische Kompartiment zur Aufrechterhaltung der synaptischen Übertragung seine Effektivität erhöht. Dies könnte unter anderem durch eine dauerhaft erhöhte Freisetzungswahrscheinlichkeit der Vesikel ermöglicht werden (Reiff et al. 2002). Dadurch könnte bei der Doppelpulsstimulation schon ein größerer Teil der Vesikel beim ersten Puls freigesetzt 
werden, so dass beim zweiten Puls eine geringere Amplitude resultiert. Interessanterweise findet sich der gleiche Phänotyp auch bei Tieren, die kein GluRIIB und nur minimal GluRIIA exprimieren (GluRIIA hypo, Schmid et al. 2006). Auch in diesem Fall wurde die Hypothese vertreten, dass eine verminderte postsynaptische Sensitivität zur chronisch erhöhten Freisetzungswahrscheinlichkeit an der Präsynapse und damit zu den beobachteten Effekten führt (Schmid et al. 2006).

Diese Hypothese könnte auch die Tatsache erklären, dass die Amplitude der eEJCs bei Stimulation mit $10 \mathrm{~Hz}$ nur etwa 19\% der Amplitude der Kontrolle erreicht, während die eEJCs bei $0,2 \mathrm{~Hz}$ nur auf etwa $26 \%$ der Kontrolle erniedrigt sind. Bei höheren Stimulationsfrequenzen ist der Unterschied als Ausdruck der stärkeren Erschöpfung des Systems also deutlicher zu sehen. 


\subsubsection{Funktionelle Analyse der Funktion von GluRIIF für die synaptische Transmission}

Vor kurzem konnte die Glutamatrezeptoruntereinheit IIF entdeckt werden, sowie ihre Expression im Rezeptorfeld an der NMJ von Drosophila nachgewiesen werden (Schwarz 2006). Um ihre Rolle für die Funktion der Synapse zu beurteilen, wurde mit Hilfe des IIF-RNAi-Konstrukts die Expression der Untereinheit unterdrückt. Die erhobenen Daten wurden mit $W 1-24 B$ verglichen. Einen Überblick über die gewonnenen Ergebnisse bietet Abbildung 3-5.
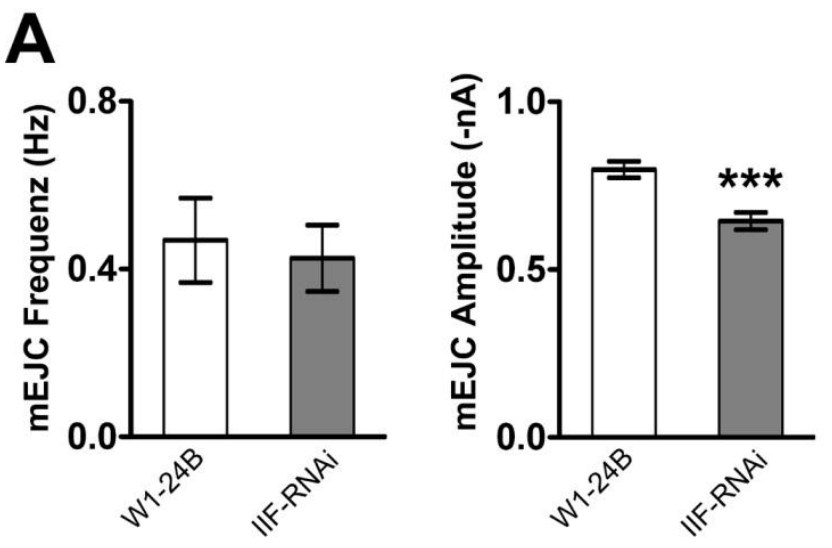

B
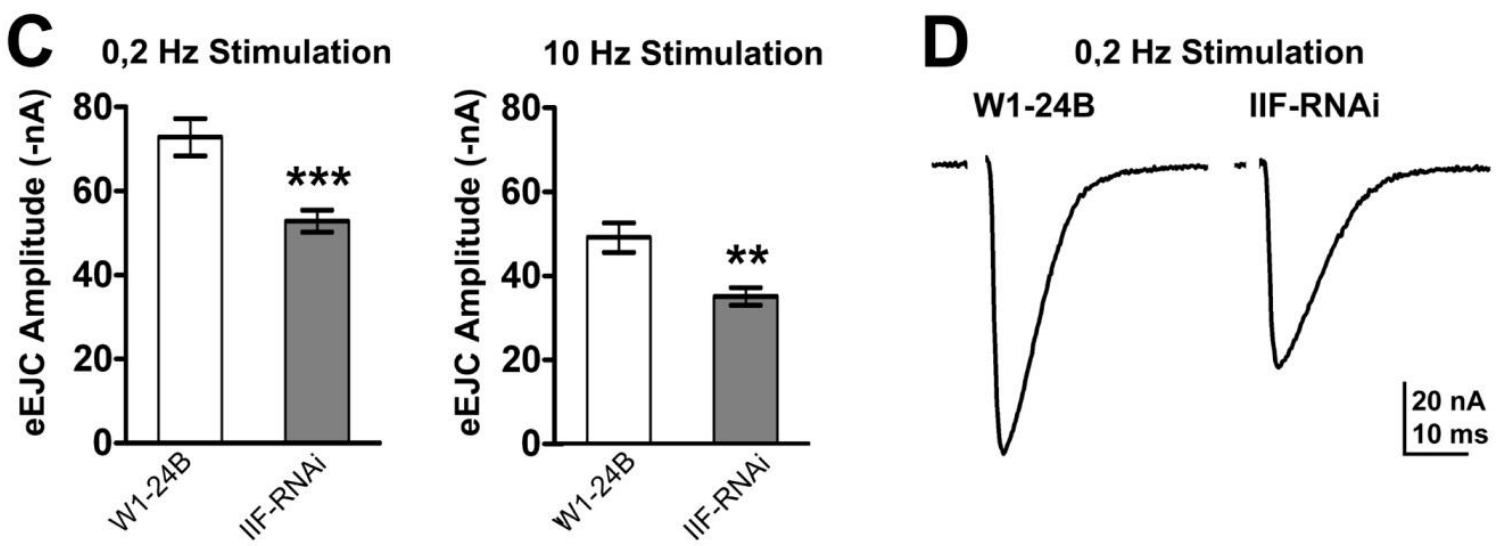

\section{Abb. 3-5. IIF-RNAi zeigt eine verminderte synaptische Übertragung.}

A, Im Vergleich zu W1-24B hat IIF-RNAi bei unveränderter Frequenz eine verminderte Amplitude der mEJCs. B, Exemplarische Spuren der mEJC-Aufnahme. C, Sowohl bei 0,2 Hz als auch bei $10 \mathrm{~Hz}$ sind die eEJC-Amplituden bei IIF-RNAi geringer als in den Kontrollen. D, Je eine Beispielspur der eEJCs bei $0,2 \mathrm{~Hz}$ Stimulationsfrequenz. 
Auch für diese Untereinheit zeigte sich ein deutlicher Unterschied zwischen WildtypLarven und IIF-RNAi. Während die Frequenz der mEJCs nicht signifikant verändert war (W1-24B: $0.4689 \pm 0.1003 \mathrm{~Hz}, \mathrm{n}=9$; IIF-RNAi: $0.4256 \pm 0.07937 \mathrm{~Hz}, \mathrm{n}=9$, $\mathrm{p}=0,7392$, nicht abgebildet), so wiesen die IIF-defizienten Larven niedrigere Amplituden der mEJCs auf (W1-24B: $0.7978 \pm 0.02408$ nA, n=9; IIF-RNAi: $0.6444 \pm$ $0.02604 n A, n=9, p=0,0005)$, sie zeigten etwa 80\% der Amplitude des Wildtyps.

Die evozierten Ströme waren ebenfalls vermindert: Bei Stimulation mit 0,2 Hz (W124B: $72.80 \pm 4.455 \mathrm{nA}, \mathrm{n}=10$; IIF-RNAi: $52.86 \pm 2.654 \mathrm{nA}, \mathrm{n}=11, \mathrm{p}=0,0009)$ und mit 10 $\mathrm{Hz}(W 1-24 B: 49.16 \pm 3.503 \mathrm{nA}, \mathrm{n}=10 ;$ IIF-RNAi: $35.11 \pm 2.136 \mathrm{nA}, \mathrm{n}=11, \mathrm{p}=0,0040)$ waren die eEJCs jeweils auf ca. $72 \%$ der Wildtyp-Amplitude erniedrigt. Interessanterweise war die Verminderung der Amplitude also sowohl bei niedriger als auch bei hoher Stimulationsfrequenz nahezu gleich stark ausgeprägt. Darüber hinaus ergab das ebenfalls durchgeführte Doppelpuls-Protokoll keinen signifikanten Unterschied zwischen W1-24B und IIF-RNAi (W1-24B: eEJC2/eEJC1 $=1.038 \pm$ 0.03068, $\mathrm{n}=9$; IIF-RNAi: eEJC2/eEJC1 $=1.091 \pm 0.04234, \mathrm{n}=7, \mathrm{p}=0,3101$, nicht abgebildet). Die Kurzzeitplastizität scheint also, anders als bei IIE, unverändert zu sein. Dies steht nicht im Widerspruch zur veränderten synaptischen Übertragung. Konnten wir uns die veränderte Plastizität bei IIE-RNAi am ehesten als Ausdruck eines Kompensationsmechanismus erklären, so lässt sich hier ähnlich argumentieren. Die Amplitude der eEJCs ist bei IIF nur um ca. ein Viertel reduziert - unter physiologischen Bedingungen könnte eine derartige Veränderung nahezu ohne Auswirkung auf die Funktion der Muskelzelle bleiben. So wäre es denkbar, dass keiner der präsynaptischen Kompensationsmechanismen aktiviert wird, da die verleibende Übertragungsrate von $75 \%$ ausreichend ist, um eine normale Muskelfunktion zu gewährleisten. Dies ist insbesondere wahrscheinlich, da die neuromuskuläre Synapse von Drosophila, wie auch Synapsen beim Säuger, über eine Funktionsreserve verfügt, die eine Muskelkontraktion auch bei deutlich verminderter Transmitterfreisetzung gewährleistet (Marrus und DiAntonio 2005). Eine veränderte synaptische Plastizität aus Kompensationsgründen ist dann nicht zu erwarten. Ein weiterer Grund für den im Vergleich zu IIE-RNAi wenig ausgeprägten Phänotyp könnte in dem verwendeten RNAi-Konstrukt liegen. Während bei IIE-RNAi eine Verminderung der mRNA auf ca. 20\% des Wildtyp-Niveaus vorlag, so konnte bei IIF- 
RNAi kein signifikanter Unterschied hinsichtlich der mRNA-Expression gefunden werden (Schwarz 2006). Die Suche nach einem stärker wirksamen RNAi-Konstrukt könnte daher in Zukunft helfen, die Funktion von IIF besser zu verstehen.

Die darüber hinaus ermittelten decay-T-Werte waren nicht signifikant unterschiedlich (W1-24B: $5.065 \pm 0.4123, \mathrm{n}=10$; IIF-RNAi: $5.103 \pm 0.1732, \mathrm{n}=11, \mathrm{p}=0,9314)$. 


\subsection{Dystroglycan}

\subsubsection{Suppression von Dystroglycan verändert die synaptische Übertragung}

Zur Beantwortung der Frage, ob Dystroglycan eine Rolle für die synaptische Übertragung spielt, erfolgte zunächst ein Vergleich von dg1554-Mutanten mit WildtypLarven, die für diese Versuche bei $25^{\circ} \mathrm{C}$ aufgezogen wurden. Die Ergebnisse dieses Experiments sind in Abbildung 3-6 zusammengefasst.

Hinsichtlich der Frequenz der mEJCs war kein signifikanter Unterschied zwischen der Dystroglycan-defizienten Mutante und den Kontrollen messbar (Kontrolle: $1.51 \pm 0.20$ $\mathrm{Hz}, \mathrm{n}=11$; dg1554: $1.68 \pm 0.24 \mathrm{~Hz}, \mathrm{n}=10, \mathrm{p}=0,5878)$. Die Amplitude der mEJCs aber war bei dg1554 erhöht (Kontrolle: $0.920 \pm 0.035 \mathrm{nA}, \mathrm{n}=11$; dg1554: $1.112 \pm 0.064 \mathrm{nA}$, $\mathrm{n}=10, \mathrm{p}=0,0139$ ). Die spontane Vesikelfreisetzung scheint also unbeeinträchtigt zu sein, jedoch wird bei der Fusion eines Vesikels entweder mehr Transmitter ausgeschüttet, oder die postsynaptische Antwort auf die Transmitterfreisetzung ist in der Mutante verstärkt. Zur Klärung dieser Frage können wir die eEJCs heranziehen. Diese waren bei niederfrequenter Stimulation mit $0,2 \mathrm{~Hz}$ in der dg1554-Mutante deutlich niedriger als in den Kontrollen (Kontrolle: -73.95 $\pm 3.47 \mathrm{nA}, \mathrm{n}=11$; dg1554: $53.86 \pm 3.88 n A, n=10, p=0,0010)$. Hieraus ergibt sich bei $d g 1554$ auch ein deutlich erniedrigter Quanteninhalt (Kontrolle: $81.08 \pm 4.08, n=11$; dg1554: $49.19 \pm 3.82, n=10$, $\mathrm{p}<0.0001)$. Die Erhöhung der mEJC-Amplitude in Verbindung mit der verminderten eEJC-Amplitude macht eine Funktionsveränderung am Rezeptor unwahrscheinlich, da in diesem Fall mEJCs und eEJCs in gleicher Weise, zumindest in die gleiche Richtung verändert sein sollten. Darüber hinaus ist die Kinetik der eEJCs unverändert: Der decay- $T$ ist zwischen dg1554 und W1 nicht signifikant unterschiedlich (Kontrolle: 5.294 $\pm 0.3332 \mathrm{~ms}, \mathrm{n}=11 ; d g 1554: 5.584 \pm 0.5870 \mathrm{n}=10, \mathrm{p}=0,6645)$.

Die erhobenen Daten führten insgesamt zu der Hypothese, dass das Fehlen von DG zu einer Beeinträchtigung der präsynaptischen Freisetzung der Vesikel bei Stimulation des Nerven führt. Die erhöhte Amplitude der mEJCs lässt sich dann am ehesten auf eine kompensatorisch vermehrte Füllung der einzelnen Vesikel zurückführen. In der Tat haben neben dem Füllungszustand auch noch die Vesikelgröße und die damit verbundene Leitfähigkeit der Fusionspore zwischen Vesikel und Plasmamembran 
erheblichen Einfluss auf die Größe des einzelnen Quantums, also die mEJCAmplitude (Karunanithi et al. 2002; Liu 2003), sodass auch diese als Kompensationsmechanismen in Frage kommen.
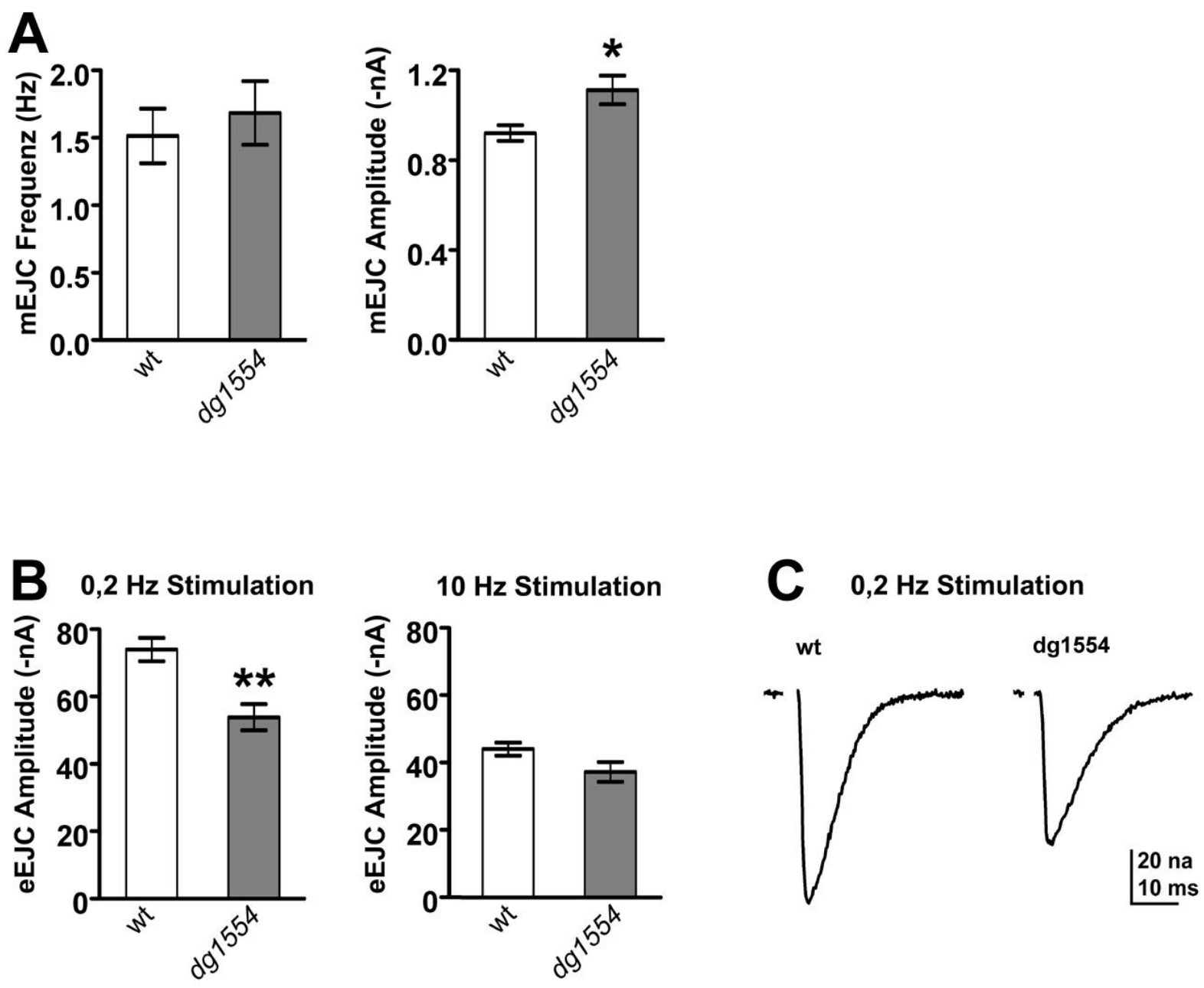

\section{Abb. 3-6. Suppression von Dystroglycan verändert die synaptische Übertragung.}

A, dg1554-Mutanten weisen eine um etwa $20 \%$ größere Amplitude der spontanen mEJCs auf, die Frequenz ist nicht signifikant unterschiedlich. B, Niederfrequente Stimulation $(0,2 \mathrm{~Hz})$ führt bei $d g 1554$ zu einer deutlich verminderten Amplitude der eEJCs, bei höherfrequenter Stimulation $(10 \mathrm{~Hz})$ ist kein signifikanter Unterschied mehr erkennbar. C, Beispielspuren der eEJC-Aufnahme bei 0,2 Hz.

In einem weiteren Protokoll wurden die Zellen nach einer Pause von 30 Sekunden für 10 Sekunden mit $10 \mathrm{~Hz}$ stimuliert. Auf diese Weise konnte die Kurzzeitdepression ausgelöst werden. Während der letzten 5 Sekunden der Stimulation war die Depression maximal und die Amplituden befanden sich auf einem 
Gleichgewichtsniveau (steady state). Bei der hochfrequenten Stimulation ergab sich eine Überraschung: Es fand sich kein signifikanter Unterschied der eEJCs im steady state (Kontrolle: $-44.05 \pm 1.92 \mathrm{nA}, \mathrm{n}=11$; dg1554: $-37.27 \pm 2.99 \mathrm{nA}, \mathrm{n}=10, \mathrm{p}=0,0665$ ). In der Tendenz ist die Amplitude von dg1554 zwar niedriger als die der Kontrollen, jedoch ist der Unterschied längst nicht so deutlich wie bei der niederfrequenten Stimulation. Die DG-Defizienz scheint sich also spezifisch auf die Freisetzung der Vesikel bei niedriger Stimulationsfrequenz auszuwirken.

Setzen wir dies in Bezug zum Modell der Vesikel-Pools, so lässt sich die Vermutung anstellen, dass die DG-Defizienz sich auf die Freisetzungswahrscheinlichkeit der verschiedenen Gruppen von Vesikeln unterschiedlich stark auswirkt. Niedrigere Stimulationsfrequenzen führen eher zur Freisetzung von Vesikeln aus dem readily releasable pool (RRP), während bei höheren Frequenzen vermehrt der recycling pool (RP) rekrutiert wird. Ist nun die eEJC-Amplitude bei dg1554 insbesondere bei niedriger Stimulationsfrequenz auffällig klein, so lässt sich daraus die Hypothese formulieren, dass der RRP stärker durch die Mutation beeinflusst wird als der RP. Dies gilt nur, sofern man davon ausgeht, dass die Rezeptorfunktion durch die DGDefizienz unverändert ist, was wie oben erwähnt wahrscheinlich ist. Ob primär die Freisetzungswahrscheinlichkeit, die Anzahl oder der Füllungszustand der Vesikel des RRP verändert ist, lässt sich aus den bisherigen Ergebnissen nicht eindeutig ableiten. Hier könnte die Zuhilfenahme weiterer Verfahren, beispielsweise der Elektronenmikroskopie, in Zukunft neue Erkenntnisse bereitstellen. 


\subsubsection{Dystroglycan beeinflusst die synaptische Kurzzeitplastizität}

Die beobachteten Veränderungen der basalen synaptischen Übertragung an der dg1554-Mutante warfen die Frage auf, inwiefern die synaptische Kurzzeitplastizität durch ein Fehlen von DG ebenfalls beeinträchtigt sein würde. Insbesondere die Möglichkeit der unterschiedlichen Beeinträchtigung von readily-releasable-pool und recycling pool verlangte nach einem modifizierten experimentellen Ansatz. Die Synapse sollte nicht nur unter den statischen Bedingungen „keine“, „moderate“ oder "starke" Stimulation untersucht werden, sondern es sollten auch die Übergänge zwischen den Stimulationsfrequenzen und damit die Auswirkung vorangehender Stimulation auf folgende synaptische Übertragung sichtbar gemacht werden. $\mathrm{Zu}$ diesem Zweck wurde ein Stimulationsprotokoll entwickelt, bei dem zunächst für 55 Sekunden mit 0,2 Hz stimuliert wurde. Darauf folgte ohne Pause die hochfrequente Stimulation mit $10 \mathrm{~Hz}$ für 10 Sekunden, im Anschluss wurde (nach einer Pause von $360 \mathrm{~ms}$ ) wieder für 55 Sekunden bei $0,2 \mathrm{~Hz}$ stimuliert, um die Vorgänge bei der „Erholung“ der Zelle zu untersuchen. Durch den direkten Übergang zwischen hochund niederfrequenter Stimulation sollte untersucht werden, ob sich diese gegenseitig beeinflussen. Die Ergebnisse dieses Versuchs im Überblick zeigt Abbildung 3-7.

Zwei wesentliche Beobachtungen lassen sich an diesem Experiment machen. Zu Beginn der hochfrequenten Stimulation zeigt dg1554 ein Verhalten, dass dem der Bruchpilot-Mutante ähnelt (Kittel et al. 2006): Die ersten Stimulation führen zu einer Zunahme der eEJC-Amplitude (nicht signifikant), die dann wieder abfällt und den steady state erreicht. Dieses Verhalten wurde bei Bruchpilot mit einer chronisch verminderten Freisetzungswahrscheinlichkeit und Delokalisierung der präsynaptischen Calcium-Kanäle erklärt. Auch für DG kommt dieser Erklärungsansatz in Frage. Es muss aber bedacht werden, dass dieser Phänotyp nur unter der Bedingung der vorangegangen $0,2 \mathrm{~Hz}$-Stimulation beobachtet werden konnte. Die zur Messung der eEJCs verwendeten $10 \mathrm{~Hz}$-Protokolle zeigten keine initiale Zunahme der eEJC-Amplitude (Daten nicht dargestellt).

Die zweite Beobachtung liegt am Anfang der Erholungsphase, ab 70 Sekunden nach Stimulationsbeginn. Hierbei zeigt dg1554 ein interessantes Verhalten: Während der Wildtyp aus dem steady state wieder seinem Durchschnittswert bei der 
niederfrequenten Stimulation am Anfang entgegenstrebt, so ist der erste Wert in der Erholungsphase (360 ms nach dem letzten Wert der Hochfrequenzstimulation) bei dg1554 niedriger (nicht signifikant) als der letzte Wert der voraus gehenden Hochfrequenzstimulation.

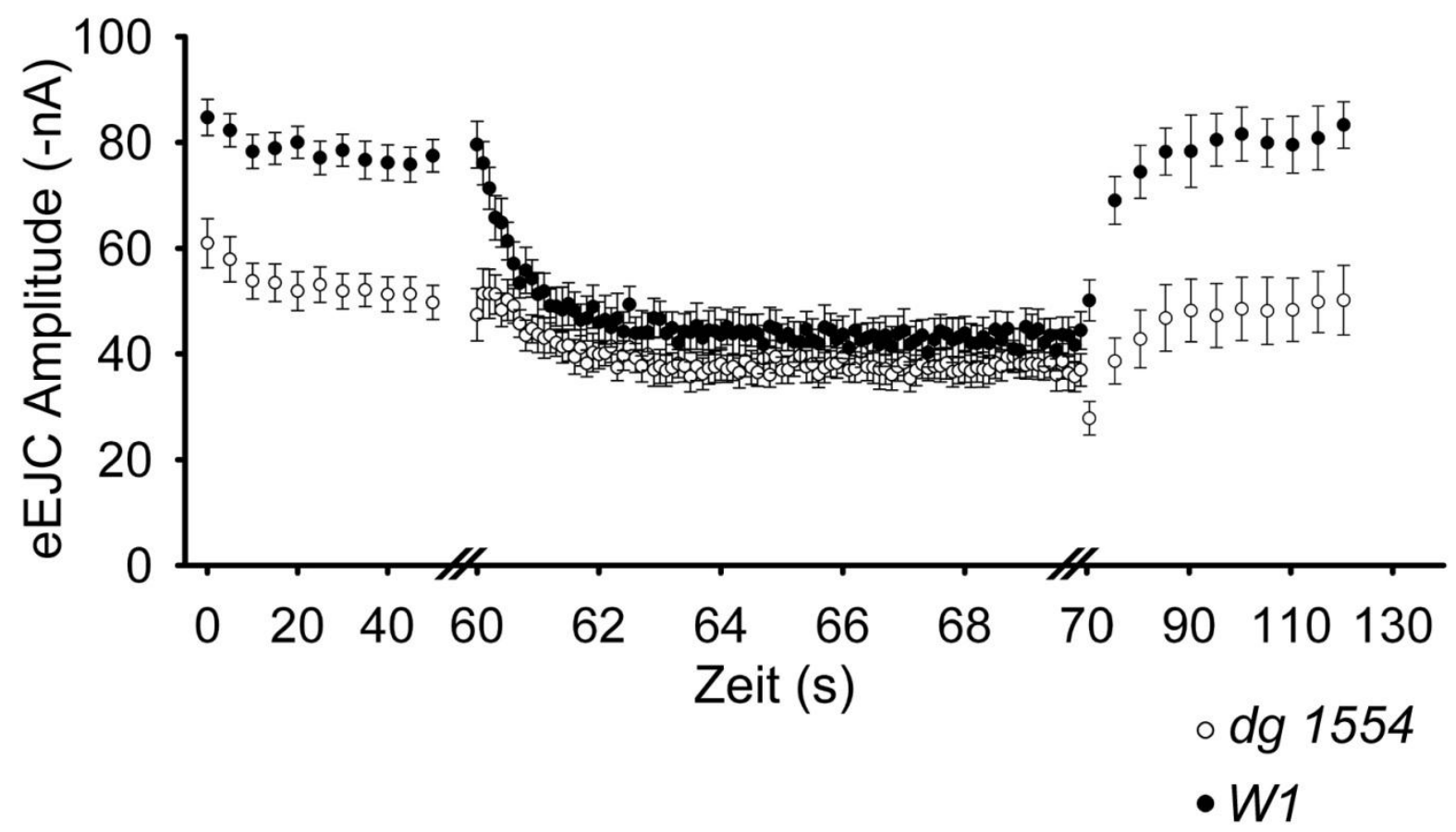

\section{Abb. 3-7. Synaptische Plastizität bei $d g 1554$.}

Dargestellt ist der komplette Ablauf des Niederfrequenz-Hochfrequenz-Messprotokolls. Zu beachten ist die aus Gründen der Übersichtlichkeit geänderte Skalierung der Zeitachse während der hochfrequenten Stimulation (Bereich 60 bis 70 Sekunden nach Messbeginn). Im Zeitabschnitt 0 - 60 s erkennt man die niedrigere Amplitude von dg1554 während der Stimulation mit 0,2 Hz. Hierbei wurden auch die Daten der vorhergehenden Experimente (3.2.1) hinzugezogen. Zu Beginn der hochfrequenten Stimulation (ab 60s) zeigt sich ein Unterschied: Während W1 eine normale STD zeigen, ist das Verhalten von dg1554 komplexer: Die Amplitude scheint zunächst etwas anzusteigen, um dann auf den steady state abzusinken, der sich nicht mehr stark vom steady state bei $W 1$ unterscheidet. In der Erholungsphase mit $0,2 \mathrm{~Hz}$, beginnend bei $70 \mathrm{~s}$, deutet sich ein weiterer Unterschied an. Während $W 1$ ausgehend vom steady state eine schrittweise Annäherung an das Ausgangsniveau zeigt, so ist insbesondere der erste Wert (nach einer Pause von 360 ms) bei dg1554 (nicht signifikant) niedriger als der steady state. Zu beachten ist, dass für Hochfrequenz- und Erholungsphase selbstverständlich nicht die Daten der vorangehenden Experimente (3.2.1) herangezogen wurden. 
Schon nach einer kurzen Pause von $360 \mathrm{~ms}$ also ist bereits wieder ein signifikanter Unterschied zwischen den eEJCs von W1 und dg1554 nachweisbar. Daraus lässt sich schlussfolgern, dass diese Pause beim Wildtyp eine vermehrte Vesikelfreisetzung beim nächsten Puls ermöglicht, was sich durch eine Regeneration des RRP erklären lässt. Als Konsequenz könnte bei dg1554 diese Regeneration gestört sein.

Insgesamt stützen die Ergebnisse dieses Experiments die Hypothese, dass sich die Mutation in dg1554 spezifisch auf die Vesikel des RRP auswirkt, die ja insbesondere während niedriger Stimulationsfrequenzen freigesetzt werden. 


\subsection{Funktionelle Analyse der Rolle von CDK5 für die synaptische Transmission}

\subsubsection{Suppression von CDK5 führt nicht zu einer Veränderung der synaptischen Transmission}

Um der Frage nach der Bedeutung von CDK5 für die neuromuskuläre Synapse nachzugehen, wurden die mutanten cdk5 null Larven mit dem Standardprotokoll untersucht. Als Kontrolltier diente cdk5wt, bei dem das Wildtyp-Gen reexprimiert wurde. Die Ergebnisse sind in Abbildung 3-8 zusammenfassend dargestellt.
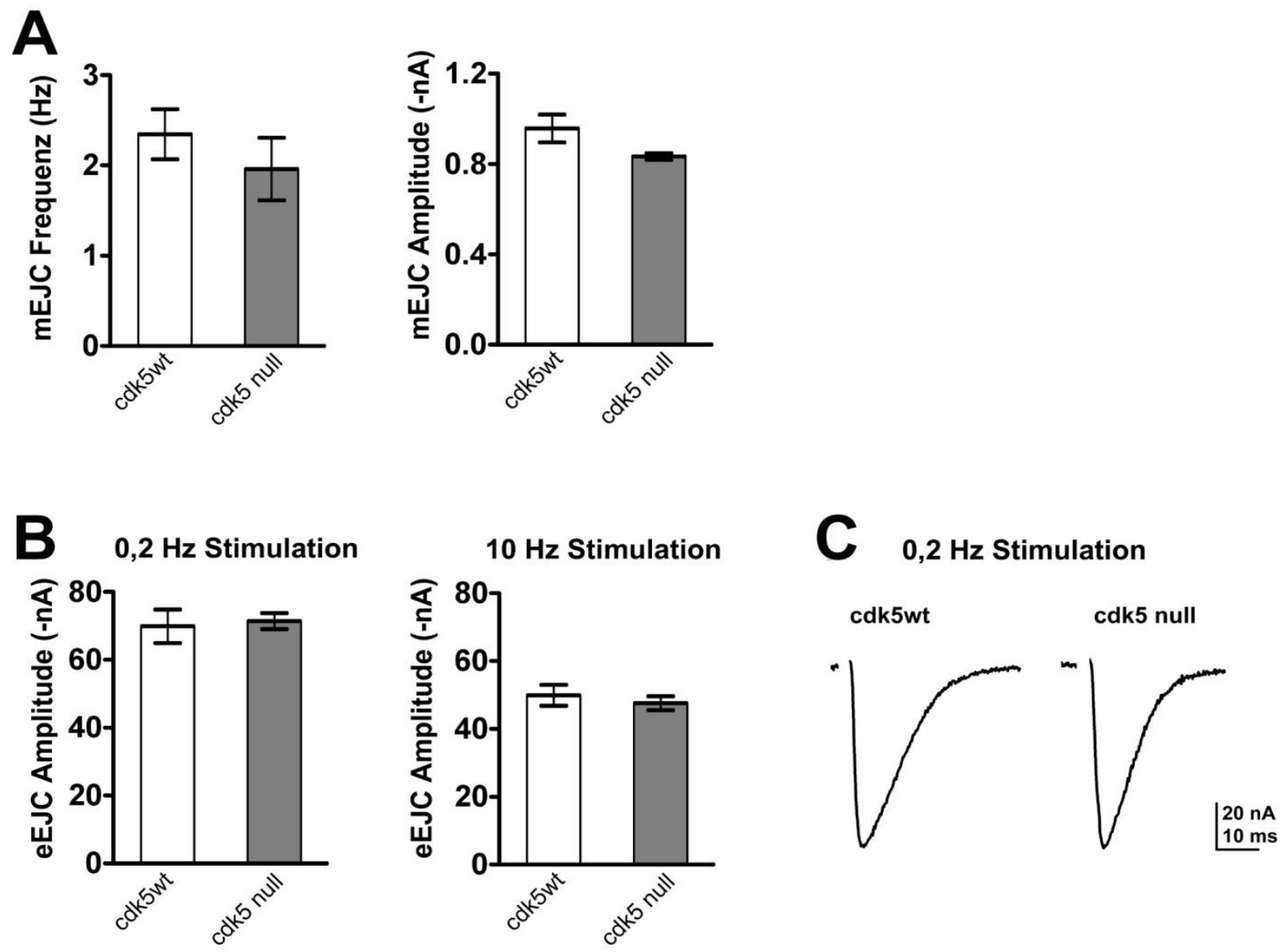

\section{Abb. 3-8. Unterdrückung von CDK5 zeigt keine veränderte synaptische Übertragung.}

A, Weder die Amplitude noch die Frequenz der mEJCs sind bei cdk5 null im Vergleich zu cdk5wt signifikant verändert. B, Auch bei der Stimulation mit $0,2 \mathrm{~Hz}$ und mit $10 \mathrm{~Hz}$ findet sich kein signifikanter Unterschied. C, Beispielspuren der Stimulation mit 0,2 Hz 
Bei den untersuchten Tieren fanden sich keine signifikanten Unterschiede in Frequenz (cdk5wt: $2.345 \pm 0.2779 \mathrm{~Hz}, \mathrm{n}=11$; cdk5 null: $1.960 \pm 0.3458 \mathrm{~Hz}, \mathrm{n}=9, \mathrm{p}=0,3906$ ) oder Amplitude der mEJCs (cdk5wt: $0.9564 \pm 0.06159 \mathrm{nA}, \mathrm{n}=11$; cdk5 null: $0.8322 \pm$ $0.01402 n A, n=9, p=0,0913)$. Auch bei der Stimulation des Nerven fanden sich keine signifikanten Abweichungen bezüglich der eEJCs, weder bei $0,2 \mathrm{~Hz}$ (cdk5wt: $69.88 \pm$ $4.946 \mathrm{nA}, \mathrm{n}=10$; cak5 null: $71.39 \pm 2.373 \mathrm{nA}, \mathrm{n}=10, \mathrm{p}=0,7858)$ noch bei $10 \mathrm{~Hz}$ Stimulationsfrequenz (cdk5wt: $49.92 \pm 3.080 \mathrm{nA}, \mathrm{n}=8$; cdk5 null: $47.58 \pm 2.044 \mathrm{nA}$, $n=10, p=0,5224$ ).

Insgesamt geben diese Daten keinen Anlass zu der Vermutung, dass die Suppression von CDK5 an der neuromuskulären Synapse von Drosophila einen bedeutsamen Einfluss auf die synaptische Übertragung und Plastizität hat. 


\section{Diskussion}

\subsection{Funktion und Aufbau des ionotropen Glutamatrezeptorkomplexes bei Drosophila}

\subsubsection{IIA und IIB}

Der Aufbau des funktionalen, endogenen ionotropen Glutamatrezeptorkomplexes bei Drosophila melanogaster ist trotz intensiver Untersuchung bislang nur unzureichend verstanden. Fest steht, dass die Untereinheiten IIC, IID und IIE und darüber hinaus entweder IIA oder IIB für die synaptische Expression von Rezeptorkomplexen notwendig sind (Marrus und DiAntonio 2005; Qin et al. 2005). Dabei scheint die Inkorporation von IIA oder IIB, also das quantitative Verhältnis von IIA zu IIB, weitreichende Bedeutung zu haben, wie aus der unterschiedlichen Kinetik des postsynaptischen Stroms hervorgeht (Abb. 3-2).

Für den postsynaptischen Strom wurde eine raschere Desensitisierung (niedrigerer decay-T) der mEJCs bei Larven mit der Untereinheit IIB festgestellt (DiAntonio et al. 1999). Dieser Befund konnte in dieser Arbeit anhand von IIB-Genomisch und IIB-GFP bestätigt werden. Darüber hinaus konnte gezeigt werden, dass die eEJCs bei solchen Larven ein ähnliches Verhalten offenbaren. Sowohl Amplitude als auch decay- $T$ sind im Vergleich zu IIA-Konstrukten vermindert (Abb. 3-1, 3-2).

Diese Ergebnisse tragen $\mathrm{zu}$ der Hypothese bei, dass die unterschiedliche Inkorporation von IIA und IIB zu funktionell differenten Rezeptorkomplexen führt. IIAKomplexe liefern einen länger anhaltenden Strom, IIB-Komplexe einen kürzeren. Darüber hinaus erhöht vermehrte Expression von IIA die Anzahl der Synapsen, PSDs und konsekutiv die Stärke der synaptischen Übertragung (Sigrist et al. 2002). Insgesamt ergibt sich ein Modell, in dem das Verhältnis IIA/IIB über die Kinetik der Rezeptorkomplexe, aber auch über die Entwicklung postsynaptischer Strukturen entscheidet. Auch über eine indirekte Beeinflussung des IIA/IIB-Verhältnisses lässt sich dieses Modell bestätigen: Haas, Miller und Broadie beschrieben vor kurzem, wie die Inhibierung des Proteasoms an der Drosophila-NMJ zu einem erniedrigten IIA/IIB- 
Verhältnis führt, welches, wie nach dem Modell zu erwarten, verminderte mEJCAmplituden und decay-T-Werte nach sich zog (Haas et al. 2007). Durch die Bestätigung aus unterschiedlichen Herangehensweisen ergibt sich ein guter Hinweis darauf, dass das IIA/IIB-Verhältnis wahrscheinlich unter physiologischen Bedingungen einen Mechanismus zur Anpassung der synaptischen Übertragungseigenschaften darstellt.

Um die Bedeutung und die Funktionsweise von IIA und IIB besser zu untersuchen, stellt die GFP-Markierung ein entscheidendes Werkzeug dar. Die elektrophysiologische Daten (Abb. 3-1) des GFP-markierten IIB geben keinen Anlass zu der Vermutung, dass die Funktion dieser Untereinheit beeinträchtigt sein könnte das Konstrukt eignet sich somit zum Einsatz für integrierte funktionelle Untersuchungen an der NMJ, die zum Verständnis von IIB und seiner Rolle in Rezeptorkinetik und Synaptogenese beitragen können. Dies ist das zweite wichtige Ergebnis dieses Experiments neben den gewonnenen Erkenntnissen zur Kinetik der IIA- und IIB-Rezeptorkomplexe.

\subsubsection{IIE}

Hinsichtlich der Untereinheit IIE war, wie erwähnt, bislang hauptsächlich bekannt, dass sie zu den überlebensnotwendigen Bausteinen der Rezeptorkomplexe gehört (Qin et al. 2005). Ihre RNAi-vermittelte Unterdrückung führt zu einer massiven Abschwächung der synaptischen Signalübertragung (Abb. 3-3).

Interessant ist in diesem Experiment die aus der Unterdrückung resultierende veränderte synaptische Plastizität (Abb. 3-4). Diese lässt sich am ehesten als Ausdruck einer überbeanspruchten präsynaptischen Kompensierung erklären: Bei einer postsynaptischen Funktionseinschränkung (z.B. der Rezeptoren) kommt es auf noch nicht vollständig geklärtem Weg zu einer erhöhten Freisetzung von Neurotransmitter im Sinne der Kompensation (Petersen et al. 1997; Paradis et al. 2001). Ist die postsynaptische Funktion massiv gestört, wie bei IIE-RNAi zu erwarten, so kann dieses System überfordert werden. Bei Doppelpuls- oder 
Hochfrequenzstimulation sinkt die Amplitude der eEJCs dann stärker ab als im Wildtyp. Die beobachtete Doppelpuls-Depression lässt sich mechanistisch sehr gut der Doppelpuls-Bahnung gegenüberstellen, die beispielsweise bei der BruchpilotMutante beobachtet wird (Kittel et al. 2006). Während bei Bruchpilot eine dauerhaft erniedrigte Freisetzungswahrscheinlichkeit zu einer Doppelpuls-Bahnung führt, so lässt sich aus der Doppelpuls-Depression bei IIE-RNAi analog eine erhöhte Freisetzungswahrscheinlichkeit ableiten.

Diese erhöhte Freisetzungswahrscheinlichkeit ist der eigentliche Kompensationsmechanismus der Präsynapse. Theoretisch besteht auch die Möglichkeit, dass die beobachteten Veränderungen der synaptischen Plastizität eine direkte Veränderung am Rezeptor selbst widerspiegeln, beispielsweise durch ein verändertes Desensitisierungsverhalten. Dies erscheint jedoch eher unwahrscheinlich, da die Kinetik der eEJCs unverändert ist (keine Änderung des decay-T).

Die unveränderten decay-T-Werte implizieren über die bisherige Betrachtung hinaus, dass das Fehlen von IIE die Rezeptorkinetik nicht verändert und dass das IIA/IIBVerhältnis dadurch ebenfalls nicht beeinflusst wird. Dies ist wichtig, da ein verändertes IIA/IIB-Verhältnis andernfalls für die beobachteten Veränderungen mit verantwortlich gemacht werden könnte. Außerdem hilft diese Beobachtung, die mögliche Funktion von IIE einzuschränken. IIE scheint nicht an der Zusammensetzung der Rezeptorkomplexe mit IIA oder IIB beteiligt zu sein, spielt aber dennoch eine essentielle Rolle für Rezeptorfunktion und Überleben der Tiere. IIE dürfte daher am ehesten für den prinzipiellen Aufbau eines Rezeptorkomplexes verantwortlich sein und als „Grundbaustein“ angesehen werden.

\subsubsection{IIF}

Bei der Frage nach der Stöchiometrie der Rezeptorkomplexe war man bisher von der Vorstellung ausgegangen, dass ionotrope Glutamatrezeptorkomplexe in Säugetieren als Tetramere vorliegen (Laube et al. 1998; Rosenmund et al. 1998; Safferling et al. 2001). Überträgt man dieses Modell auf Drosophila, so ergeben sich, ausgehend von den essentiellen Untereinheiten, die möglichen Zusammensetzungen 
(IIA)(IIC)(IID)(IIE) sowie (IIB)(IIC)(IID)(IIE) (Qin et al. 2005). Da es sich jedoch nur um eine Übertragung handelt, dürfen auch andere Stöchiometrien mit mehr als vier Untereinheiten nicht ausgeschlossen werden (Qin et al. 2005).

Die funktionelle Charakterisierung der Untereinheit IIF hat direkte Konsequenzen für diese Überlegung. Nachdem mittels Immunfluoreszenz bereits die Anwesenheit von IIF-Untereinheiten im Rezeptorfeld der neuromuskulären Synapse dargestellt werden konnte (Tobias Schwarz, persönliche Kommunikation), zielte der nächste Schritt auf die funktionelle Bedeutung von IIF. Die RNAi-vermittelte Abschwächung von IIF führt zu einer deutlichen Beeinträchtigung der synaptischen Übertragung (Abb. 3-5), die Amplitude sowohl der eEJCs als auch der mEJCs ist erniedrigt. Die dramatische Herabsetzung der postsynaptischen Sensitivität macht einen proportionalen Zusammenhang mit der Menge von funktionalen GluRIIE sehr wahrscheinlich. Diese Beobachtung spricht für die Hypothese, dass IIF einen funktionell bedeutsamen Bestandteil der Glutamatrezeptorkomplexe in vivo darstellt. In Zusammenhang mit den bisherigen Ergebnissen zur Bedeutung der anderen Untereinheiten spricht dies gegen ein tetrameres Modell, da nun neben den vier bisher betrachteten Untereinheiten IIA/IIB,IIC,IID,IIE auch noch eine fünfte, nämlich IIF, für einen normal funktionierenden Glutamatrezeptorkomplex nötig zu sein scheint. Denkbar wäre also eine pentamere Rezeptorstruktur - mögliche Komplexe wären (IIA)(IIC)(IID)(IIE)(IIF) und (IIB)(IIC)(IID)(IIE)(IIF). Nicht ausgeschlossen werden kann in diesem Zusammenhang die Möglichkeit, dass es sich bei den IIF-Komponenten um separate, monomere Glutamatrezeptoren handelt, die parallel $\mathrm{zu}$ den beschriebenen Rezeptorkomplexen an der Synapse vorkommen.

Des Weiteren ist die Beobachtung wichtig, dass die Unterdrückung von IIF nicht zu einer Veränderung des decay- $\tau$ führt. Dies hat zwei wichtige Konsequenzen. Zum einen lässt sich der Schluss ziehen, dass IIF selbst keinen Einfluss auf die Kinetik des postsynaptischen Stroms hat. Zum anderen lässt sich folgern, dass IIF das Verhältnis der Expression von IIA und IIB nicht verändert, denn ein verändertes IIA/IIB-Verhältnis ließe eine Veränderung des decay-t erwarten (Abb. 3-2). Insgesamt scheint IIF also die Rezeptorkinetik nicht zu verändern, den postsynaptischen Strom aber zu verstärken. Ob dies durch eine veränderte Anzahl von Rezeptorkomplexen oder durch 
eine funktionelle Veränderung des einzelnen Komplexes zustande kommt, lässt sich aus den bisherigen Daten nicht ermitteln.

Das unveränderte decay-t lässt aber noch eine weitere Überlegung zu. Wie erwähnt, könnte es sich bei IIF auch um den Teil eines eigenständigen Rezeptorkomplexes handeln, der parallel zu den üblichen IIA/IIB-enthaltenden Komplexen existiert. Diese Möglichkeit wird durch die unveränderten decay-т-Werte bei IIF-RNAi eher unwahrscheinlich. Wäre IIF Bestandteil eines funktionalen separaten Rezeptors, so würde das Fehlen von IIF den decay-t nur dann nicht verändern, wenn der separate Rezeptor die exakt gleichen kinetischen Eigenschaften besäße wie die IIA/IIBRezeptorkomplexe - dies erscheint jedoch höchst unwahrscheinlich. Die unveränderten decay-T-Werte führen also zu der Hypothese, dass IIF einen Bestandteil der bekannten Rezeptorkomplexe darstellt oder für deren Funktion bzw. Bereitstellung auf andere Weise verantwortlich ist. 


\subsection{Die Bedeutung des Proteins Dystroglycan für die Synapse}

Die Funktion von Dystroglycan im Rahmen der synaptischen Übertragung ist bislang unzureichend erforscht. Einige Studien deuten auf eine Beeinflussung der Langzeitplastizität an Säugersynapsen hin (Moore et al. 2002; Anderson et al. 2005). Über die direkte Beeinflussung der synaptischen Übertragung oder der Kurzzeitplastizität jedoch ist wenig bekannt. Für das Verständnis insbesondere der mentalen Funktionseinschränkungen, die bei Dystrophinopathien auftreten können, sind Einblicke in die Arbeitsweise von DG an der Synapse von großem Interesse.

Betrachten wir zunächst die Veränderungen bei dg1554-Mutanten im Rahmen der basalen synaptischen Übertragung (Abb. 3-6). Die verminderte Amplitude der eEJCs bei etwas größeren mEJCs lässt zunächst auf eine Beeinflussung der präsynaptischen Vesikelfreisetzung schließen. Die erhöhten mEJCs sind als Zeichen der Kompensation zu werten (Vgl. 3.2.1). Die im Vergleich zu W1 weniger starke Abnahme der eEJCs bei hochfrequenter Stimulation führt zu der Hypothese, dass DG spezifisch die Freisetzung, Anzahl oder Bereitstellung der Vesikel des RRP beeinflusst. Im steady state bei $10 \mathrm{~Hz}$ findet sich kein signifikanter Unterschied mehr zwischen W1 und dg1154. Die Freisetzung der Vesikel des RP scheint also unverändert. Ein weiteres Argument für eine selektive Beeinflussung des RRP liefert der bei dg1554 deutlich verminderte QC. Kidokoro und Kollegen konnten zeigen, dass der exo/endo cycling vesicle pool, ein optisch gemessenes Korrelat des RRP, direkt mit der Größe des QC korreliert (Kidokoro et al. 2004). Der verminderte QC weist also ebenfalls auf eine spezifische Beeinträchtigung des RRP hin.

Diese Beobachtung könnte weitreichende Konsequenzen für das Verständnis der Funktion von DG haben. Bislang ist leider nicht ausreichend geklärt, wie und ob sich die theoretische Einteilung der Vesikel in RRP, RP und RSP auch in tatsächlich unterschiedlichen Vesikelpopulationen widerspiegelt. Die spezifische Beeinträchtigung des RRP bei dg1554 stellt jedoch eine interessante Möglichkeit dar, solche Unterschiede zwischen den einzelnen Pools zu untersuchen. Insofern liefert der an dg1554 beobachtete Phänotyp nicht nur für das Verständnis von DG, sondern auch für das Konzept der Vesikel-Pools neue Impulse. 
Wie die Art der Beeinflussung des RRP durch DG aussieht, darüber kann bislang nur spekuliert werden. Ein möglicher Mechanismus, dem in Zukunft verstärktes Interesse gelten sollte, ist die Endozytose. Für DG-defiziente Fibroblasten in Zellkultur konnte eine erhöhte Endozytoserate nachgewiesen werden (Zhan et al. 2005). Dies ist jedoch als Erklärung eines beeinträchtigten RRP wahrscheinlich nicht direkt auf dg1554 zu übertragen. Da aber die Endozytose für die Bereitstellung von Vesikeln auch des RRP von großer Bedeutung ist, so sollte der Einfluss von DG auf die Endozytose auch im Rahmen der synaptischen Übertragung näher untersucht werden, da er als Erklärung für die den dg1554-Phänotyp in Frage kommt.

Über einen Einfluss auf postsynaptische Funktionsabläufe gibt uns der decay-T Hinweise. Dieser ist bei dg1554 im Vergleich zu W1 unverändert. Das Verhältnis zwischen IIA und IIB-Rezeptorkomplexen scheint also unverändert zu sein, DG scheint keinen Einfluss auf die Rezeptorkomposition an der Postsynapse zu haben. Dies spricht für die Hypothese, dass es sich bei den durch DG hervorgerufenen Veränderungen um weitgehend präsynaptische Effekte handelt.

Weitaus komplexer sind die Vorgänge bei den Experimenten zur synaptischen Plastizität (Abb. 3-7). Betrachten wir zunächst die beobachtete transiente Zunahme der eEJC-Amplitude bei der hochfrequenten Stimulation. Wie erwähnt, konnte diese (nicht signifikante) Zunahme nur beobachtet werden, wenn direkt vorher eine niederfrequente Stimulation durchgeführt wurde. Bei Bruchpilot (Kittel et al. 2006) konnte ein ähnlicher Phänotyp direkt unter Ruhebedingungen ausgelöst werden und durch eine chronisch erniedrigte Freisetzungswahrscheinlichkeit der Vesikel erklärt werden. Eine mögliche Erklärung für den dg1554-Phänotyp wäre, dass die höhere präsynaptische $\mathrm{Ca}^{2+}$-Konzentration bei der hochfrequenten Stimulation die Freisetzung der Vesikel des RRP vereinfacht, da deren Freisetzungswahrscheinlichkeit erniedrigt ist. Analog zu Bruchpilot würde also eine (durch mutiertes DG verursachte) Erniedrigung der Freisetzungswahrscheinlichkeit die beobachtete Potenzierung verursachen. Dies erklärt jedoch nicht, warum der Effekt erst nach vorangehender niederfrequenter Stimulation auftritt. Hier müssen also komplexere Mechanismen in Betracht gezogen werden, etwa eine aktivitätsabhängige Veränderung der Freisetzungswahrscheinlichkeit. Da der hier beobachtete Effekt 
darüber hinaus nicht signifikant ist, lässt sich diese Frage nicht zweifelsfrei klären.

Das zweite beobachtete Phänomen ist die beeinträchtigte Erholung nach der hochfrequenten Stimulation. Geht man auch hier davon aus, dass während dieser Phase die kontinuierliche Wiederauffüllung des RRP für die bei $W 1$ beobachtete Regeneration der eEJC-Amplitude verantwortlich ist, so fügt sich die gestörte Regeneration von dg1554 in die Hypothese des spezifisch beeinflussten RRP ein. Dabei darf allerdings nicht übersehen werden, dass diese Art der Beeinflussung des RRP von der bei der synaptischen Übertragung postulierten verschieden ist: Während für die synaptische Übertragung von einer Verminderung der Freisetzungswahrscheinlichkeit oder Anzahl der RRP-Vesikel auszugehen ist, so spricht eine verminderte Regeneration eher für eine gestörte Wiederauffüllung des RRP. Für die beobachteten Effekte bei synaptischer Übertragung auf der einen Seite und synaptischer Plastizität auf der anderen Seite müssen also unter Umständen unterschiedliche Mechanismen verantwortlich gemacht werden.

Gemeinsam mit den Ergebnissen der Untersuchung der basalen synaptischen Übertragung stützt also der Plastizitätsversuch die Hypothese, dass die dg1554Mutation zu einer spezifischen Beeinträchtigung des RRP führt. Offen bleibt, welche der Komponenten Freisetzungswahrscheinlichkeit, Anzahl und Füllungszustand der Vesikel sowie Regeneration des RRP in welchem Ausmaß betroffen und für die beobachteten Effekte verantwortlich sind. Insbesondere die Möglichkeit mehrerer beteiligter Mechanismen sollte in Betracht gezogen werden, da die Vorgänge bei der synaptischen Übertragung am ehesten durch beeinträchtigte Vesikelfreisetzung des RRP erklärt werden können, während die veränderte synaptische Plastizität mit einer gestörten Regeneration des RRP in Einklang zu bringen ist.

Vor kurzem konnte $\beta-D G$ als primäres Substrat der Matrix-Metalloproteinase-9 identifiziert werden (Michaluk et al. 2007), einem Molekül, dass durch Proteolyse die Menge extrazellulärer Komponenten an der Synapse kontrolliert und mit der synaptischen Plastizität in Verbindung gebracht wurde (Meighan et al. 2006). Obwohl höchstwahrscheinlich nicht für den dg1554-Phänotyp verantwortlich, so spricht dieser Zusammenhang für eine Effektorfunktion von DG im Rahmen der synaptischen Plastizität. Dieser Befund, erhöht die Wahrscheinlichkeit, dass die beobachteten Effekte auch eine Bedeutung für die synaptische Funktion in vivo haben und es sich 
nicht um zufällige Störeffekte durch die Mutation in DG handelt.

Die weitere Untersuchung von DG an der NMJ von Drosophila-Larven erscheint aus diesem Grund lohnenswert und bietet einen viel versprechenden Ansatz zum Verständnis von Freisetzung, Regeneration und Kinetik der synaptischen Vesikelpools. 


\subsection{CDK5}

Für das Protein CDK5 sind vielfältige Funktionen postuliert worden und zahlreiche Untersuchungen hatten einen Einfluss von CDK5 auf die synaptische Übertragung zum Thema. Insbesondere im Licht einer möglichen Beteiligung an der Pathogenese der Alzheimer'schen Erkrankung stellt CDK5 einen interessanten Ansatzpunkt zum besseren Verständnis der synaptischen Vorgänge bei dieser Krankheit dar. Anhand der NMJ von Drosophila-Larven sollte in einem einfach zugänglichen und gut erforschten synaptischen System die Rolle von CDK5 näher charakterisiert werden. Die Ergebnisse dieses Versuches geben keinen Anhalt dafür, dass die basale synaptische Funktion der Drosophila-NMJ durch das Fehlen von CDK5 wesentlich beeinflusst wird (Abb. 3-8). Dieses Ergebnis zeigt, dass CDK5 für die prinzipielle Funktion dieser glutamatergen Synapse entbehrlich ist.

Die Erklärungsmöglichkeiten hierfür sind vielfältig, jedoch sollte nicht der Schluss gezogen werden, dass CDK5 ohne Bedeutung für die synaptische Funktion bei Drosophila ist. Bisherige Untersuchungen konnten einen Einfluss von CDK5 insbesondere auf morphologische Eigenschaften aufzeigen. Dazu gehören z.B. gestörte axonale Wachstumsmuster und Kortexarchitektur sowohl bei Drosophila (Connell-Crowley et al. 2000) als auch in Mäusen (Gilmore et al. 1998). Dies weist darauf hin, dass CDK5 in den unterschiedlichen Organismen ähnliche Funktionen übernimmt. Es kann also als wahrscheinlich angesehen werden, dass die an Säugern beobachteten Veränderungen der synaptischen Übertragung (Fletcher et al. 1999; Tomizawa et al. 2002; Angelo et al. 2006) auch in Drosophila vorkommen. Dies wirft die Frage auf, wieso die hier durchgeführten Experimente keine derartige Beeinflussung nachweisen konnten. Wie erwähnt gibt es viele Erklärungsansätze. Geht man von den oben genannten Untersuchungen aus, so fällt ins Gewicht, dass bislang keine eindeutige Rolle für CDK5 bei der synaptischen Übertragung gefunden wurde, sondern sowohl die Transmission verstärkende als auch hemmende Effekte beobachtet wurden. Diese funktionelle Heterogenität macht klar, dass CDK5 alleine keine spezifische Funktion ausübt, sondern seine Aufgabe vom untersuchten Gewebe und gleichzeitig exprimierten Aktivatoren abhängt. In den untersuchten Larven könnten sich beispielsweise die genannten Effekte gegenseitig aufheben, so dass 
keine „Brutto“-Veränderung der Transmission zu erkennen ist. Auch wäre denkbar, dass Kompensationsmechanismen greifen, die die synaptische Funktion auch in Abwesenheit von CDK5 gewährleisten. Dies kommt insbesondere in Betracht, da auch in den Experimenten zu Glutamatrezeptoren und Dystroglycan Kompensationsmechanismen der NMJ beobachtet werden konnten, die die Beurteilung der tatsächlich zugrunde liegenden Veränderungen an der Synapse erschweren. Die NMJ von Drosophila-Larven im Stadium L3 könnte also schlicht der falsche Ort oder der falsche Zeitpunkt sein, um einen Phänotyp der CDK5-Defizienz zu entdecken. Ein weiterer Grund für fehlende Beeinträchtigung der NMJ könnte mit der Expression der Aktivatoren (p35, p39) von CDK5 in Zusammenhang stehen, die bei Säugetieren hauptsächlich im ZNS zu finden sind (Angelo et al. 2006). Sollte die Expression in Drosophila einem ähnlichen Muster folgen, könnte dies eine Erklärung für die unbeeinflusste synaptische Übertragung sein.

Die Ergebnisse dieser Untersuchung und die verwendete Mutante könnten darüber hinaus dazu dienen, die vorgeschlagenen Mechanismen der Funktion von CDK5 zu überprüfen. Nach der Hypothese von Tomizawa und Kollegen (Tomizawa et al. 2002) vermindert CDK5 durch Phosphorylierung von P/Q-Typ $\mathrm{Ca}^{2+}$-Kanälen deren Aktivität. Sollte sich dies auf Drosophila übertragen lassen, dann könnte die Drosophila-CDK5Mutante evtl. sensibler auf pharmakologische Beeinflussung von $\mathrm{Ca}^{2+}$-Kanälen reagieren als Kontrolltiere. Auf diesem Weg könnte sich also ein Phänotyp eluieren lassen, der in der hier erfolgten Untersuchung verborgen blieb.

Trotz des hier nicht nachweisbaren Einflusses auf die NMJ sollte CDK5 an der Synapse also weiter untersucht werden. Seine Beteiligung einerseits an der synaptischen Transmission, andererseits als „klassische“ Kinase an der Pathophysiologie der Alzheimer-Erkrankung könnte miteinander in Zusammenhang stehen. Schließlich ist bislang nicht klar, ob bei die histologisch und immunhistochemisch nachweisbaren Neurofibrillenbündel der Ausgangspunkt für zellulären Funktionsverlust und sukzessiven Zelluntergang sind, oder ob eventuell synaptische Funktionsveränderungen die primäre Krankheitsursache darstellen und es sich bei den Neurofibrillenbündeln um sekundäre Veränderungen handelt. Unabhängig von der Pathogenese spielt für die Behandlung der Erkrankung auch eine 
Rolle, ob allgemeiner Zelluntergang oder spezifische synaptische Funktionsstörungen für die Symptomatik betroffener Patienten verantwortlich zu machen sind. Das Verständnis der synaptischen Vorgänge bei Alzheimer könnte den Weg für neue Therapieformen ebnen und eine veränderte Sichtweise auf diese Erkrankung zulassen. 


\section{Publikationen zur Dissertation}

Bogdanik L, Framery B, Frölich A, Franco B, Mornet D, Bockaert J, Sigrist SJ, Grau Y and Parmentier ML (2008). "Muscle dystroglycan organizes the postsynapse and regulates presynaptic neurotransmitter release at the Drosophila neuromuscular junction." PloS ONE 3(4):e2084.

Kissler AE, Frölich AM, Sigrist SJ and Suter B (2009). "Drosophila cdk5 is needed for locomotive behaviour and NMJ formation, but seems dispensible for synaptic transmission." Dev Neurobiol 69(6):365-77.

Schmid A, Hallerman S, Kittel RJ, Khorramshahi O, Frölich AM, Quentin C, Rasse TM, Mertel S, Heckmann M and Sigrist SJ (2008). "Activity-dependant sitespecific changes of glutamate receptor composition in vivo." Nature Neuroscience $\underline{6}: 659-66$. 


\section{Abkürzungsverzeichnis}

\begin{tabular}{|c|c|c|}
\hline AMPA & - & a-Amino-3-Hydroxy-5-Methyl-4-Isoxazolpropionsäure \\
\hline AP & - & Aktionspotential \\
\hline ATP & - & Adenosintriphosphat \\
\hline$A Z$ & - & Aktive Zone \\
\hline $\mathrm{C}$ & - & Kapazität eines Kondensators \\
\hline CDK5 & - & Cyclin-abhängige Kinase 5 (cyclin dependant kinase 5) \\
\hline DG & - & Dystroglycan \\
\hline DGK & - & Dystrophin-Glykoprotein-Komplex \\
\hline $\mathrm{E}$ & - & Diffusionspotential \\
\hline eEJC & - & $\begin{array}{l}\text { evozierter exzitatorischer postsynaptischer Strom } \\
\text { (evoked excitatory junctional current) }\end{array}$ \\
\hline EPSP & - & exzitatorisches postsynaptisches Potential \\
\hline $\mathrm{G}$ & - & elektrische Leitfähigkeit \\
\hline GFP & - & Grün fluoreszierendes Protein \\
\hline GluRIIA & - & Glutamatrezeptor-Untereinheit IIA (entsprechend IIB, IIC etc.) \\
\hline HEPES & - & N-(2-Hydroxyethyl)-piperazin-N'-2-ethansulfonsäure \\
\hline I & - & elektrische Stromstärke \\
\hline iGluR & - & ionotroper Glutamatrezeptor \\
\hline $\ln$ & - & Haltestrom \\
\hline$\| A$ & - & Glutamatrezeptor-Untereinheit IIA (entsprechend IIB, IIC etc.) \\
\hline IPSP & - & inhibitorisches postsynaptisches Potential \\
\hline L1, L2, L3 & - & Larvenstadien L1, L2 und L3 von Drosophila melanogaster \\
\hline ME1, ME2 & - & Mikroelektrode 1, 2 \\
\hline mEJC & - & $\begin{array}{l}\text { Miniatur-exzitatorischer postsynaptischer Strom } \\
\text { (miniature excitatory junctional current) }\end{array}$ \\
\hline mPSP & - & $\begin{array}{l}\text { spontane postsynaptische Potentiale } \\
\text { (miniature postsynaptic potentials) }\end{array}$ \\
\hline $\mathrm{N}$ & - & Anzahl der Freisetzungsorte von Vesikeln \\
\hline NMDA & - & N-Methyl D-Aspartat \\
\hline NMJ & - & neuromuskuläre Synapse (neuromuscular junction) \\
\hline
\end{tabular}




\begin{tabular}{|c|c|c|}
\hline$p$ & - & $\begin{array}{l}\text { Freisetzungswahrscheinlichkeit eines Vesikels } \\
\text { (release probability) }\end{array}$ \\
\hline PSC & - & postsynaptischer Strom (postsynaptic current) \\
\hline PSD & - & postsynaptische Verdichtung (postsynaptic density) \\
\hline PTP & - & post-tetanische Potenzierung \\
\hline q & - & $\begin{array}{l}\text { Quantengröße, d.h. Amplitude eines Quantums } \\
\text { (quantal size) }\end{array}$ \\
\hline QC & - & $\begin{array}{l}\text { Anzahl der pro Stimulus freigesetzten Vesikel } \\
\text { (quantal content) }\end{array}$ \\
\hline $\mathrm{R}$ & - & elektrischer Widerstand \\
\hline $\mathrm{RP}$ & - & recycling pool \\
\hline RRP & - & readily releasable pool \\
\hline RSP & - & reserve pool \\
\hline SE & - & Ansaugelektrode (suction electrode) \\
\hline STD & - & $\begin{array}{l}\text { synaptische Kurzzeitabschwächung } \\
\text { (short-term synaptic depression) }\end{array}$ \\
\hline STE & - & $\begin{array}{l}\text { synaptische Kurzzeitverstärkung } \\
\text { (short-term synaptic enhancement) }\end{array}$ \\
\hline TEVC & - & $\begin{array}{l}\text { Zwei-Elektroden Spannungsklemme } \\
\text { (two-electrode voltage clamp) }\end{array}$ \\
\hline$U$ & - & elektrische Spannung \\
\hline UAS/Gal4 & - & Gal4-responsive upstream activating sequence \\
\hline $\mathrm{V}_{\mathrm{m}}$ & - & Ruhemembranpotential \\
\hline $\mathrm{V}_{\text {rev }}$ & - & Umkehrpotential \\
\hline$V_{c m d}$ & - & Haltepotential \\
\hline WT & - & Wildtyp \\
\hline
\end{tabular}




\section{Abbildungen und Tabellen}

\section{Abbildungen}

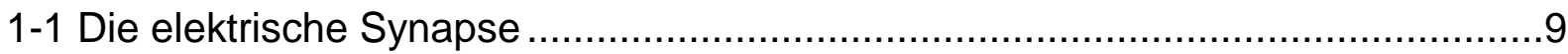

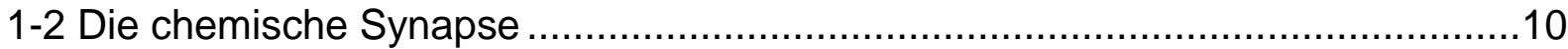

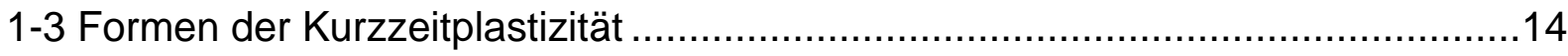

1-4 Der Lebenszyklus von Drosophila melanogaster........................................18

1-5 Struktur der neuromuskulären Synapse von Drosophila .................................21

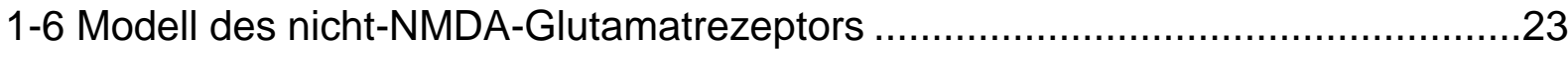

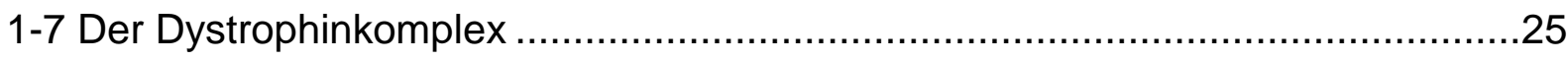

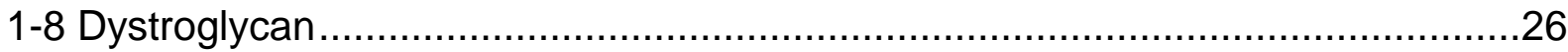

2-1 Vereinfachtes elektrisches Modell der Zellmembran .........................................34

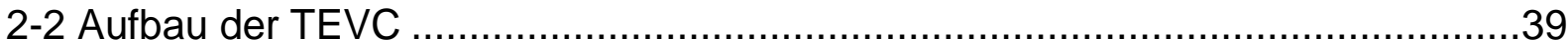

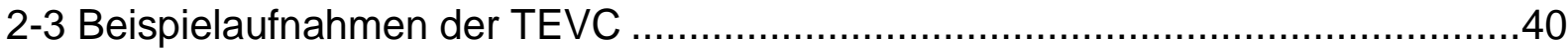

2-4 Lade- und Entladevorgang der Zellmembran bei der TEVC .............................41

3-1 IIB-GFP zeigt keinen Hinweis auf eine Veränderung der

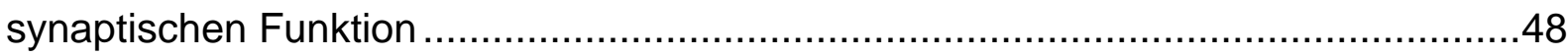

3-2 Unterschiede der eEJC decay $\mathrm{t}$ in Wildtyp, IIA- und IIB-Konstrukten ...................49

3-3 Stark verminderte synaptische Übertragung bei IIE-RNAi...............................52

3-4 Doppelpuls-Stimulation bei IIE-RNAi offenbart STD ........................................54

3-5 IIF-RNAi zeigt eine veränderte synaptische Übertragung ...............................56

3-6. Suppression von Dystroglycan verändert die synaptische Übertragung.............60

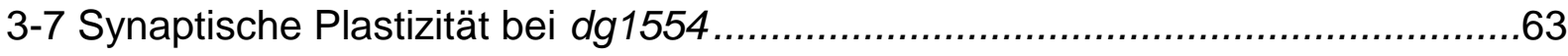

3-8 Unterdrückung von CDK5 zeigt keine veränderte synaptische Übertragung .......65

\section{Tabellen}

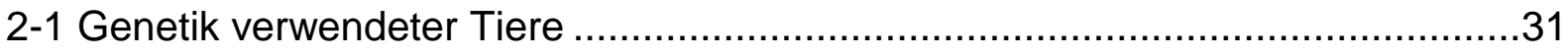

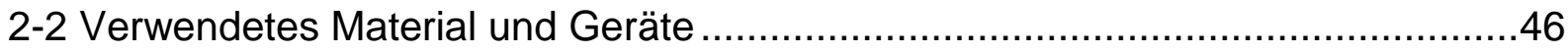




\section{Literaturverzeichnis}

Aberle $\mathrm{H}$, Haghighi AP, Fetter RD, McCabe BD, Magalhaes TR and Goodman CS (2002): "wishful thinking encodes a BMP type II receptor that regulates synaptic growth in Drosophila." Neuron 33(4): 545-58.

Ahn AH and Kunkel LM (1993): "The structural and functional diversity of dystrophin." Nat Genet 3(4): 283-91.

Anderson JL, Head SI and Morley JW (2005): "Synaptic plasticity in the dy2J mouse model of laminin alpha2-deficient congenital muscular dystrophy." Brain Res 1042(1): 23-8.

Angelo M, Plattner F and Giese KP (2006): "Cyclin-dependent kinase 5 in synaptic plasticity, learning and memory." J Neurochem 99(2): 353-70.

Atwood HL, Govind CK and Wu CF (1993): "Differential ultrastructure of synaptic terminals on ventral longitudinal abdominal muscles in Drosophila larvae." $\underline{\mathrm{J}}$ Neurobiol 24(8): 1008-24.

Bate M, Landgraf M and Ruiz Gomez Bate M (1999): "Development of larval body wall muscles." Int Rev Neurobiol 43: 25-44.

Bogdanik L, Mohrmann R, Ramaekers A, Bockaert J, Grau Y, Broadie K and Parmentier ML (2004): "The Drosophila metabotropic glutamate receptor DmGluRA regulates activity-dependent synaptic facilitation and fine synaptic morphology." J Neurosci 24(41): 9105-16.

Bogdanik L, Framery B, Frölich A, Franco B, Mornet D, Bockaert J, Sigrist SJ, Grau Y and Parmentier ML (2008): "Muscle dystroglycan organizes the postsynapse and regulates presynaptic neurotransmitter release at the Drosophila neuromuscular junction." PloS ONE 3(4):e2084.

Boron WF, Boulpaep EL: Medical Physiology. A Cellular and Molecular Approach. $1^{\text {st }}$ edition, Saunders / Elsevier Science, Philadelphia, Pennsylvania, USA, 2003

Brand A and Perrimon N (1993): "Targeted gene expression as a means of altering cell fates and generating dominant phenotypes." Development. 118(2): 40115.

Castiglioni MC (1951): "Distribution of pigments in the eye of alleles of white and their compounds in Drosophila melanogaster." Sci Genet 4(1-2): 57-60.

Charlton MP, Smith SJ and Zucker RS (1982): "Role of presynaptic calcium ions and channels in synaptic facilitation and depression at the squid giant synapse." $\underline{\mathrm{J}}$ Physiol 323: 173-93.

Cheung ZH, Fu AK and Ip NY (2006): "Synaptic roles of Cdk5: implications in higher cognitive functions and neurodegenerative diseases." Neuron 50(1): 13-8.

Connell-Crowley L, Le Gall M, Vo DJ and Giniger E (2000): "The cyclin-dependent kinase Cdk5 controls multiple aspects of axon patterning in vivo." Curr Biol 10(10): 599-602. 
Despopoulos A, Silbernagl S: Taschenatlas der Physiologie. 6. Auflage, Thieme Verlag, Stuttgart / New York, 2003

DiAntonio A, Petersen SA, Heckmann M and Goodman CS (1999): "Glutamate receptor expression regulates quantal size and quantal content at the

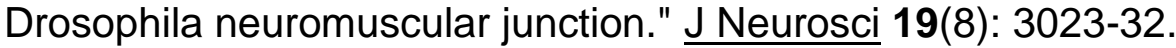

Dingledine R, Borges K, Bowie D and Traynelis SF (1999): "The glutamate receptor ion channels." Pharmacol Rev 51(1): 7-61.

Fisher SA, Fischer TM and Carew TJ (1997): "Multiple overlapping processes underlying short-term synaptic enhancement." Trends Neurosci 20(4): 170-7.

Fletcher Al, Shuang R, Giovannucci DR, Zhang L, Bittner MA and Stuenkel EL (1999): "Regulation of exocytosis by cyclin-dependent kinase 5 via phosphorylation of Munc18." J Biol Chem 274(7): 4027-35.

Gilmore EC, Ohshima T, Goffinet AM, Kulkarni AB and Herrup K (1998): "Cyclindependent kinase 5-deficient mice demonstrate novel developmental arrest in cerebral cortex." J Neurosci 18(16): 6370-7.

Grady RM, Zhou H, Cunningham JM, Henry MD, Campbell KP and Sanes JR (2000): "Maturation and maintenance of the neuromuscular synapse: genetic evidence for roles of the dystrophin--glycoprotein complex." Neuron 25(2): 279-93.

Greener MJ and Roberts RG (2000): "Conservation of components of the dystrophin complex in Drosophila." FEBS Lett 482(1-2): 13-8.

Haas KF, Miller SL, Friedman DB and Broadie K (2007): "The ubiquitin-proteasome system postsynaptically regulates glutamatergic synaptic function." Mol Cell Neurosci 35(1): 64-75.

Hodgkin AL, Huxley AF and Katz B (1952): "Measurement of current-voltage relations in the membrane of the giant axon of Loligo." J Physiol 116(4): 424-48.

Ibraghimov-Beskrovnaya O, Ervasti JM, Leveille CJ, Slaughter CA, Sernett SW and Campbell KP (1992): "Primary structure of dystrophin-associated glycoproteins linking dystrophin to the extracellular matrix." Nature 355(6362): 696-702.

Jan LY and Jan YN (1976): "L-glutamate as an excitatory transmitter at the Drosophila larval neuromuscular junction." J Physiol 262(1): 215-36.

Johansen J, Halpern ME, Johansen KM and Keshishian H (1989): "Stereotypic morphology of glutamatergic synapses on identified muscle cells of Drosophila larvae." J Neurosci 9(2): 710-25.

Jones MV and Westbrook GL (1996): "The impact of receptor desensitization on fast synaptic transmission." Trends Neurosci 19(3): 96-101.

Kamiya H and Zucker RS (1994): "Residual Ca2+ and short-term synaptic plasticity." Nature 371(6498): 603-6.

Karunanithi S, Marin L, Wong K and Atwood HL (2002): "Quantal size and variation determined by vesicle size in normal and mutant Drosophila glutamatergic synapses." J Neurosci 22(23): 10267-76.

Katz B and Miledi R (1968): "The role of calcium in neuromuscular facilitation." $\underline{\mathrm{J}}$ Physiol 195(2): 481-92. 
Kidokoro Y, Kuromi H, Delgado R, Maureira C, Oliva C and Labarca P (2004):

"Synaptic vesicle pools and plasticity of synaptic transmission at the Drosophila synapse." Brain Res Brain Res Rev 47(1-3): 18-32.

Kissler AE, Frölich AM, Sigrist SJ and Suter B (2009): "Drosophila cdk5 is needed for locomotive behaviour and NMJ formation, but seems dispensible for synaptic transmission." Dev Neurobiol 69(6):365-77.

Kittel RJ, Wichmann C, Rasse TM, Fouquet W, Schmidt M, Schmid A, Wagh DA, Pawlu C, Kellner RR, Willig KI, Hell SW, Buchner E, Heckmann M and Sigrist SJ (2006): "Bruchpilot promotes active zone assembly, Ca2+ channel clustering, and vesicle release." Science 312(5776): 1051-4.

Laube B, Kuhse $\mathrm{J}$ and Betz $\mathrm{H}$ (1998): "Evidence for a tetrameric structure of recombinant NMDA receptors." J Neurosci 18(8): 2954-61.

Lee VM, Goedert M and Trojanowski JQ (2001): "Neurodegenerative tauopathies." Annu Rev Neurosci 24: 1121-59.

Liu G (2003): "Presynaptic control of quantal size: kinetic mechanisms and implications for synaptic transmission and plasticity." Curr Opin Neurobiol 13(3): 324-31.

Madden DR (2002): "The structure and function of glutamate receptor ion channels." Nat Rev Neurosci 3(2):91-101.

Marrus SB and DiAntonio A (2005): "Investigating the safety factor at an invertebrate neuromuscular junction." J Neurobiol 63(1): 62-9.

Meighan SE, Meighan PC, Choudhury P, Davis CJ, Olson ML, Zornes PA, Wright JW and Harding JW (2006): "Effects of extracellular matrix-degrading proteases matrix metalloproteinases 3 and 9 on spatial learning and synaptic plasticity." $\underline{\mathrm{J}}$ Neurochem 96(5): 1227-41.

Mi K and Johnson GV (2006): "The role of tau phosphorylation in the pathogenesis of Alzheimer's disease." Curr Alzheimer Res 3(5): 449-63.

Michaluk P, Kolodziej L, Mioduszewska B, Wilczynski GM, Dzwonek J, Jaworski J, Gorecki DC, Ottersen OP and Kaczmarek L (2007): "beta-Dystroglycan as a Target for MMP-9, in Response to Enhanced Neuronal Activity." $\underline{\mathrm{J} \text { Biol Chem }}$ 282(22): 16036-41.

Montanaro F and Carbonetto S (2003): "Targeting dystroglycan in the brain." Neuron 37(2): 193-6.

Moore SA, Saito F, Chen J, Michele DE, Henry MD, Messing A, Cohn RD, RossBarta SE, Westra S, Williamson RA, Hoshi T and Campbell KP (2002): "Deletion of brain dystroglycan recapitulates aspects of congenital muscular dystrophy." Nature 418(6896): 422-5.

Morgan DO (1995): "Principles of CDK regulation." Nature 374(6518): 131-4.

Muschler J, Levy D, Boudreau R, Henry M, Campbell K and Bissell MJ (2002): "A role for dystroglycan in epithelial polarization: loss of function in breast tumor cells." Cancer Res 62(23): 7102-9.

Paradis S, Sweeney ST and Davis GW (2001): "Homeostatic control of presynaptic release is triggered by postsynaptic membrane depolarization." Neuron 30(3): 
737-49.

Pawlu C, DiAntonio A and Heckmann M (2004): "Postfusional control of quantal current shape." Neuron 42(4): 607-18.

Pei JJ, Grundke-lqbal I, lqbal K, Bogdanovic N, Winblad B and Cowburn RF (1998):

"Accumulation of cyclin-dependent kinase 5 (cdk5) in neurons with early stages of Alzheimer's disease neurofibrillary degeneration." Brain Res 797(2): 267-77.

Petersen SA, Fetter RD, Noordermeer JN, Goodman CS and DiAntonio A (1997): "Genetic analysis of glutamate receptors in Drosophila reveals a retrograde signal regulating presynaptic transmitter release." Neuron 19(6): 1237-48.

Qin G, Schwarz T, Kittel RJ, Schmid A, Rasse TM, Kappei D, Ponimaskin E, Heckmann M and Sigrist SJ (2005): "Four different subunits are essential for expressing the synaptic glutamate receptor at neuromuscular junctions of Drosophila." J Neurosci 25(12): 3209-18.

Rasse TM, Fouquet W, Schmid A, Kittel RJ, Mertel S, Sigrist CB, Schmidt M, Guzman A, Merino C, Qin G, Quentin C, Madeo FF, Heckmann M, Sigrist SJ (2005): "Glutamate receptor dynamics organizing synapse formation in vivo." Nat Neurosci 8(7):898-905.

Reiff DF, Thiel PR and Schuster CM (2002): "Differential regulation of active zone density during long-term strengthening of Drosophila neuromuscular junctions." J Neurosci 22(21): 9399-409.

Rizzoli SO and Betz WJ (2005): "Synaptic vesicle pools." Nat Rev Neurosci 6(1): 5769.

Rosenmund C, Stern-Bach Y and Stevens CF (1998): "The tetrameric structure of a glutamate receptor channel." Science 280(5369): 1596-9.

Safferling M, Tichelaar W, Kummerle G, Jouppila A, Kuusinen A, Keinanen K and Madden DR (2001): "First images of a glutamate receptor ion channel: oligomeric state and molecular dimensions of GluRB homomers." Biochemistry 40(46): 13948-53.

Sakaba T and Neher E (2001): "Calmodulin mediates rapid recruitment of fastreleasing synaptic vesicles at a calyx-type synapse." Neuron 32(6): 1119-31.

Schmid, A: The role of glutamate receptors in formation and maturation of Drosophila neuromuscular synapses. Biol. Diss. Göttingen 2006

Schmid A, Hallerman S, Kittel RJ, Khorramshahi O, Frölich AM, Quentin C, Rasse TM, Mertel S, Heckmann M and Sigrist SJ (2008): "Activity-dependant sitespecific changes of glutamate receptor composition in vivo." Nat Neurosci 6:659-66.

Schneggenburger R, Sakaba T and Neher E (2002): "Vesicle pools and short-term synaptic depression: lessons from a large synapse." Trends Neurosci 25(4): 206-12.

Schuster CM, Ultsch A, Schloss P, Cox JA, Schmitt B and Betz H (1991): "Molecular cloning of an invertebrate glutamate receptor subunit expressed in Drosophila muscle." Science 254(5028): 112-4. 
Schwarz, T: Characterisation of key elements involved in glutamate receptor assembly and functionality at the Drosophila neuromuscular junction. Biol. Diss. Hannover 2007

Schwarz, T: European Neuroscience Institute Göttingen, AG Synaptische Plastizität, persönliche Kommunikation 2006.

Sciandra F, Schneider M, Giardina B, Baumgartner S, Petrucci TC and Brancaccio A (2001): "Identification of the beta-dystroglycan binding epitope within the Cterminal region of alpha-dystroglycan." Eur J Biochem 268(16): 4590-7.

Sgambato A and Brancaccio A (2005): "The dystroglycan complex: from biology to cancer." J Cell Physiol 205(2): 163-9.

Shcherbata HR, Yatsenko AS, Patterson L, Sood VD, Nudel U, Yaffe D, Baker D and Ruohola-Baker H (2007): "Dissecting muscle and neuronal disorders in a Drosophila model of muscular dystrophy." Embo J 26(2): 481-93.

Sherman-Gold R (Hrsg.): The Axon Guide. A Guide to Electrophysiology \& Biophysics Laboratory Techniques. $2^{\text {nd }}$ edition, Molecular Devices Corporation, Union City, California, USA, 2006

Sigrist SJ, Thiel PR, Reiff DF and Schuster CM (2002): "The postsynaptic glutamate receptor subunit DGluR-IIA mediates long-term plasticity in Drosophila." $\underline{\mathrm{J}}$ Neurosci 22(17): 7362-72.

Sprengel R, Aronoff R, Volkner M, Schmitt B, Mosbach R and Kuner T (2001): "Glutamate receptor channel signatures." Trends Pharmacol Sci 22(1): 7-10.

Stewart BA, Atwood HL, Renger JJ, Wang J and Wu CF (1994): "Improved stability of Drosophila larval neuromuscular preparations in haemolymph-like physiological solutions." J Comp Physiol [A] 175(2): 179-91.

Tomizawa K, Ohta J, Matsushita M, Moriwaki A, Li ST, Takei K and Matsui H (2002): "Cdk5/p35 regulates neurotransmitter release through phosphorylation and downregulation of P/Q-type voltage-dependent calcium channel activity." $\underline{\mathrm{J}}$ Neurosci 22(7): 2590-7.

Wang JZ, Grundke-lqbal I and Iqbal K (2007): "Kinases and phosphatases and tau sites involved in Alzheimer neurofibrillary degeneration." Eur J Neurosci 25(1): 59-68.

Weigmann K, Klapper R, Strasser T, Rickert C, Technau G, Jackle H, Janning W and Klambt C (2003): "FlyMove--a new way to look at development of Drosophila." Trends Genet 19(6): 310-1.

Weingarten MD, Lockwood AH, Hwo SY and Kirschner MW (1975): "A protein factor essential for microtubule assembly." Proc Natl Acad Sci U S A 72(5): 1858-62.

Winder SJ (2001): "The complexities of dystroglycan." Trends Biochem Sci 26(2): 118-24.

Zaccaria ML, Perrone-Capano C, Melucci-Vigo G, Gaeta L, Petrucci TC and Paggi P (2001): "Differential regulation of transcripts for dystrophin Isoforms, dystroglycan, and alpha3AChR subunit in mouse sympathetic ganglia following postganglionic nerve crush." Neurobiol Dis 8(3): 513-24.

Zamore PD, Tuschl T, Sharp PA and Bartel DP (2000): "RNAi: double-stranded RNA 
directs the ATP-dependent cleavage of mRNA at 21 to 23 nucleotide intervals." Cell 101(1): 25-33.

Zhai RG and Bellen HJ (2004): "The architecture of the active zone in the presynaptic nerve terminal." Physiology (Bethesda) 19: 262-70.

Zhan Y, Tremblay MR, Melian N and Carbonetto S (2005): "Evidence that dystroglycan is associated with dynamin and regulates endocytosis." J Biol Chem 280(18): 18015-24.

Zucker RS and Regehr WG (2002): "Short-term synaptic plasticity." Annu Rev Physiol 64: 355-405. 


\section{Zusammenfassung}

Die larvale neuromuskuläre Synapse von Drosophila melanogaster stellt ein gut zugängliches Modellsystem zur Untersuchung synaptischer Funktionen dar. In dieser Arbeit wurde mit Hilfe der Elektrophysiologie die Bedeutung der Glutamatrezeptoruntereinheiten GluRIIB, GluRIIE und GluRIIF, des DystrophinAssoziierten Glykoproteins Dystroglycan (DG) sowie der Cyclin-abhängigen Kinase 5 (CDK5) untersucht.

Für Larven, die GluRIIB exprimieren, jedoch nicht GluRIIA, konnte ein im Vergleich zu Wildtyp-Larven schnellerer Abfall (verminderter decay-T) und verminderte Amplitude evozierter postsynaptischer Ströme (eEJCs) nachgewiesen werden. Diese Ergebnisse tragen zu der Hypothese bei, dass die Kinetik und Funktion der Glutamatrezeptorkomplexe in vivo von dem Verhältnis des exprimierten GluRIIA zu GluRIIB abhängt. Darüber hinaus konnte gezeigt werden, dass eine Fluoreszenzmarkierung des IIB-Konstruktes keine Veränderung der synaptischen Übertragung zeigte und das markierte Konstrukt sich für weitere Experimente eignet (Schmid et al. 2008). In RNAi-Konstrukten mit reduzierter Expression von GluRIIE konnte eine stark verminderte synaptische Übertragung gezeigt werden, die in Einklang mit der Beobachtung steht, dass es sich bei GluRIIE um eine essentielle Untereinheit handelt. Der bei diesen Tieren unveränderte decay- $t$ spricht dafür, dass GluRIIE das IIA/IIB-Verhältnis nicht verändert. RNAi-Unterdrückung des kürzlich neu entdeckten GluRIIF führt zu kleineren eEJCs, dies spricht für eine funktionelle Bedeutung dieser Untereinheit in vivo. Auch hier fand sich kein Einfluss auf das IIA/IIB-Verhältnis (unveränderter decay-T).

Mit Hilfe der Mutante dg1554 konnte ein Beitrag des Dystroglycan auf die basale Neurotransmission nachgewiesen werden. Interessanterweise war hierbei auch die präsynaptische Seite betroffen, d.h. der Verlust von Dystroglycan wird wahrscheinlich transsynaptisch wahrgenommen (Bogdanik et al. 2007).

Die Untersuchung CDK5-defizienter Larven ließ keinen direkten Einfluss dieses Proteins auf die basale synaptische Übertragung bei Drosophila erkennen (Kissler et al. 2009). Dieser Befund sollte eine Eingrenzung des Pathogenitätsmechanismus der CDK5 erlauben. 


\section{Danksagung}

Für die Anregung und kontinuierliche wissenschaftliche Betreuung gilt mein besonderer Dank meinem Doktorvater Herrn Prof. Sigrist, der für meine Fragen und Ideen stets ein offenes Ohr hatte und mir so erlaubte, seinen überaus spannenden Forschungsbereich näher kennen zu lernen.

Darüber hinaus bedanke ich mich herzlich bei meinem Betreuer Herrn Dr. Robert Kittel, der mich in die Technik der Elektrophysiologie einführte und mir jederzeit mit großem Sachverstand und enormer Geduld beiseite stand. Er erlaubte es mir nicht nur, die komplizierte Technik der Larvenpräparation und elektrophysiologischen Messung zu erlernen, sondern stand mir auch bei jeglichen Schwierigkeiten stets mit Rat und Tat zur Seite.

Bedanken möchte ich mich auch bei Sara Mertel, Dr. Werner Fouquet, Dr. Tobias Rasse, Dr. Andreas Schmid, Dr. Manuela Schmid und Dr. Carolin Wichmann für umfangreiche und stets anregende wissenschaftliche Diskussionen, Hilfestellung sowie die Anregung verschiedener Experimente.

Allen oben genannten und zahlreichen hier nicht namentlich genannten Personen möchte ich ganz herzlich dafür danken, dass sie bei vielen kleinen und großen Problemen stets rasch mit kompetenter Hilfe zur Stelle waren und immer dafür gesorgt haben, dass ich mich auch in schwierigen Phasen nie alleine gelassen fühlte! 